
U nordon 



\section{Northern Lights on TIMSS and PIRLS 2011}

Differences and similarities in the Nordic countries

Kajsa Yang Hansen, Jan-Eric Gustafsson, Monica Rosén, Sari Sulkunen, Kari Nissinen, Pekka Kupari, Ragnar F. Ólafsson, Júlíus K. Björnsson, Liv Sissel Grønmo, Louise Rønberg, Jan Mejding, Inger Christin Borge and Arne Hole

TemaNord 2014:528 
Northern Lights on TIMSS and PIRLS 2011

Differences and similarities in the Nordic countries

Kajsa Yang Hansen, Jan-Eric Gustafsson, Monica Rosén, Sari Sulkunen, Kari Nissinen,

Pekka Kupari, Ragnar F. Ólafsson, Júlíus K. Björnsson, Liv Sissel Grønmo, Louise Rønberg,

Jan Mejding, Inger Christin Borge and Arne Hole

ISBN 978-92-893-2772-5

ISBN 978-92-893-2773-2 (EPUB)

http://dx.doi.org/10.6027/TN2014-528

TemaNord 2014:528

ISSN 0908-6692

(C) Nordic Council of Ministers 2014

Layout: Hanne Lebech

Cover photo: ImageSelect

Print: 07 Media a.s

Copies: 416

Printed in Norway

This publication has been published with financial support by the Nordic Council of Ministers. However, the contents of this publication do not necessarily reflect the views, policies or recommendations of the Nordic Council of Ministers.

\section{www.norden.org/en/publications}

\section{Nordic co-operation}

Nordic co-operation is one of the world's most extensive forms of regional collaboration, involving Denmark, Finland, Iceland, Norway, Sweden, and the Faroe Islands, Greenland, and Åland.

Nordic co-operation has firm traditions in politics, the economy, and culture. It plays an important role in European and international collaboration, and aims at creating a strong Nordic community in a strong Europe.

Nordic co-operation seeks to safeguard Nordic and regional interests and principles in the global community. Common Nordic values help the region solidify its position as one of the world's most innovative and competitive.

\section{Nordic Council of Ministers}

Ved Stranden 18

DK-1061 Copenhagen $\mathrm{K}$

Phone (+45) 33960200

www.norden.org 


\section{Content}

Foreword

1. Introduction Northern Lights Report on TIMSS and PIRLS 2011 ..................... 11

1.1 What are TIMSS and PIRLS?................................................................. 11

1.2 Why participate in international studies? .................................................. 13

1.3 Northern Lights Report: secondary analyses across Nordic

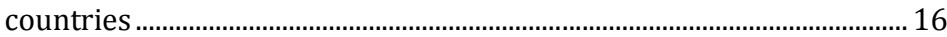

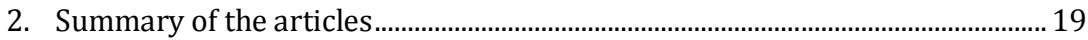

2.1 School performance differences and policy variations in Finland, Norway and Sweden

2.2 Characteristics of low and top performers in reading and mathematics. Exploratory analysis of 4th grade PIRLS and TIMSS data in the Nordic countries.

2.3 Teacher attitudes and practices in international studies and their relationship to PISA performance: Nordic countries in an international context

2.4 Mathematics in the Nordic countries - Trends and challenges in students' achievement in Norway, Sweden, Finland and Denmark ..... 22

2.5 A Nordic comparison of national objectives for reading instruction and teachers' responses about actual reading practice.

3. School performance differences and policy variations in Finland, Norway and Sweden

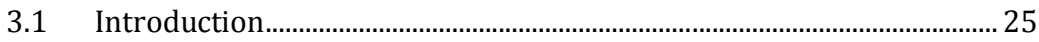

3.2 Policy changes in Finland, Norway and Sweden ..................................... 26

3.3 Research on determinants of school and classroom variation in

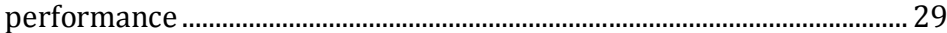

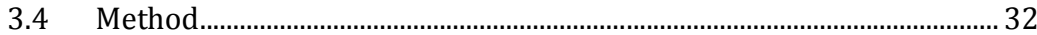

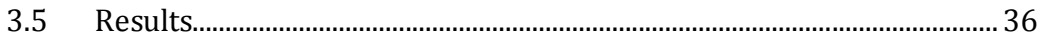

3.6 Discussion and Conclusions .................................................................... 41

3.7 References.............................................................................................. 45 
4. Characteristics of low and top performers in reading and mathematics. Exploratory analysis of $4^{\text {th }}$ grade PIRLS and TIMSS data in the Nordic

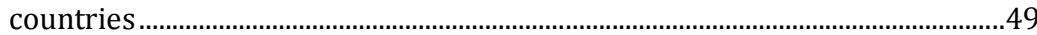

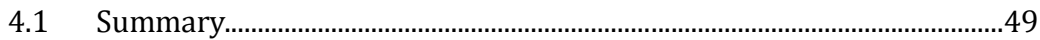

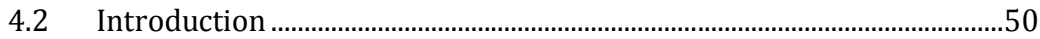

4.3 Previous findings on predicting performance in reading and

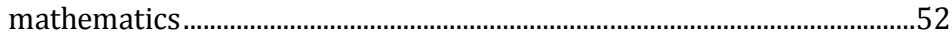

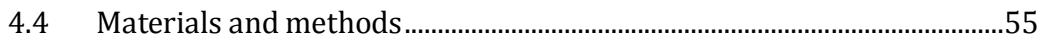

4.5 Low and top performers in the Nordic countries.....................................58

4.6 Characteristics predicting low performance in reading and in

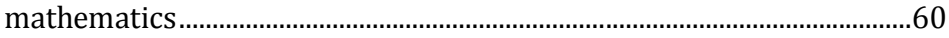

4.7 Characteristics predicting top performance in reading and in

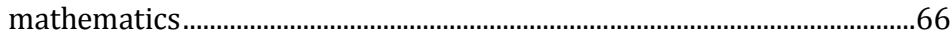

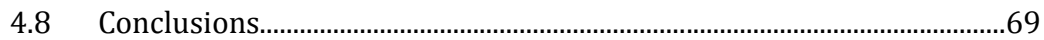

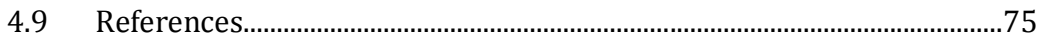

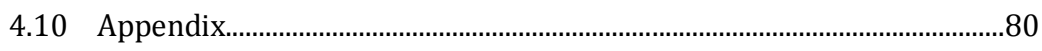

5. Teacher attitudes and practices in international studies and their relationships to PISA performance: Nordic countries in an international

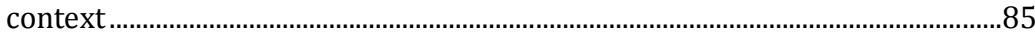

5.1 Summary

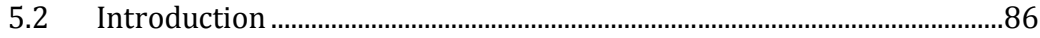

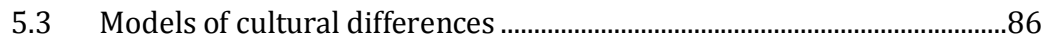

5.4 A culture of observation, feedback and improvement.............................8

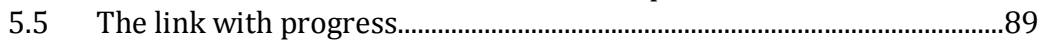

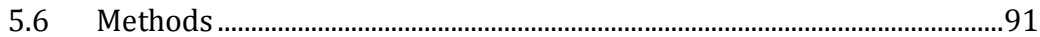

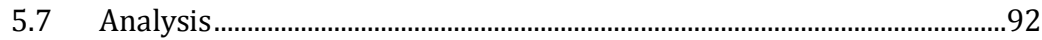

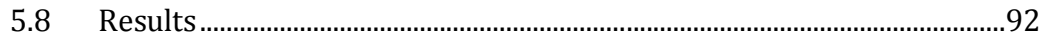

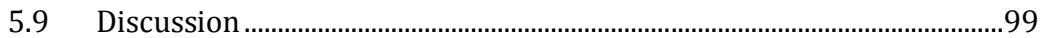

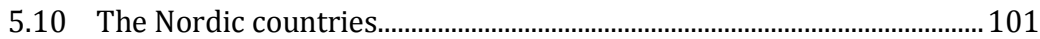

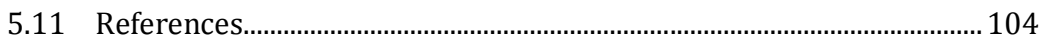

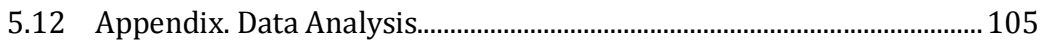

6. Mathematics in the Nordic countries - Trends and challenges in students' achievement in Norway, Sweden, Finland and Denmark ................ 107

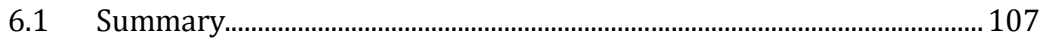

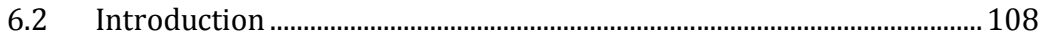

6.3 Mathematics Performance and School Emphasis on Academic Success (SEAS)......................................................................................... 112

6.4 What Characterises Mathematics Performance in the Nordic

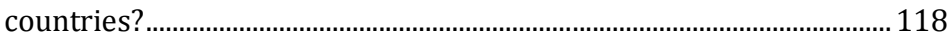

6.5 Students' Opportunity to Learn (OTL) Mathematics..............................121

6.6 Summary and Conclusions - Discussions on How to Improve Students' Achievement in Mathematics in the Nordic Countries........ 128

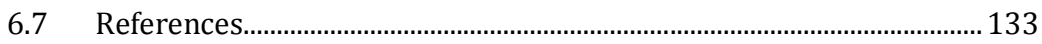


7. A Nordic comparison of national objectives for reading instruction and teachers' responses about actual reading practice.

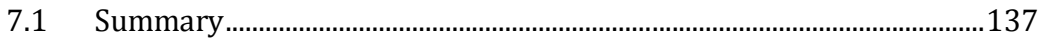

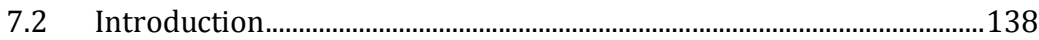

7.3 The present study....................................................................................... 142

7.4 Formal objectives of reading in the Nordic countries ............................143

7.5 The Nordic countries' definition of reading ability ...............................145

7.6 Research-based elements in the national objectives............................147

7.7 Analysis of Nordic teachers' reading instruction based on data from PIRLS 2011 .........................................................................................150

7.8 Materials and genres as a basis or supplement for reading instruction

7.9 The use of literary and informational text types during reading

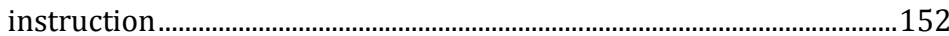

7.10 Activities during and after reading instruction ....................................156

7.11 Emphasis on the evaluation of students' progress in reading..............159

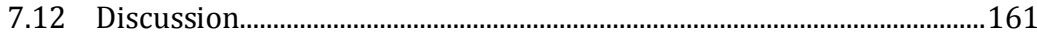

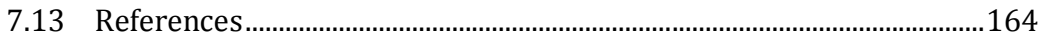

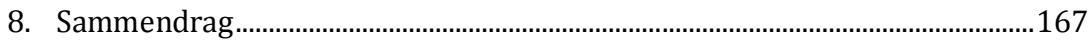




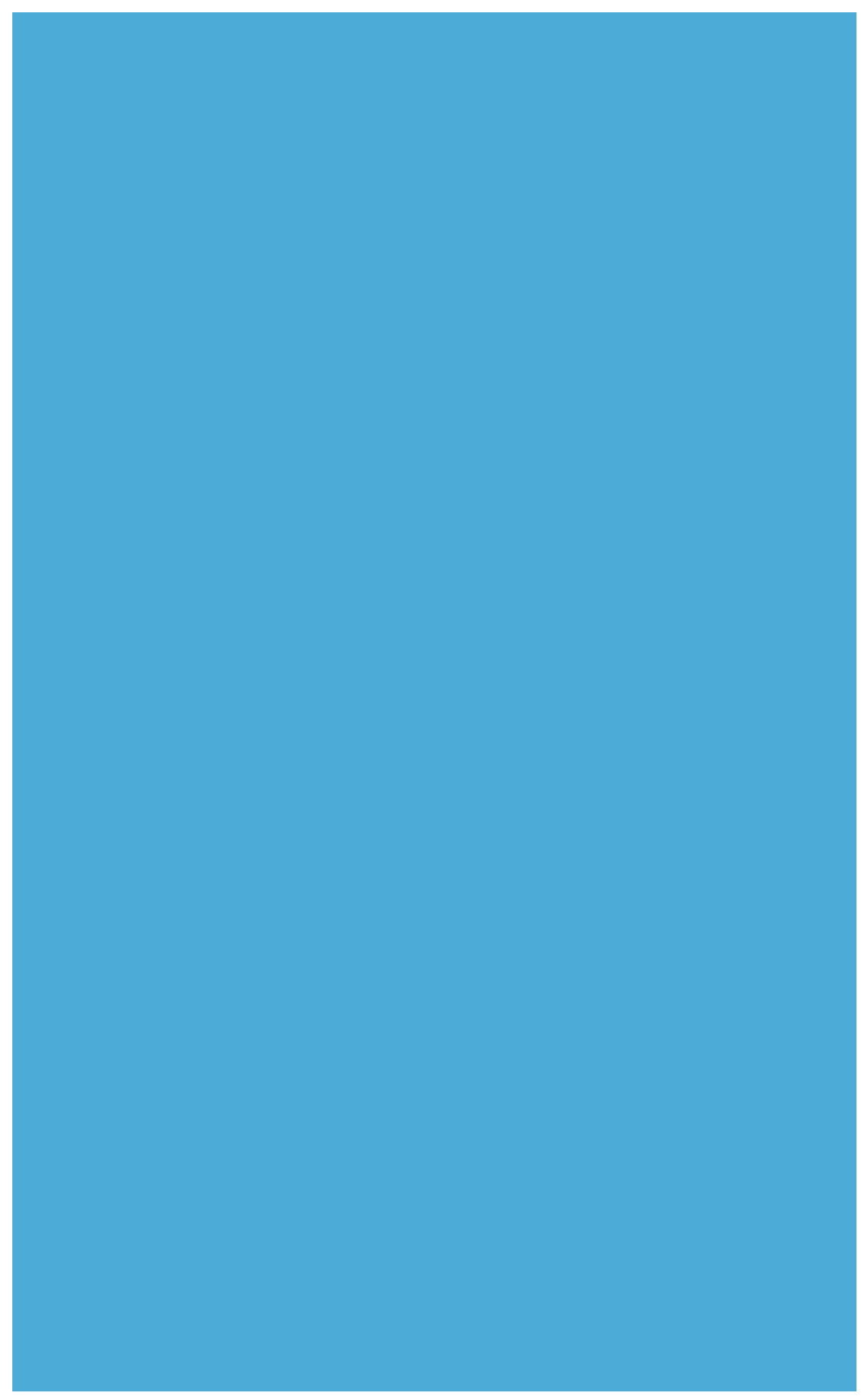




\section{Foreword}

This publication is the first Northern Lights edition based on the TIMSS and PIRLS studies. Earlier editions in the Northern Lights series have mainly focused on PISA. As with former editions, this one has received financial support from the Nordic Council of Ministers.

An editorial group appointed by the Nordic Evaluation Network has been responsible for developing the report. Ann-Kristin Boström, Jouni Välijärvi, Ragnar F. Olafsson, Elsebeth Aller, Anne Berit Kavli and Rolf Vegar Olsen has participated in the editorial group. The group has been led by Hallvard Thorsen. All the articles in this publication have been reviewed by the editorial group.

On behalf of the editorial group I would like to thank the authors who have contributed with articles.

We hope that this publication will be of interest for policymakers in the Nordic countries and that we achieve our ambition to give input to further policy development.

Oslo March 2014

Hallvard Thorsen 


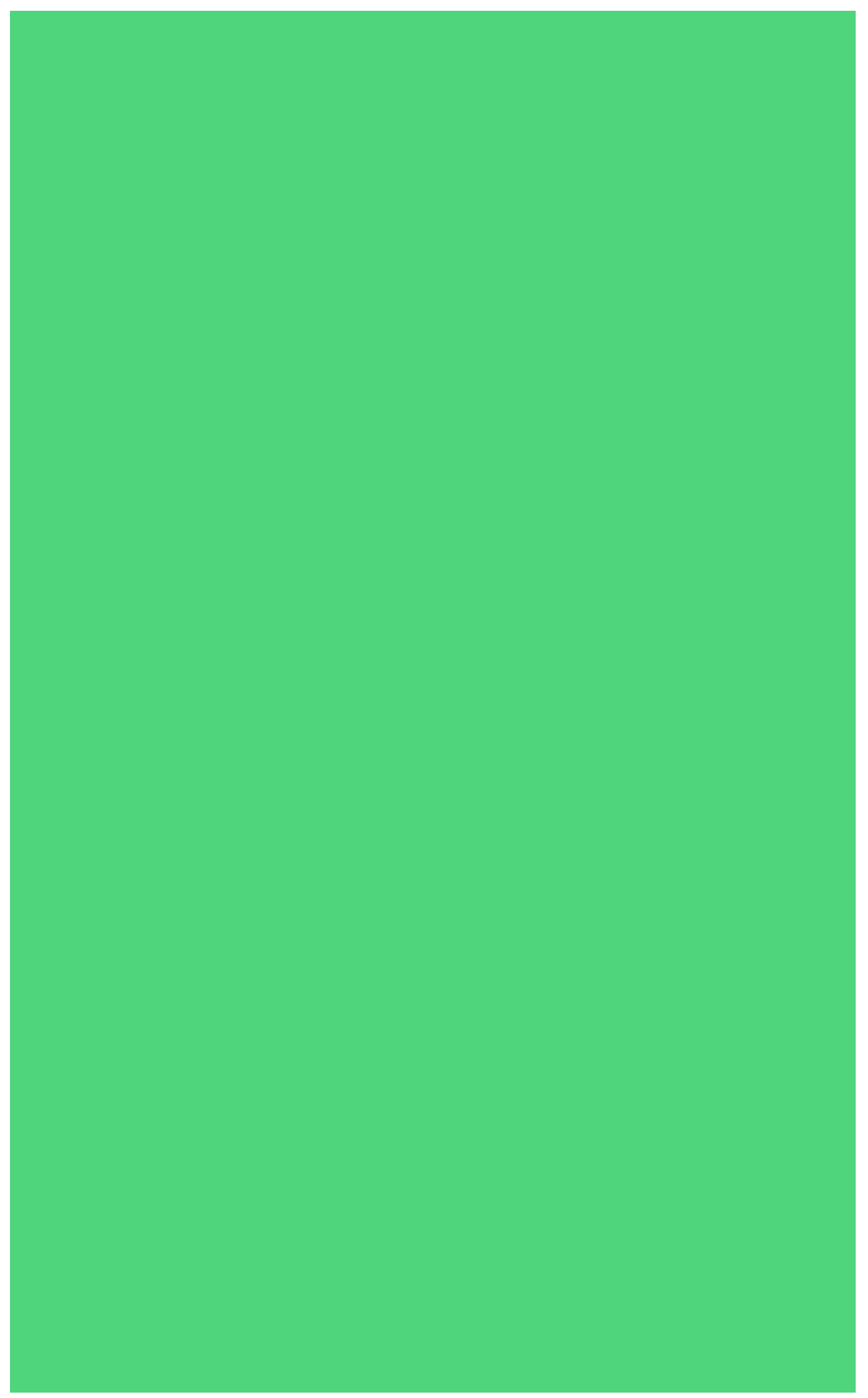




\section{Introduction Northern Lights Report on TIMSS and PIRLS 2011}

By Anne Berit Kavli and Hallvard Thorsen, The Norwegian Directorate for Education and Training

- How is reading literacy taught in Nordic classrooms, and how is this influenced by the curricula?

- How can we improve mathematics teaching in Nordic classrooms?

- What is the relationship between school performance and policy variations?

- How do teachers' attitudes, beliefs and practices influence pupils' learning outcomes?

- What characterizes the top performing pupils, and how can we stimulate more pupils to perform at the highest levels?

These are some of the questions that are discussed in this collection of articles that are based on the results of the IEA studies TIMSS and PIRLS 2011. Some of the articles also use data from the OECD studies PISA and TALIS.

\subsection{What are TIMSS and PIRLS?}

Trends in Mathematics and Science Study (TIMSS) and Progress in Reading Literacy Study (PIRLS) are both large-scale international comparative studies developed and conducted by the International Association for the Evaluation of Educational Achievement (IEA). 
IEA was founded as a non-governmental membership organisation in 1958, and it now has 70 members representing countries and education systems all over the world. The main goal for the IEA is to conduct large international comparative studies of educational achievement and other aspects of education, with the aim of gaining an in-depth understanding of the effects of policies and practices within and across systems of education. The IEA studies are grade-based studies designed to measure the effect that schooling has on a variety of subjects. The subjects range from basic skills in reading literacy to pupils' skills in mathematics and science, computer literacy focusing on information and communication skills and pupils' knowledge and understanding of democracy and citizenship. In addition to the tests, the IEA studies also contain surveys of background information for pupils, teachers, principals and sometimes also parents.

PIRLS is a trend study of the reading literacy capacity of pupils that are in their fourth year of compulsory schooling. The development of adequate reading literacy is crucial for learning in all other subjects; therefore, it is of high importance for education systems to both assess and follow the pupils' reading skills development at an early stage, and to see how this relates to reading instruction. Beginning in 2001, PIRLS has been conducted every fifth year. A number of countries also participated in IEA's first Reading Literacy Study, which was conducted in 1990-91, and it is possible to see trends even from that study's findings.

TIMSS assesses pupils' knowledge and skills in mathematics and science at the end of Grade 4 and Grade 8. TIMSS has been conducted every fourth year since 1995. In 2011, both TIMSS and PIRLS were conducted at the same time, and many countries then used that opportunity to test the same pupils in all three subjects at Grade 4.

All of the Nordic countries except Iceland participated in TIMSS and PIRLS 2011 at Grade 4, and Finland, Norway and Sweden also participated in TIMSS at Grade 8. Finland, Norway and Sweden tested the same pupils in both in TIMSS and PIRLS at Grade 4, while Denmark chose to have different samples for the two studies.

TIMSS and PIRLS are comparative studies designed to test the outcomes of schooling in the tested subjects. The grade-based design has strong analytical powers because entire classes are tested. The tests are followed by background questionnaires sent to principals, parents, pupils 
and teachers. The questions in those surveys address important aspects of the environment for teaching and learning. The studies are also followed by a system-level questionnaire that is sent to countries. That survey describes the various curricula and school systems.

Because the age for starting school varies across countries, the gradebased samples have caused some challenges in comparing results across the Nordic countries. In Norway, children start school the year they turn 6 without any preschool, while in Denmark, Sweden and Finland most pupils attend preschool the year they turn 6 and then start school at the age of 7. In Denmark, this preschool year is compulsory, while in Finland and Sweden most children attend preschool even if doing so is optional. The content of the preschool year in Denmark, Finland and Sweden is quite comparable to the Grade 1 curriculum taught in Norwegian schools. This means that in Grade 5 Norwegian pupils are the same age and have had the same amount of schooling as pupils in Grade 4 in Denmark, Sweden and Finland. For this reason, Norway has tested a smaller additional sample at Grade 5, in order to be able to perform more relevant comparisons with other Nordic countries.

The variation in average age across all participating countries at the time of testing is quite large, ranging from 9.7 to 10.9 years for pupils in Grade 4. In Norway, the mean age in Grade 4 is 9.7 years, and in Grade 5 the mean age is 10.7 years. In Denmark, Finland and Sweden the mean age at the time of testing varies from 10.7 to 10.9 years. The effect of one year of age difference is around half a standard deviation, approximately 40 points on the scales. For the next rounds of TIMSS and PIRLS in 2015 and 2016, it has been decided that Norway will participate by using pupils in Grade 5 and Grade 9 as their main sample in order to make the comparisons more relevant.

\subsection{Why participate in international studies?}

In all the Nordic countries, participation in large scale international studies of learning outcomes is an important part of the national strategy for the quality assessment of educational systems. Textbox 1 and Textbox 2 
provide an overview of the current international comparative studies and Nordic participation in those studies.

Participation in international comparative studies provides countries with an opportunity to assess the strengths and weaknesses of their educational systems. The studies provide important measures of trends in students' learning outcomes, and through surveys the countries also receive rich background information on students, their learning environment and the organisation of the schools. This combination of tests and background questionnaires offers a unique basis for in-depth analyses of the relationship between the learning environment and learning outcomes.

The results from these international studies should also always be analysed in a national context. The studies can never give a complete picture of a country's educational system; however, combined with national data and research they provide an important background assessing the quality of schools. Basic skills, like reading and mathematics literacy, are of crucial importance for learning across all subjects, and longitudinal analyses have shown that these competencies are also highly correlated with furthering the students' educational achievement.

\section{Textbox 1: Overview of current international studies}

\section{IEA Studies}

- Trends in Mathematics and Science Study (TIMSS) aims to study international trends in mathematics and science achievement at the fourth and eighth grades. TIMSS has been conducted every four years since 1995, and it reports students' achievement in mathematics and science. TIMSS also collects detailed information about curriculum and curriculum implementation, instructional practices and school resources.

- TIMSS Advanced assesses final-year secondary students' achievement in advanced mathematics and physics. The study also collects policy-relevant data about curriculum emphasis, technology use and teacher preparation and training. TIMSS Advanced was conducted in 1997 and 2008. It will be conducted again in 2015 . 
- Progress in International Reading Literacy Study (PIRLS) is an assessment of reading comprehension that has been monitoring trends in achievement at five-year intervals in countries around the world since 2001. PIRLS provides internationally-comparative data about how well children read after four years of primary schooling. In addition, the study also collects extensive information about home supports for literacy, curriculum and curriculum implementation, instructional practices and school resources in each participating country.

- $\quad$ PPIRLS is a new extension of PIRLS that will be implemented in 2016. ePIRLS is an innovative assessment of online reading, making it possible for countries to assess how successful they are in preparing fourth grade students to read, comprehend and interpret online information.

- The International Computer and Information Literacy Study (ICILS) examines the outcomes of student computer and information literacy (CIL) across countries. CIL refers to an individual's ability to use computers to investigate, create and communicate in order to participate effectively at home, at school, in the workplace and in the community. ICILS was conducted for the first time in 2013, and its findings will be reported in November 2014. Grade 8 is the main target grade for ICILS.

\section{OECD Studies}

- Programme for International Student Assessment (PISA) is a triennial international survey that aims to evaluate education systems worldwide by testing the skills and knowledge of 15 -year-old students. The tests are designed to assess the extent to which students at the end of compulsory education can apply their knowledge to real-life situations and be equipped for full participation in society. The information collected through background questionnaires also provides a context for the application of that knowledge, which can help analysts interpret the results.

- The OECD Teaching and Learning International Survey (TALIS) is an international, large-scale survey that focuses on the working conditions of teachers and the learning environment in schools. TALIS covers themes such as initial teacher education and professional development, teachers' instructional beliefs and pedagogical practices, appraisal and feedback to teachers, the school climate and school leadership. 


\begin{tabular}{llll}
\hline Organisation & Study & Participating Countries & Target Group \\
\hline IEA & TIMSS 2011 & DK, F, N, S & DK, F, N, S \\
& NIMSS 2015 & Grade 4 (5) and 8 \\
& TIMSS Advanced 2015 & GKade 4(5) and 8(9) & Grade 11(12) \\
IEA & PIRLS 2011 & DK, F, N, S & Grade 4(5) \\
& PIRLS 2016 & DK, N & Grade 4(5) \\
IEA & ICILS 2013 & DK, N, S & Grade 8 (9) \\
IEA & ICCS 2016 & all & Grade 8 (9) \\
OECD & PISA 2012 & all & 15 year olds \\
& PISA 2015 & all & 15 year olds \\
OECD & TALIS 2013 & & Teachers and principals \\
\hline
\end{tabular}

\subsection{Northern Lights Report: secondary analyses across Nordic countries}

The Nordic countries provide a unique opportunity for relevant crosscountry analyses. To a large extent, these countries share a common cultural background; however, at the same time they have chosen different ways of developing and organising their educational systems. The pattern of achievement has also been rather different among these countries, and this provides a background for relevant policy analyses where countries can learn from each other.

Since PISA 2000, the Nordic Council of Ministers'has funded Nordic analytical reports after each PISA study; these are known as the "Northern Lights on PISA" reports. This report is the first Northern Lights report based on TIMSS and PIRLS, and the future intention is to use the entire rich datasets based on all the international studies.

The aim of these analytical reports is to conduct common Nordic analyses, which can shed light on the equalities and differences between the Nordic educational systems; this enables the countries to learn from each other and use the results as input to further policy development. These analyses will also provide input to the joint Nordic initiatives on educational development and further research. 
The articles in this volume aim to provide input for important policy discussions and further policy development within the Nordic countries. Therefore, the main target groups are educational ministers and policymakers at all levels.

Since the first PISA results were published in 2001, we have seen a large increase in the interest in and the impact of international studies, and especially the impact of PISA. A major policy-related message from these studies has been the focus on basic skills, like reading and mathematics literacy, and the importance of developing these skills as a basis for learning across all subjects. Furthermore, the comparative international studies have emphasised the importance of a qualified teacher force and, by that, they have also identified teacher education and professional development of teachers as being the main strategic measures for the improvement of learning outcomes. As a consequence of this focus on the development of learning outcomes, many countries have also established and improved their national systems for quality assessment.

All results from these international studies have to be analysed in a national context in order to be relevant for further policy development. By stimulating secondary analyses in a Nordic context, the Nordic countries can receive valuable input to further the development of their educational systems. In this report, Nordic researchers have used data from TIMSS and PIRLS to gain research-based knowledge on important issues, such as the learning environment and the opportunity for learning, characteristics of top and low performers, the relationship between curriculum and teaching practice, school performance differences and policy variations and teacher's beliefs and practices and their influence on learning outcomes.

Researchers representing all the Nordic countries have contributed to the articles in this book. 


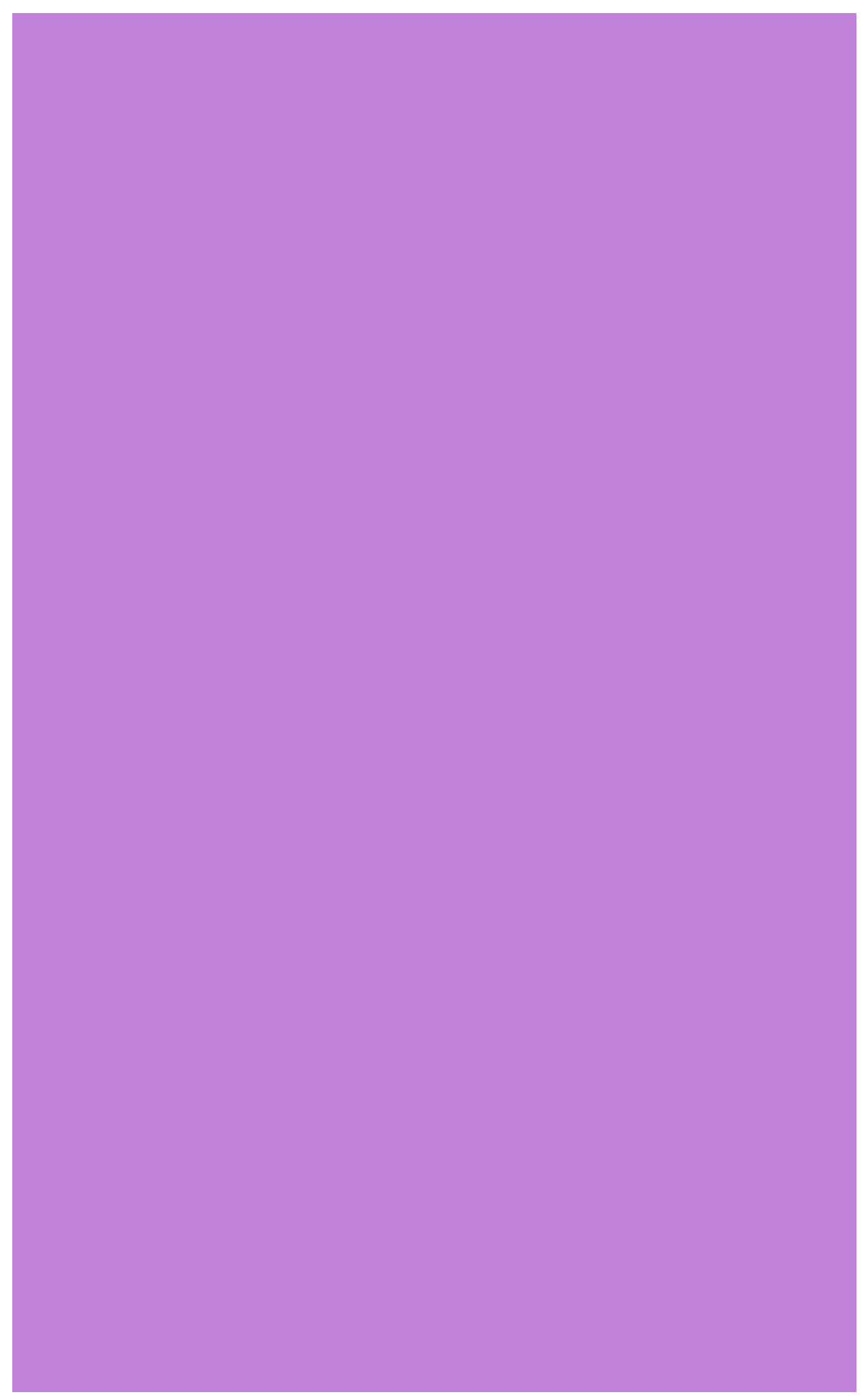




\section{Summary of the articles}

\subsection{School performance differences and policy variations in Finland, Norway and Sweden}

By Kajsa Yang Hansen, Jan-Eric Gustafsson and Monica Rosén, University of Gothenburg

This article focuses on the differences in the amount of variation in the level of performance between schools and classrooms in Grade 4 and Grade 8 in Finland, Norway and Sweden. Variability in the level of performance between different schools is of great interest both from a research perspective and from a policy perspective. A large amount of observed differences in the level of performance between schools may be indicative of a segregated school system in which students of different levels of ability are sorted into different schools through processes of selection or selfselection. However, the performance variability between schools may also reflect differences in the level of the quality of the education offered by different schools. Therefore, it is essential both to describe the amount of performance variability between schools and to determine which factors could account for that variation.

However, teaching typically is organised within more or less flexibly organised groups of students within a school, normally in the form of classes. Given that different classes are normally taught by different teachers and that the students within a particular class influence one another, systematic variation in the level of performance of different classes may be expected. Therefore, in order to correctly determine the amount of school performance differences, it is also necessary to determine the amount of differences between the classes within different schools.

This article concludes that there are substantial performance differences between schools in Norway and Sweden, which may be due to both 
segregation of living and school choice. In Finland, there are no school differences; instead, very substantial classroom differences have been identified. It will be interesting for further research to determine the sources of these school and classroom differences.

\subsection{Characteristics of low and top performers in reading and mathematics. Exploratory analysis of 4 th grade PIRLS and TIMSS data in the Nordic countries.}

By Sari Sulkunen, Kari Nissinen and Pekka Kupari, University of Jyväskylä

This article focuses on studying the background variables that predict low and top performance in reading and mathematics during the primary years of school in four Nordic countries: Denmark, Finland, Norway and Sweden. The purpose of the study is to provide information about low and top performance in the two important key competences in order to develop educational systems to better meet the students' diverse needs.

PIRLS and TIMSS 2011 datasets were used in the analysis, which consisted of country-specific, three-level logistic regression models. Potential predictors for low and top performance were selected on the basis of earlier research findings.

The results of the study showed that students' basic skills in reading, their home resources, as well as the attitudes and activities related to reading and mathematics, predicted their performance in all the Nordic countries. Class and school level variables predicted the students' performance only in Denmark and Sweden, and they clearly played a less important role in predicting performance than the student-level variables.

The article emphasises the importance of providing individual support for pupils who need it. The individualized approach provides a solid framework for learning for students who have a weak start and students who have a disadvantage at school for one reason or another. In addition, top performers need individualized education, which includes materials 
and tasks challenging enough to develop their competencies to the level of their full potential.

The need for an individual approach places a great deal of pressure on teachers' education and continuous professional development in topics such as teaching materials and methods, assessment and diagnosing learning problems. Still, this article states that resources and opportunities for continuous professional development for teachers are not adequate in the Nordic countries, particularly in Finland.

\subsection{Teacher attitudes and practices in international studies and their relationship to PISA performance: Nordic countries in an international context}

By Ragnar F. Ólafsson and Júlíus K. Björnsson, Educational Testing Institute - Reykjavik

The objective of this article is to explore cultural differences in teaching practices and attitudes among European countries, with a special focus on Nordic countries. The international PIRLS and TIMSS studies provide information about teachers' attitudes and practices as well as indicators of pupils' achievement in reading, math and science. This data provides an excellent opportunity in which to explore cultural differences in the context of teaching and the findings could be used to identify certain types of teaching practices that may be conducive to higher achievement in reading, mathematical and science literacy, which are assessed by PISA, another international OECD educational research program.

Teachers' responses to the PIRLS and TIMSS questions about their teaching practices and their attitudes towards teaching in general, including math, reading and science, were subjected to Multidimensional Scaling Analysis, based on OECD country means on each of 325 questionnaire items. Country groups (or clusters) were identified. These groups/clusters consisted of East-European, Mediterranean, Anglo-Saxon, Germanic and Nordic countries, with some overlaps, indicating differences in teaching culture 
across these OECD countries. A main dimension of engagement was identified differentiating largely between Eastern European and Western countries. The former showed greater engagement, which consisted of greater teacher self-confidence, greater use of specific teaching strategies, more test administration and home-work follow up. In the PISA survey, a correlation was found between engagement and progress in reading and math literacy, indicating that more engaging teaching practices are associated with more progress. The limitations of the approach are discussed.

\subsection{Mathematics in the Nordic countries - Trends and challenges in students' achievement in Norway, Sweden, Finland and Denmark}

By Liv Sissel Grønmo, Inger Christin Borge and Arne Hole, University of Oslo

The aim of this article is to provide an overview of the important characteristics of mathematics as a school subject in Nordic countries, and to point out the issues that should be addressed in order to improve students' learning of mathematics. The analyses in the article provide evidence of the important educational factors that can explain the trends in students' achievement.

The article presents results from analysing several factors that may have contributed to an understanding of trends in Norway, Sweden and Finland. This includes analyses and discussions of factors such as School Emphasis on Academic Success (SEAS) and Students' Opportunity to Learn (OTL) mathematics. The results of the analyses of what characterizes mathematics in schools in Nordic countries are also presented. This article also refers to the results from other international comparative studies, such as PISA, TIMSS Advanced and TEDS-M, in order to obtain a solid basis for discussions about how to make improvement in students' achievement in mathematics.

The analyses show that the increased School Emphasis on Academic Success and improvement on students' Opportunity to Learn that is measured in Norwegian schools is an important factor for explaining the im- 
proved results measured in Grade 8. This is likely to reflect changes in educational policy and curriculum in Norway, with an increased emphasis on students' performance in schools. Another issue stressed in the article is the low emphasis that Nordic countries place on pure mathematics, such as algebra. This low emphasis is likely to influence the possibility of students pursuing studies and professions using advanced mathematics.

\subsection{A Nordic comparison of national objectives for reading instruction and teachers' responses about actual reading practice}

By Louise Rønberg and Jan Mejding, Aarhus University, Department of Education (DPU)

This article presents a comparison of the Nordic countries' official objectives for reading and analyses of 1005 Nordic teachers' responses regarding their reading instruction. The specificity and transparency vary greatly in the objectives, from broad outlines in Norway to more specific and functional goals in Finland. It appears that the Finnish descriptions are more aligned with current empirical research on reading comprehension.

Swedish and Norwegian teachers have the most varied used of both literary and informational text types during a week, whereas Finnish teachers give informational texts a higher priority than literary texts - and the opposite is apparent for Danish teachers. The Finnish and Norwegian teachers prioritise activities that enhance students' oral reading fluency, which is important for reading comprehension development, to a greater extent than teachers in Denmark and Sweden do. The Nordic teachers in general appear to prioritise advanced comprehension activities to a lesser extent than teachers in the English-speaking countries do. Furthermore, Danish teachers put the least emphasis on formative assessments compared to the other Nordic countries.

It is important that national objectives correspond with empirical research on reading instruction and that they are functional and transparent as they set the stage for the actual instruction in class. 


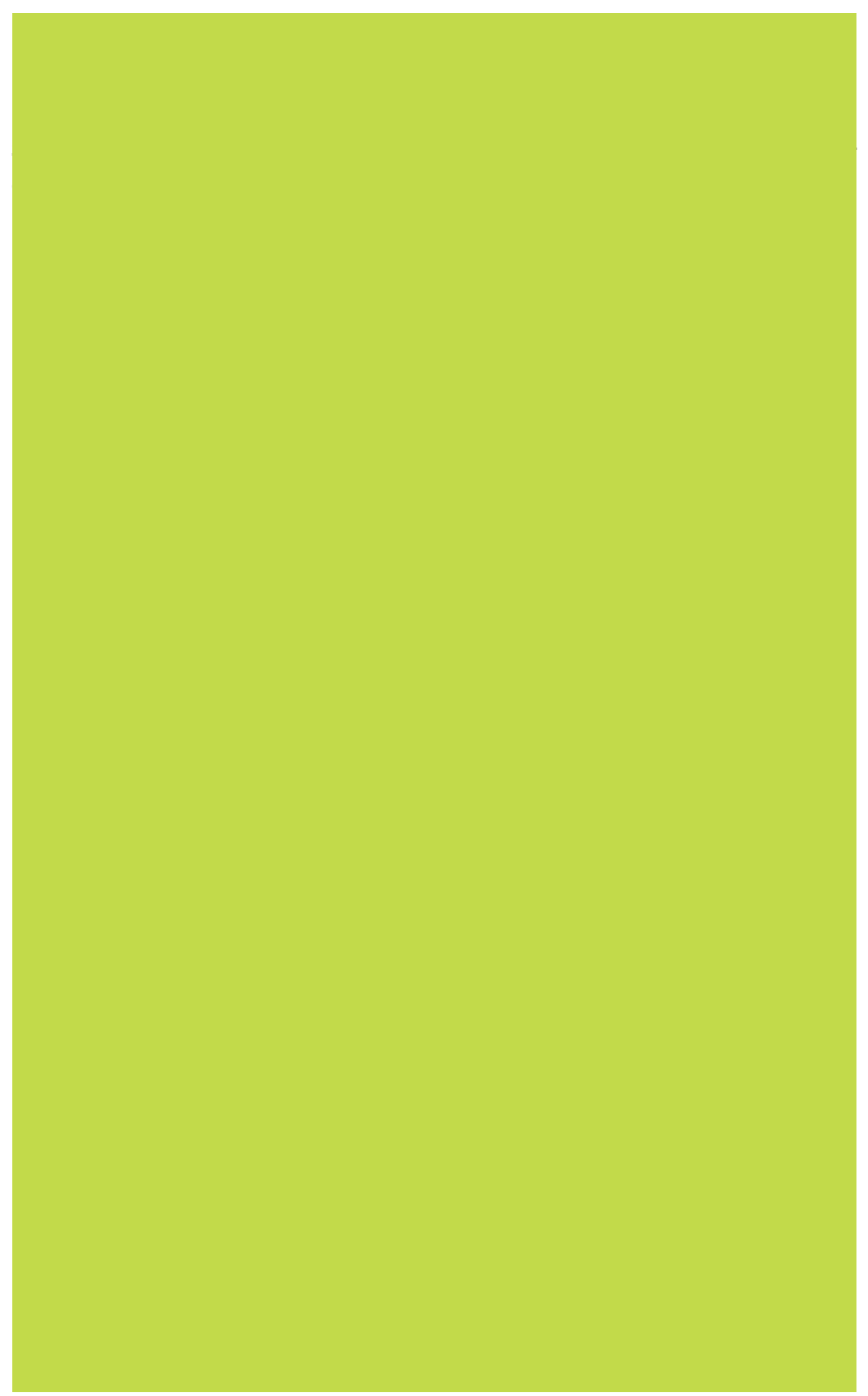




\section{School performance differences and policy variations in Finland, Norway and Sweden}

By Kajsa Yang Hansen, Jan-Eric Gustafsson and Monica Rosén, University of Gothenburg

\subsection{Introduction}

The present study focuses on differences in the amount of variation in level of performance between schools and classrooms for Grade 4 and Grade 8 in Finland, Norway and Sweden. Variability in the level of performance between different schools is of great interest both from research and policy perspectives. A large amount of observed differences in level of performance between schools may be indicative of a segregated school system in which students of different levels of ability are sorted into different schools through processes of selection or self-selection. However, performance variability between schools may also reflect differences in the level of quality of the education offered by different schools. It is therefore essential both to describe the amount of performance variability between schools and to determine which factors can account for the variation.

However, teaching typically is organised within more or less flexibly organised groups of students within a school, normally in the form of classes. Given that different classes are usually taught by different teachers and that the students within a particular class influence one another, systematic variation in the level of performance of different classes may be expected. In order to correctly determine the amount of school perfor- 
mance differences, it is, therefore, also necessary to determine the amount of differences between the classes within different schools. In the present study, we use multi-level modelling techniques which separate the total observed variation into factors due to students, classes and schools. Data from the International Association for the Evaluation of Educational Achievement (IEA) 2011 Trends in International Mathematics and Science Study. (TIMSS) for Grade 4 and Grade 8 and Progress in International Reading Literacy Study (PIRLS) for Grade 4 form the basis of form the basis of these analyses.

We use a comparative approach focusing on differences between the Nordic countries, and originally we aimed to include all five Nordic countries in the analyses. Regrettably, however, Iceland did not participate in the 2011 TIMSS and PIRLS studies, so we had to exclude Iceland from the study. For Denmark, data are available for Grade 4, but the sampling design of the study was such that it does not allow separation of variation due to schools and classes, so we had to exclude Denmark as well.

Our study is, therefore, restricted to comparisons between Finland, Norway and Sweden. One main aim is to determine the magnitude of school and classroom performance differences for Grade 4 and Grade 8 in the three countries, and another main aim is to investigate school and classroom performance differences as a function of the location of the school (urban or rural) and the students' socio-economic status.

Given that school and classroom performance differences are likely to be determined by educational policies, we first review educational policy changes in Finland, Norway and Sweden.

\subsection{Policy changes in Finland, Norway and Sweden}

The educational systems in the Nordic countries share common values and ideologies for geographic, cultural and historical reasons. During the last 50 years, the Nordic welfare state has been established as a unique model, with a strong emphasis on equity of access to education of a high level of quality. During the 1960s and 1970s, the organisationally differentiated compulsory education was, in the Nordic countries, replaced with comprehensive compulsory schooling for at least nine years. 
One global trend in educational reforms since the 1980s has been to adopt market principles in the realm of schooling. The reforms thus have been characterised by an orientation towards output of schooling rather than on input of resources. Decentralisation and deregulation of decision making, accountability, choice and competition have also been clearly visible global trends (e.g. Sahlberg, 2011). Such educational reform ideas have also influenced the Nordic countries, albeit to a different extent and in different ways.

\subsubsection{Finland}

The comprehensive education system in Finland was introduced in the 1970s, following the introduction of comprehensive schooling in Sweden in the 1950s and in Norway in the 1960s (Kerr, Pekkarinen, \& Uusitalo, 2013). Since that time, Finland has not made any major school-reform (Sahlberg, 2010, 2011).

However, in Finland too decision making has been decentralised. In 1993, local authorities were given more autonomy in the allocation of school resources. They no longer received earmarked funds from the central government; instead, a lump sum was allocated that the local government could distribute to different purposes (see, e.g., Aho, Pitkänen, \& Sahlberg, 2006; Rinne et al., 2002). Since there is no central regulation concerning the allocation of school funds, there has been great diversity among the principles of funding used by different local authorities.

In 1998, it was made explicit that parents could choose any school for their child within the municipality. However, Finland has very few schools that have providers other than the municipality. Since Finnish schools are decentralised in terms of curricula, teaching methods and other pedagogical practices and profiles, choice of school was a meaningful policy change. However, admission to school still gives priority to the local students. Schools are allowed to recruit students from outside the local catchment area only when there are places left after enrolment of the local students. 


\subsubsection{Norway}

Norway has also implemented several reforms. During the 1980s and 1990s, the previously strongly centralised school system was decentralised in several respects. A radical step towards decentralisation and local autonomy was the introduction of a new funding system in 1986, which implied a change from state-determined and earmarked allocation of funds to municipally decided priorities. The 1992 Local Government Act gave the local authorities and school leaders greater responsibility for allocating funds, providing education and assuring its quality. Schools also got an increased amount of autonomy, which included budgeting, recruitment, education management and competence development. The length of compulsory education in Norway was extended to 10 years in 1997 (see Helg, Oslash, \& Homme, 2006 for a more detailed comparison between Norway and Sweden).

The Norwegian Independent School Act of 2003 made it easier to start independent schools and for authorised independent schools to receive financial support from the state. The number of independent compulsory schools has increased since 2003, but still the great majority of students, approximately $98 \%$, attend public schools. This is because enrolment in primary and lower secondary schools still largely follows the proximity principle. However, in the large cities of Norway, systems of school-choice have now been introduced, which are similar to those introduced in Finland, as is described above.

\subsubsection{Sweden}

The Swedish school system has undergone fundamental changes since the late 1980s (see SOU 2014:5 for a thorough description and analysis). In 1989 the municipalities took over responsibility from the state as employers for the teachers and other categories of school personnel. Furthermore, decision-making concerning the organisation of schooling was decentralised to the municipalities and considerable local autonomy was allowed (Björklund et al., 2004). The decentralisation was thus followed by a deregulation of principles of funding, giving the municipalities considerable freedom to allocate funds. Many decisions, such as hiring teach- 
ers, were also decentralised to municipalities and schools, and here, too, a previously strict system of eligibility of employment was deregulated.

A voucher system to support free school choice was launched in the beginning of the 1990s. It allows students to choose the school of their preference, which broke with the proximity principle and made it possible for students to choose schools outside of their neighbourhood. A system of independent (private) schools was introduced at the same time, and the number of students attending independent schools has successively increased. Currently, over $16 \%$ of the compulsory schools are independent schools, and around 13\% of the comprehensive school students attend independent schools.

In 1994, new curricula, primarily describing which goals were to be reached but not how to reach them, were introduced for both compulsory school and for upper secondary school. New criterion-related grading systems were also introduced.

These reforms, and others, have thoroughly transformed the Swedish school system from being highly centralised and regulated to being very decentralised and deregulated (Lundahl, 2002; Lundahl, et al., 2013).

In summary, different educational policy changes in Finland, Norway and Sweden have taken place, even though they all tend to be in the direction of decentralisation and deregulation of decision making.

\subsection{Research on determinants of school and classroom variation in performance}

In this section, we provide a brief overview of research on factors influencing variation between schools and classrooms.

\subsubsection{Selection of students to different schools}

Previous research has shown that the most important determinant of school level performance differences is the composition of the schools' student body with respect to social and ethnic background, and with respect to previous level of performance (e.g. Coleman, et al., 1966; Jencks \& Mayer, 1990; Thrupp \& Lupton, 2006; Yang, 2003). 
Explicit selection of students into schools on the basis of previous performance is an important factor in causing school differences. Thus, school systems which use organisational differentiation to track students into academic and non-academic schools are characterised by very substantial school performance differences, which may amount to $40-50 \%$ of the total amount of performance differences (see, e.g., OECD, 2013; Yang, 2003). Germany and Austria are two examples of countries with such organisational differentiation. In the 1960s and 1970s, the Nordic countries abolished organisational differentiation and introduced comprehensive compulsory schooling; so, in these countries, school performance differences are smaller and typically account for less than $10 \%$ of the total performance variation. However, even school differences of this magnitude may be of substantial importance (e.g. Yang, 2003).

Given that students often attend neighbourhood schools, the socioeconomic and ethnic composition of schools tends to reflect the sociodemographic characteristics of the neighbourhood that the school serves. Therefore, residential segregation with respect to socio-economic background and ethnicity affects school performance differences. If students and parents are allowed free school choice, this may also affect school performance differences. Students sorting themselves into schools on the basis of socio-economic and ethnic factors may cause school performance differences to increase over and above the differences caused by residential segregation. However, students sorting themselves into schools on the basis of ambition and ability may reduce the effects of residential segregation but increase segregation on the basis of performance (Gustafsson, 2006).

There is quite a rich body of literature of international research on different mechanisms of school segregation and their relative importance (see, e.g., Palardy, 2013; Sahlgren, 2013). However, results tend to be inconsistent across studies, and so far little consensus has been achieved. The main reason for this is probably that the mechanisms to a large extent are specific to different cultures and school systems. This suggests that it is important to investigate these issues within the Nordic countries as well.

As has been described above, there have in Finland, Norway and Sweden been reforms of the educational systems, which to a varying extent have allowed students and parents increased possibilities of school choice. 
This may influence the amount of school differences, and particularly so in urban areas where there are real possibilities of choice.

If attendance at different schools is determined by residential segregation and/or school choice, it may be expected that this will cause differences between schools with respect to the students' socio-economic status (SES). Such differences will also be reflected in performance differences between schools, given the strong relationship between SES and performance, particularly at the school level (Sirin, 2005). These performance differences are likely to be observed primarily at the school level unless allocation of students to different classrooms is made on the basis of previous levels of performance.

\subsubsection{Classroom differences in performance}

Previous research has shown that classroom differences in level of performance often are of substantial magnitude and that they often are larger than school differences (see e.g., Creemers \& Kyriakides, 2008). While classroom differences may be due to the sorting of students into different classes, they also may reflect differences in quality of instruction and differences between classrooms with respect to teacher-student relations, for example. Thus, the determinants of classroom differences in performance are likely to differ from those causing differences in level of performance between different schools.

Furthermore, many studies confound variation between schools and classrooms, by not separating their relative contributions. This is sometimes due to the fact that this is not possible because it requires that the different schools be represented by two or more classrooms and also that the classroom to which each student belongs is correctly represented in the data. When school and classroom variance is confounded, the results typically are reported in terms of school differences. However, such estimated school differences may to a considerable extent reflect classroom differences. Confounding of the two sources of variation may thus systematically bias the findings from studies on school variation. 


\subsubsection{Research questions}

The TIMSS and PIRLS data include information about different characteristics of the schools, such as location (urban/rural) and students' socioeconomic background. This information can be used to investigate the different mechanisms behind school variation more closely. Thus, school choice is mainly an urban phenomenon, and the effects of school choice can therefore primarily be expected to be seen in urban areas. Residential segregation is also primarily an urban phenomenon, and it may be expected that this is a more important factor for students in lower grades than in higher grades. Comparisons of differences in the amount of observed school performance differences in urban and rural schools for Grades 4 and 8 in the three countries may therefore be a way to investigate the impact of school choice and residential segregation.

The following research questions will be focused upon:

- What differences are there in the magnitude of school and classroom performance differences for Grade 4 and Grade 8 in Finland, Norway and Sweden?

- What differences are there in the magnitude of school and classroom performance differences in urban and rural schools in Finland, Norway and Sweden?

- To what extent are school and classroom performance differences related to students' SES in Finland, Norway and Sweden?

\subsection{Method}

In this section, samples, variables and analytical methods used in the analyses are presented.

\subsubsection{Samples}

Grade 4 and Grade 8 data from the TIMSS 2011 study were included in the analyses. For Grade 4, data from the PIRLS 2011 study, take away "literacy test" were also included. 


\begin{tabular}{|c|c|c|c|c|c|c|c|c|c|c|c|c|}
\hline & \multicolumn{6}{|c|}{ Grade 4} & \multicolumn{6}{|c|}{ Grade 8} \\
\hline & \multicolumn{2}{|c|}{ Finland } & \multicolumn{2}{|c|}{ Norway } & \multicolumn{2}{|c|}{ Sweden } & \multicolumn{2}{|c|}{ Finland } & \multicolumn{2}{|c|}{ Norway } & \multicolumn{2}{|c|}{ Sweden } \\
\hline & Rural & Urban & Rural & Urban & Rural & Urban & Rural & Urban & Rural & Urban & Rural & Urban \\
\hline $\mathrm{N}$ students & 2,114 & 2,383 & 714 & 2,290 & 1,622 & 2,525 & 2,137 & 1,791 & 2,833 & 3,778 & 2,390 & 2,277 \\
\hline $\mathrm{N}$ classes & 133 & 125 & 55 & 135 & 91 & 131 & 133 & 102 & 48 & 118 & 111 & 110 \\
\hline $\mathrm{N}$ schools & 78 & 63 & 40 & 75 & 61 & 74 & 78 & 58 & 44 & 87 & 64 & 63 \\
\hline \multicolumn{13}{|l|}{ Total } \\
\hline $\mathrm{N}$ students & \multicolumn{2}{|c|}{4,638} & \multicolumn{2}{|c|}{3,004} & \multicolumn{2}{|c|}{4,663} & \multicolumn{2}{|c|}{4,622} & \multicolumn{2}{|c|}{3,862} & \multicolumn{2}{|c|}{5,573} \\
\hline $\mathrm{N}$ classes & \multicolumn{2}{|c|}{268} & \multicolumn{2}{|c|}{185} & \multicolumn{2}{|c|}{252} & \multicolumn{2}{|c|}{258} & \multicolumn{2}{|c|}{170} & \multicolumn{2}{|c|}{266} \\
\hline $\mathrm{N}$ schools & \multicolumn{2}{|c|}{145} & \multicolumn{2}{|c|}{115} & \multicolumn{2}{|c|}{152} & \multicolumn{2}{|c|}{145} & \multicolumn{2}{|c|}{134} & \multicolumn{2}{|c|}{153} \\
\hline
\end{tabular}

Note: The number of urban and rural students does not sum up to the total number of observations due to missing information in the urban/rural variable for some schools.

As is shown in Table 1, there were 12,305 students, 412 schools and 705 classes from Grade 4, and there were 14,057 students, 432 schools and 694 classes from Grade 8 included in the analysis. The students were distributed over urban and rural schools, and in general there were more urban schools than rural and more students enrolled in urban schools than were enrolled in rural schools.

\subsubsection{Variables}

The variables used in the analyses are presented in Table 2, along with descriptive statistics.

Information about number of books at home was used to measure SES. This variable in particular captures differences in cultural capital (Bourdieu, 1997) among the homes, which has been shown to be the aspect of SES most strongly tied to achievement (Gustafsson, Yang, \& Rosén, 2013; Yang, 2003; Yang \& Gustafsson, 2004). While there are also other indicators of SES available in the TIMSS and PIRLS data, such as level of parental education, the variable representing number of books is the only one which is comparable across Grade 4 and Grade 8. We therefore use this variable as the sole indicator of SES.

Mathematics and science achievement scores were outcome variables for both Grade 4 and Grade 8, and for Grade 4 reading achievement was also measured. These are estimated as so called "plausible values" which are multiple imputed scores, taking advantage of all available 
responses to both test items and background variables (von Davier, Gonzalez, \& Mislevy, 2009).

The variable "Type of community" is dummy coded, with rural schools coded as 0 and urban schools coded as 1 . This variable is based a question asking about "the type of immediate area of the school's location". The response alternatives "Urban", "Sub-urban" and "Medium size city" were collapsed into the "urban" category, while "Small town" and "Remote rural" were collapsed into the "rural" category. However, this information is missing in the Grade 8 data for Norway. The question "how many people live in the area where the school is located" was therefore used for classifying urban vs. rural schools in the Norwegian data. For both Grade 4 and Grade 8, communities where over 15,001 people live were defined as urban, while communities with less than 15,000 people were defined as rural. This implies that comparisons with respect to urban-rural differences between Norway on the one hand, and Finland and Sweden on the other hand, should be interpreted with caution. 


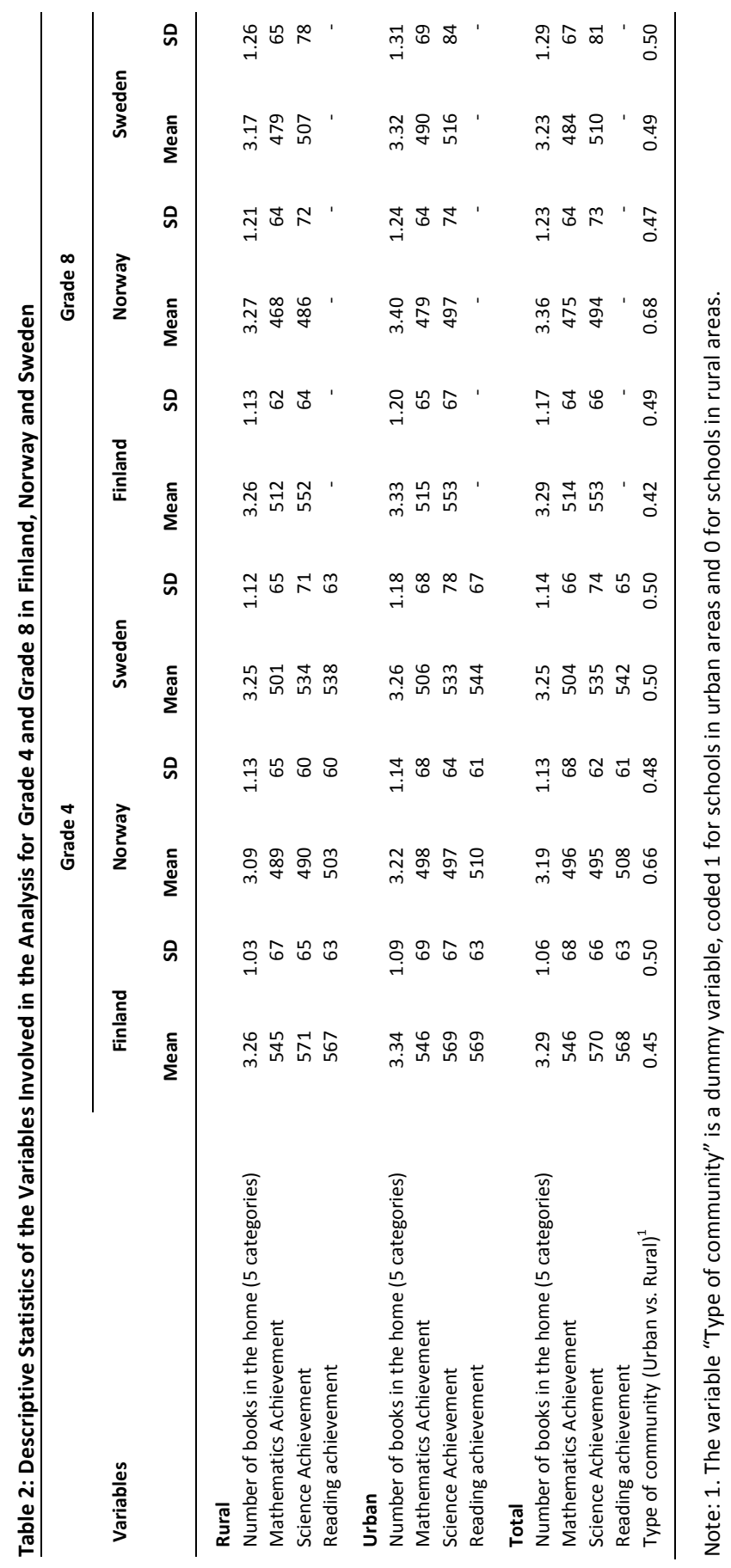




\subsubsection{Analytical method}

Multi-level regression techniques were used to separate the total variation in outcomes into three different parts: one that is due to the differences among individual students within classrooms, a second that is due to differences between classrooms within schools, and a third that is due to performance differences between schools. The SES-related variable "Number of books at home" was then introduced into the analysis as an independent variable, and it was investigated as to how much variance this variable accounted for at each of the three levels of observation.

The analyses were done with the Mixed Models procedure in the SPSS system, using individual case weights. The models were estimated using the first plausible value of the mathematics, science and reading achievement scores.

\subsection{Results}

Results pertaining to the research questions are presented below.

\subsubsection{School and classroom performance differences}

The magnitude of between-school and between-class differences in mathematics, science, and reading performance can be measured by the Intraclass Correlation Coefficient (ICC), which expresses the proportion of variation in a variable that can be explained by belonging to different groups, such as schools or classrooms. When there are large mean differences in the level of performance between the different groups, the ICC becomes large. It may be noted though that even though the ICC is referred to as a correlation measure, it is rather a squared correlation, expressing amount of variance explained. Table 3 shows the estimated ICCs for TIMSS and PIRLS 2011 in Finland, Norway and Sweden for Grades 4 and 8. 
Table 3: Estimated School- and Class-level ICCs of Mathematics, Science and Reading Achievement for Grade 4 and Grade 8

\begin{tabular}{lllcccc}
\hline Country & Level & \multicolumn{2}{c}{ Grade 4} & \multicolumn{2}{c}{ Grade 8 } \\
& & Mathematics & Science & Reading & Mathematics & Science \\
\hline \multirow{2}{*}{ Finland } & Class & .13 & .12 & .13 & .26 & .30 \\
& School & .04 & .04 & .02 & .02 & .03 \\
\multirow{3}{*}{ Norway } & Class & .08 & .05 & .02 & .02 & .03 \\
& School & .10 & .07 & .09 & .10 & .10 \\
\multirow{5}{*}{ Sweden } & & .03 & .03 & .04 & .07 & .09 \\
& Class & .15 & .19 & .15 & .08 & .12 \\
\hline
\end{tabular}

Different patterns of ICCs were observed in the three countries. For Finland, the school ICCs were close to zero, while the classroom ICCs were large, and particularly so for Grade 8 where the ICC approached .30 for both mathematics and science. For Norway, the school ICCs were relatively large (around .10) for both Grade 4 and Grade 8. The classroom ICCs were small, even though estimates were somewhat higher for mathematics and science for Grade 4. For Sweden, the school ICCs were large, and particularly so for Grade 4. In Grade 8, there were both classroom- and school-differences. These results thus show substantial differences between the countries in terms of whether there are performance differences at the classroom- or the school-level.

One reason for these differences may be that students are sorted into schools and classrooms according to different principles. In particular, it is of interest to investigate to what extent student SES accounts for the performance differences at different levels. Table 4 presents results from a model in which the variable "Number of books at home" (or SES) has been added to the model. For each component of variance in the model, it is shown how much variance in performance the SES variable accounted for. However, for ICCs .06 or lower, the percentage estimates have been set to zero so as not to disturb the pattern of results with trivially small estimates. The .06 limit was somewhat arbitrarily chosen on the basis of considerations of both practical and statistical significance. 
Table 4: Percentage of Variance in Mathematics, Science and Reading Achievement at School-, Class- and Student-levels Explained by Number of Books at Home

\begin{tabular}{|c|c|c|c|c|c|c|}
\hline \multicolumn{2}{|c|}{ Explained Variance } & \multicolumn{3}{|c|}{ Grade 4} & \multicolumn{2}{|c|}{ Grade 8} \\
\hline & & Mathematics & Science & Reading & Mathematics & Science \\
\hline \multirow[t]{3}{*}{ Finland } & Student & 5 & 8 & 6 & 5 & 10 \\
\hline & Class & 7 & 13 & 13 & 20 & 24 \\
\hline & School & 0 & 0 & 0 & 0 & 0 \\
\hline \multirow[t]{3}{*}{ Norway } & Student & 5 & 7 & 6 & 14 & 14 \\
\hline & Class & 1 & 0 & 0 & 0 & 0 \\
\hline & School & 18 & 29 & 21 & 36 & 50 \\
\hline \multirow[t]{3}{*}{ Sweden } & Student & 7 & 9 & 6 & 9 & 13 \\
\hline & Class & 0 & 0 & 0 & 27 & 29 \\
\hline & School & 41 & 42 & 44 & 47 & 52 \\
\hline
\end{tabular}

Note: The explained variance has been set to zero for ICC estimates 0.06 or lower (see Table 3).

In Sweden, school performance differences were to a substantial degree (40-50\%) accounted for by the SES variable for both Grade 4 and Grade 8. For Norway, a similar pattern of results was observed for Grade 8, while the estimates were lower, but still large, for Grade 4 (20-30\%). In Finland, SES differences did not account for any school performance differences, but it should be noted that such differences were almost non-existent in Finland.

In Finland, classroom differences were of substantial magnitude and, particularly for Grade 8, they could be accounted for by SES differences. In Sweden, too, SES accounted for a part of the classroom differences (a little less than 30\%) for Grade 8, while for Grade 4, the amount of classroom differences was too small to make it meaningful to try to account for these in terms of SES. In the Norwegian data, there were no classroom differences, neither for Grade 4 nor in Grade 8.

At the student level, SES accounted for more variance in Grade 8 than in Grade 4, with the exception of mathematics in Grade 8 in Finland, where SES accounted for only $5 \%$ of the variance. This low relationship at the student level may be related to the large magnitude of classroom differences in Finland, which to a certain extent could be accounted for by SES. 


\subsubsection{School and classroom performance differences among urban and rural schools}

Given that opportunities for choice of school vary across urban and rural areas, it is of interest to investigate to what extent the amount of variance associated with schools and classrooms was different for schools located in different types of areas. Table 5 presents estimates of the ICCs for Grade 4 and Grade 8.

Table 5: Estimated School- and Class-level ICCs by Urban and Rural Schools for Grade 4 and Grade 8

\begin{tabular}{|c|c|c|c|c|c|c|c|c|c|c|c|}
\hline & & \multicolumn{6}{|c|}{ Grade 4} & \multicolumn{4}{|c|}{ Grade 8} \\
\hline & & \multicolumn{2}{|c|}{ Mathematics } & \multicolumn{2}{|c|}{ Science } & \multicolumn{2}{|c|}{ Reading } & \multicolumn{2}{|c|}{ Mathematics } & \multicolumn{2}{|c|}{ Science } \\
\hline & & Rural & Urban & Rural & Urban & Rural & Urban & Rural & Urban & Rural & Urban \\
\hline \multirow[t]{2}{*}{ Finland } & Class & .13 & .12 & .12 & .10 & .14 & .11 & .22 & .22 & .26 & .25 \\
\hline & School & .03 & .05 & .03 & .05 & .00 & .04 & .00 & .06 & .01 & .06 \\
\hline \multirow[t]{2}{*}{ Norway } & Class & .07 & .09 & .03 & .06 & .02 & .03 & .01 & .02 & .01 & .03 \\
\hline & School & .09 & .10 & .11 & .07 & .07 & .10 & .05 & .11 & .05 & .11 \\
\hline \multirow[t]{2}{*}{ Sweden } & Class & .04 & .04 & .05 & .03 & .05 & .05 & .06 & .09 & .06 & .13 \\
\hline & School & .06 & .21 & .05 & .27 & .04 & .21 & .02 & .14 & .05 & .20 \\
\hline
\end{tabular}

For both Finland and Norway, the patterns of results were quite similar across schools located in urban and rural areas, even though there was a tendency for the magnitude of school differences to be larger for urban schools than for rural schools for Grade 8. For Sweden, the results were strikingly different - the amount of school differences being larger in urban than in rural areas for both Grade 4 and Grade 8.

Only small school differences in level of performance could thus be observed among rural schools in all three countries. Among urban schools, there were at least some school differences, and the pattern of differences among countries was similar for Grade 4 and Grade 8 - the largest differences being observed for Sweden, the lowest for Finland and Norway in between. In Finland, there were large classroom differences among both urban and rural schools in both grades, while in Sweden there were classroom differences primarily among urban schools for Grade 8. This suggests that the classroom differences observed in Sweden and Finland may be due to different determinants. 
Table 6: Percentage of Variance Explained by Number of Books at Home in Urban and Rural Schools (\%)

\begin{tabular}{|c|c|c|c|c|c|c|c|c|c|c|c|}
\hline \multicolumn{2}{|c|}{ Explained variance (\%) } & \multicolumn{6}{|c|}{ Grade 4} & \multicolumn{4}{|c|}{ Grade 8} \\
\hline & & \multicolumn{2}{|c|}{ Mathematics } & \multicolumn{2}{|c|}{ Science } & \multicolumn{2}{|c|}{ Reading } & \multicolumn{2}{|c|}{ Mathematics } & \multicolumn{2}{|c|}{ Science } \\
\hline & & Rural & Urban & Rural & Urban & Rural & Urban & Rural & Urban & Rural & Urban \\
\hline \multirow[t]{3}{*}{ Finland } & Student & 4 & 6 & 7 & 10 & 4 & 8 & 4 & 7 & 9 & 12 \\
\hline & Class & 1 & 12 & 5 & 21 & 13 & 16 & 16 & 21 & 15 & 26 \\
\hline & School & 0 & 0 & 0 & 0 & 0 & 0 & 0 & 0 & 0 & 0 \\
\hline \multirow[t]{3}{*}{ Norway } & Student & 5 & 4 & 6 & 7 & 5 & 7 & 9 & 17 & 8 & 17 \\
\hline & Class & 0 & 7 & 0 & 0 & 0 & 0 & 0 & 0 & 0 & 0 \\
\hline & School & 12 & 19 & 11 & 31 & 0 & 25 & 0 & 40 & 0 & 52 \\
\hline \multirow[t]{3}{*}{ Sweden } & Student & 6 & 7 & 9 & 8 & 6 & 7 & 9 & 9 & 11 & 14 \\
\hline & Class & 0 & 0 & 0 & 0 & 0 & 0 & 0 & 28 & 0 & 35 \\
\hline & School & 0 & 44 & 0 & 41 & 0 & 44 & 0 & 59 & 0 & 56 \\
\hline
\end{tabular}

Note: The explained variance has been set to zero for ICC estimates 0.06 or lower (see Table 7).

Table 6 presents the amount of variance accounted for by SES. For Sweden, the school differences for urban schools in both Grade 4 and Grade 8 were to a large degree accounted for by SES. For the Swedish rural schools, the ICCs were too small to allow estimation of SES impact. In the Norwegian data, school differences were accounted for by SES in both rural and urban schools for both grades, except that estimates were not computed for Grade 8 in rural schools. For Finland, SES did not account for any school differences. Thus, for Sweden and Norway, SES accounted for school variance in urban schools, and in Norway, this also held true for Grade 4 in rural schools. However, as has already been pointed out the somewhat different definition of the urban-rural distinction in Norway makes it necessary to interpret this result with caution. For Grade 8 urban schools, SES accounted for quite large amounts of school variance in Norway and Sweden.

In Sweden, there were classroom differences in performance particularly among urban Grade 8 schools. These differences could, to around $30 \%$, be accounted for by SES, suggesting that in urban Grade 8 schools students may be allocated to different classrooms on the basis of level of achievement. In Finland, there were classroom differences among both rural and urban schools for both Grade 4 and Grade 8, but differences were larger in Grade 8. The classroom differences among urban Grade 4 
schools could to a certain extent be accounted for by SES, as could the classroom differences among urban Grade 8 schools.

At the student level, SES accounted for somewhat less variance in achievement in rural schools than in urban schools in all three countries. In other respects, the patterns of relationships with SES were similar to those observed in the overall analysis.

\subsection{Discussion and Conclusions}

One main aim of the current study is to determine the amount of school and classroom performance differences in Grade 4 and Grade 8 in Finland, Norway and Sweden. Another main aim is to find explanations for the patterns of differences between the countries and the grades, particularly in terms of mechanisms related to the sorting of students across schools.

The results show a clear pattern of school-level differences in performance between the three Nordic countries. In Finland, there are no school differences, neither in Grade 4 nor in Grade 8. In Sweden, in contrast, the school differences in level of performance are quite substantial, and this is also the case for Norway. In Norway around $10 \%$ of the student differences in performance are accounted for by school differences for both Grade 4 and Grade 8. In Sweden, the school differences for Grade 8 are of the same size, but they are larger for Grade 4 (15-19\%).

In the academic year 2010-2011, 9\% of the Swedish Grade 4 students attended independent schools, while $15 \%$ of the Grade 8 students did. These numbers indicate that the frequency of school choice in Sweden is larger in the higher grades of compulsory school than it is in the lower grades. Therefore, the larger magnitude of school differences in Grade 4 is an unexpected result, given that the school differences are hypothesised to be partly due to school choice.

The Swedish results also show that for both Grade 4 and Grade 8, the school differences are to a considerable extent accounted for by SES differences among the students. Thus, the quite substantial decrease in the amount of school differences between Grade 4 and Grade 8 is associated with a fairly stable, or slightly increasing, relationship to SES. This pattern of results suggests that in Grade 4, the school differences are mainly due 
to segregation of living, the SES impact being driven by cost of living in different parts of the three metropolitan areas in Sweden. The increased opportunity for school choice in the higher grades may have been taken advantage of by high SES students representing both lower and higher levels of performance, but to some extent also by low SES students of high ability and ambition. The combined effect of these different categories of students sorting themselves into attractive schools could be decreased performance differences between schools, while the strength of relationship to SES is maintained. One possible explanation of the decrease in the amount of school differences in the higher grades in Sweden thus is that increased school choice counteracts the effects of segregation of living (see, e.g., Yang Hansen \& Gustafsson, 2012). However, there also are other possible explanations. In 2010-2011, there were in Sweden about twice as many Grade 8 students in each school than there were Grade 4 students. This implies that the catchment areas are larger in Grade 8 than they are in Grade 4, which in turn should imply that the catchment areas are more heterogeneous in Grade 8 than in Grade 4. This larger heterogeneity could explain the smaller magnitude of school differences in Grade 8.

In Norway, the amount of school differences remained constant between Grade 4 and Grade 8, but SES accounted for a larger part of the school differences for Grade 8 than for Grade 4. The smaller school differences in level of performance and the relatively weak SES relationship for Grade 4 suggests that the impact of segregation of living is lower in Norway than it is in Sweden. It may be hypothesised that in Norway, too, more opportunities of school choice are made available for Grade 8, which may cause the SES impact on school differences to increase. It is interesting to note, however, that the magnitude of school differences does not increase between Grade 4 and Grade 8, which suggests that the high SES students who actively choose their schools do not as a group perform better than other students.

For Swedish Grade 4 schools, there is a much higher school variation among urban schools than among rural schools. Assuming that school variation in the early school years is determined most of all by segregation of living, this suggests that such segregation is primarily an urban phenomenon in Sweden, and it may be hypothesised that it is particularly connected to the three metropolitan areas in Sweden. In Norway, there is 
no difference in the amount of school variation for Grade 4 between schools in rural and urban areas, suggesting that there is an equal amount of segregation of living in the two categories of areas in Norway. For Grade 8, there is only little school variation among rural schools in both Norway and Sweden. This may be explained by the fact that such schools tend to be larger than those for Grade 4 and therefore have more heterogeneous catchment areas. In Norway, both the amount of school variance and the SES impact is for Grade 8 higher in urban than in rural schools, which pattern suggests an impact of school choice. It should also be noted that the classification of urban and rural schools in Norway was based on the number of inhabitants in the community, rather than the community type, as used in Sweden and Finland.

Perhaps the most striking empirical result of the present study is the very substantial amount of classroom variation in Finland, amounting to $12-13 \%$ for Grade 4 and at least twice as much for Grade 8. The estimates are highly similar across rural and urban schools. This was an unexpected finding, and our study includes few variables that could help us understand this result. In urban schools, a part of the between-class variance (around $20-25 \%$ ) is due to SES, and for rural Grade 8 schools, SES accounts for about $13 \%$. Thus, a part of the classroom variance may be due to the sorting of students into different classrooms on the basis of level of performance.

Kupari and Nissinen (2013) also conducted three-level analyses of the TIMSS 2011 data and reported that the three-level model for the TIMSS 2011 data suggests that about a quarter of the total variation is contributed by the classroom differences. However, they did not report results from analyses which included explanatory variables, so this still remains to be done.

One of the things that is clearly brought out in descriptions of the Finnish school system is the high degree of autonomy of the Finnish teachers (e.g. Sahlberg, 2011). With the exception of the matriculation exam at the end of upper secondary school, there is little external accountability and control. Furthermore, the curriculum gives the teacher considerable freedom in making decisions about what to teach and how to teach. A system which decentralises much of the control of the teaching process to the teachers may, of course, also cause considerable variation both in how the teaching is organised and in the results that are achieved. Given that a considerable amount of information from the teachers is available in the 
questionnaires that are part of the TIMSS study, this information could be analysed to see to what extent there are similarities and differences among the teachers at different schools.

\subsubsection{Limitations}

While the analyses reported in this article are based upon high quality data, it must be observed that the data and the analyses are also afflicted by limitations. One main limitation of the study is that it did not prove possible to include all Nordic countries, which was originally planned. Iceland did not participate at all in TIMSS 2011. While Denmark participated in the TIMSS and PIRLS 2011 studies, the sampling design was such that the school and classroom variance could not be separated. It was, therefore, only possible to include three of the Nordic countries in the study. In future research, it may be worthwhile to try to take advantage of the data available in all the TIMSS and PIRLS studies. This could allow further countries to be included in the analyses, and it could also provide interesting information about trends in the development of contributions of variance at the school-, class-, and student-levels.

It must also be emphasised that in some cases, the information was not optimal for the purpose of separating school and classroom variance. Thus, for rural schools, it was quite common to have only one classroom, which caused standard errors for the estimated variance components to be large. We also observed that in some cases, there were schools with only one class comprising some 50-60 students. This is most likely a problem of coding to which class the students belong, and it does seem essential that care be taken to enter the full and correct information about this.

Another limitation of the current study is that we have relied on the single measure of "Number of books at home" to represent SES. While this is a simple and powerful indicator of cultural capital for both younger and older students, it does not represent other important aspects of SES, such as economic capital (Yang, 2003; Yang \& Gustafsson, 2004). It is conceivable that the mechanisms of segregation of living and school choice relate differentially to cultural and economic capital, so for both theoretical and empirical reasons, it may in future research be important to try to capture aspects of SES other than cultural capital. 
Yet another limitation of the study is that very few explanatory variables were included in the study. This was partly intentional because of the exploratory nature of the three-level modelling approach that was adopted. However, while SES does seem to be a powerful variable in accounting for school differences, the school questionnaire includes many interesting measures of school characteristics that should be systematically analysed to better understand the sources of the school-level differences in performance observed in Norway and Sweden. As has already been discussed, it also is important to establish a deeper understanding of the substantial classroom differences identified in the Finnish data.

\subsubsection{Conclusions}

This article had the aim of describing and understanding sources of performance variation at different levels of observation in three Nordic countries. We have found that there are performance differences between schools in Norway and Sweden, which may be due to both segregation of living and school choice. In Finland, there are no school differences, but instead we have identified very substantial classroom differences. It will be interesting tasks for further research to find the sources of these school and classroom differences.

\subsection{References}

Aho, E., Pitkänen, K., \& Sahlberg, P. (2006). Policy development and reform principles of basic and secondary education in Finland since 1968. Working Paper Series: the World Bank.

Björklund, A., P-A. Edin, P. Fredriksson, \& A. Krueger (2004). Education, equality, and efficiency - An analysis of Swedish school reforms during the 1990s. IFAU report, Uppsala. http://www.ifau.se/upload/pdf/se/2004/r04-01

Bourdieu, P. (1997). The forms of capital. In A. H. Halsey, H. Lauder, P. Brown \& A. Stuart-Wells (Eds.), Education: culture, economy, and society, (pp. 46-58). Oxford: Oxford University Press.

Coleman, J. S., Campbell, E., Hobson, C., McPartland, J., Mood, F., Weinfeld, F. et al. (1966). Equality of educational opportunity. Washington, DC: U.S. Government Printing Office. 
Creemers, B. P. M., \& Kyriakides, L. (2008). The dynamics of educational effectiveness: A contribution to policy, practice and theory in contemporary schools. London, UK: Routledge.

Gustafsson, J.-E. (2006). Barns utbildningssituation. Bidrag till ett kommunalt barnindex. Stockholm: Rädda Barnen.

Gustafsson, J.-E., Yang Hansen, K., \& Rosén, M. (2013). Effects of home background on student achievement in reading, mathematics, and science at the fourth grade. In M. O. Martin \& I. V. S., Mullis (Eds.), TIMSS and PIRLS 2011: Relationships among reading, mathematics, and science achievement at the fourth gradeimplications for early learning. Boston College, USA, Chestnut Hill, MA: TIMSS \& PIRLS International Study Center, Boston College.

Helg, I., Oslash, Y., \& Homme A. (2006). Policy tools and institutional change: Comparing education policies in Norway, Sweden and England. Journal of Public Policy, 26(2), 141-165.

Jencks, C., \& Mayer, S. E. (1990). The social consequences of growing up in a poor neighborhood. In L. Lynn Jr. \& M. G. H. McGeary (Eds.), Inner-city poverty in the United States (pp. 111-186). Washington, DC: National Academy Press.

Kerr, S. P., Pekkarinen, T., \& Uusitalo, R. (2013). School tracking and development of cognitive skills. Journal of Labor Economics, 31(3), 755-602.

Kupari and Nissinen (2013). Background factors behind mathematics achievement in Finnish education context: Explanatory models based on TIMSS 1999 and TIMSS 2011 data. Paper presented at the European Conference on Educational Research (ECER), Istanbul, Turkey, September, 2013.

Lundahl, L. (2002). Sweden: Decentralization, deregulation, quasi-markets - And then what? Journal of Education Policy, 17(6), 687-697.

Lundahl, L., Erixon Arreman, I, Holm, A. S., \& Lundström, U. (2013). Educational marketization the Swedish way. Education Inquiry, 4(3), 497-517.

OECD (2013). PISA 2012 results: What students know and can do: student performance in mathematics, reading and science (volume I). Paris: OECD.

Palardy, G. (2013). High school socioeconomic segregation and student attainment. American Educational Research Journal, 50(4), 714-754.

Rinne, R., Kivirauma, J., \& Simola, H. (2002). Shoots of revisionist education policy or just slow readjustment? The Finnish case of educational reconstruction. Journal of Education Policy, 17(6), 643-58.

Sahlberg, P. (2010). Educational change in Finland. In A. Hargreaves, M. Fullan, A. Lieberman \& D. Hopkins (Eds.), Second international handbook of educational change (pp. 323-348). New York: Springer.

Sahlberg, P. (2011). The fourth way of Finland. Journal of Educational Change, 12(2), 173-185.

Sahlgren, G. H. (2013). Dis-location. School choice, residential segregation and educational inequality (Research report 4). Centre for Market Reform of Education, London.

Sirin, S. R. (2005). Socioeconomic status and academic achievement: A metaanalytic. Review of Educational Research 75(3), 417-453. 
SOU (2014:5). Staten får inte abdikera - om kommunalisering. Stockholm: Utbildningsdepartementet.

Thrupp, M., \& Lupton, R. (2006). Taking school contexts more seriously: The social justice challenge. British Journal of Educational Studies, 54(83), 308-328.

von Davier, M., Gonzalez, E., \& Mislevy, R. J. (2009). What are plausible values and why are they useful? IERI Monograph Series. Vol 2, 9-36.

Yang, Y. (2003). Measuring socioeconomic status and its effects at individual and collective levels: A cross-country comparison. Gothenburg: Acta Universitatis Gothoburgensis, Gothenburg Studies in Educational Science 193.

Yang, Y., \& Gustafsson, J.-E. (2004). Measuring socioeconomic status at individual and collective levels. Educational Research and Evaluation, 10(3), 259-288.

Yang Hansen, K., \& Gustafsson, J-E. (2012). Causes of educational segregation in sweden - school choice or residential segregation. Paper presented at the European Conference on Educational Research (ECER), Cadiz, Spain, September, 2012. 


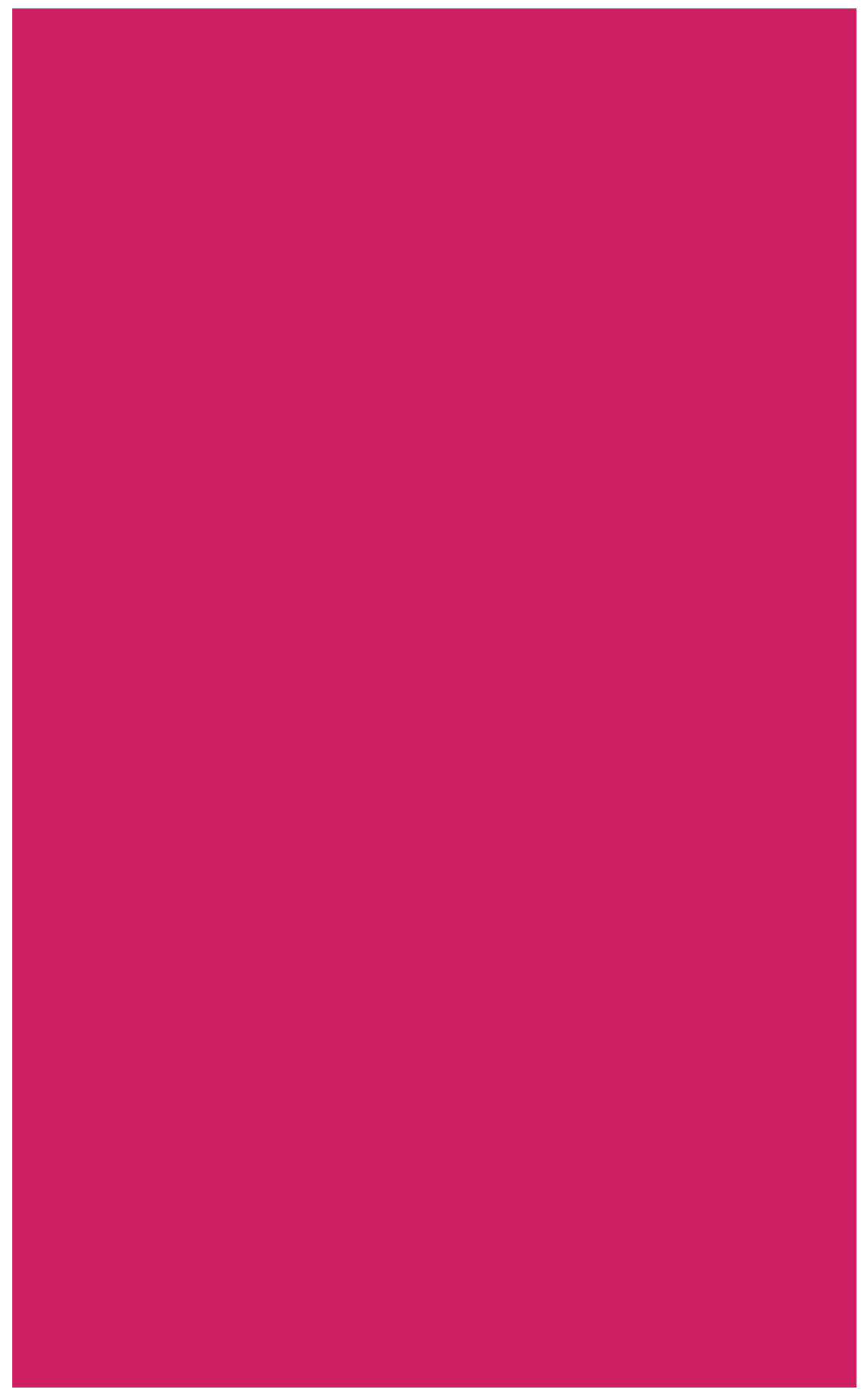




\section{Characteristics of low and top performers in reading and mathematics.} Exploratory analysis of $4^{\text {th }}$ grade PIRLS and TIMSS data in the Nordic countries

By Sari Sulkunen, Kari Nissinen and Pekka Kupari, ${ }^{1}$ University of Jyväskylä

\subsection{Summary}

This article focuses on studying the background variables predicting low and top performance in reading and in mathematics during the primary years of school in the four Nordic countries of Denmark, Finland, Norway and Sweden. The purpose of the study is to provide information about low and top performance in the two important key competences in order to develop educational systems to meet the students' diverse needs better. The Progress in International Reading Literacy Study (PIRLS) and Trends in International Mathematics and Science Study (TIMSS) 2011 datasets were used in the analysis which comprised country-specific three-level logistic regression models. Potential predictors for low and top perfor-

\footnotetext{
${ }^{1}$ Acknowledgements: The authors would like to thank the Norwegian co-NRC for PIRLS 2011 Victor van Daal, who generously provided the Norwegian Grade 5 data from the PIRLS 2011 study for the authors' use.
} 
mance were selected on the basis of earlier research findings. The results of the study showed that students' basic skills in reading and their home resources as well as attitudes and activities related to reading and mathematics predicted their performance in all the Nordic countries. Class and school level variables predicted students' performance only in Denmark and in Sweden, and they had clearly less important roles in predicting performance than student-level variables.

\subsection{Introduction}

It has been widely accepted in many countries that the quality of education is the key to any nation's - and individual's - success (OECD 2010a). Often, the perspective of economy is emphasised, but social and cultural wellbeing is also attributed to the quality and level of education. Consequently, international assessments of learning outcomes have become a regular exercise in many school systems as they can provide information on the relative weaknesses and strengths of the system, which is useful in developing education. In all the currently implemented international assessments for children, young people and adults alike, the focus is on key competences (EC 2007), which are important basic skills in all further learning at school and out of school, in everyday life, for active citizenship and at work. These competences include reading and mathematics, whether they are in the framework of reading comprehension, reading literacy or literacy, mathematics, mathematical literacy or numeracy (Mullis, Martin, Kennedy, Trong \& Sainsbury 2009; Mullis, Martin, Ruddock, O'Sullivan \& Preuschoff 2009; OECD 2009, 2012, 2013). In the recent International Association for the Evaluation of Educational Achievement (IEA) study PIRLS 2011, the focus was on Grade 4 students' reading comprehension, and in TIMSS 2011, which was implemented at the same time, the focus was on mathematics and science learning outcomes.

In addition to average performance, countries participating in international assessments pay attention to both ends of the student distribution. The percentage of low-performers indicates the extent to which the educational systems succeed in providing all students equal learning opportunities and the support they need. A number of studies report that poor 
key competences are in relation to a higher risk of dropping out of upper secondary education and becoming marginalised from further education altogether (e.g. OECD 2010b; Alatupa et al. 2007). This may also have significant consequences at the national level. The Organisation for Economic Co-operation and Development (OECD) has estimated that the quality of learning outcomes has greater impact than the length of the educational careers on nations' economic success (OECD 2010a). For an individual, becoming marginalised would mean not only being left out of education but also possibly lead to financial and social problems as well as a passive role in society. For the society, this would mean direct and indirect costs (HLG 2012, 23-26).

At the higher end of the student distribution, the interest is on the percentage of top performers, which indicates how well the country is prepared for the demands of expertise and innovations in the global context. Both ends of the student distribution have an important impact on the average performance as well. Several countries that have succeeded in improving their average performance, such as in the PISA reading assessment, have decreased the percentage of low performers (OECD 2010c; Sulkunen 2013).

The crucial question for countries is how to minimise the number of low performers and maximise the number of top performers. In answering this, more information is needed on the background factors related to performance levels in reading and mathematics. The purpose of the current study is to explore the characteristics of the top and low performers in reading and mathematics in the four Nordic countries based on the enormously rich PIRLS and TIMSS 2011 datasets. The specific research question is as follows: Which background variables predict the low and top performance in reading and in mathematics? Additionally, recommendations for supporting low and top performers' learning are given. 


\subsection{Previous findings on predicting performance in reading and mathematics}

There are several national and international studies on the reading and mathematics performance of school-aged children and adolescents summarizing factors behind learning outcomes. Additionally, there are some studies explaining low performance and somewhat fewer studies on top performance. These studies may have rather different approaches in terms of target group, data used, countries in question and methodology, but the results are still quite consistent. The focus in this section is on research relevant for the Nordic countries of Denmark, Finland, Norway and Sweden.

At the student level, home background and, more specifically, socioeconomic status measured as parents' educational level and/or occupation (Linnakylä, Malin \& Taube 2004, 2006; Linnakylä \& Malin 2007) or as economic, social and cultural status (Sulkunen \& Nissinen 2012; Fredriksson et al. 2012) is one of the most important predictors of reading literacy performance. Home background also explains some of the differences between schools (Myrberg \& Rosen 2006; Alivernini 2013). However, there is evidence that cultural capital and social capital are more important predictors of reading performance than the economic status of the family (Jensen \& Turmo 2012). Especially in the case of low performers, this means that low appreciation of culture and reading at home - reflected in the number of cultural items and books - is a risk for low performance in reading even if home is relatively wealthy (Sulkunen \& Nissinen 2012). The significance of home background for Grade 4 students' reading literacy is evident also in recent studies conducted on PIRLS 2011 data (Sulkunen \& Nissinen 2013; van Daal et al. 2012).

Also in mathematics, the results from various studies have shown that home background and socio-economic status are strongly related to students' mathematics achievement in school (Kupari 2006; Kupari \& Nissinen 2013; Lamb \& Fullarton 2000; Marks et al. 2006). Brese and Mirazchiyski (2008) focused on the TIMSS 2007 and PISA 2006 studies and covered five aspects of home background, revealing that the variables on parents' education and home possessions were strong predictors of mathematics achievement. Furthermore, studies in numerous countries 
have shown that the socio-economic profile of schools in strongly associated with student mathematics achievement (McConney \& Perry 2010).

Another important home-related predictor of reading performance is students' language background. Home language differing from the language of instruction at school increases the risk for low performance in reading. This is evident in the most recent PIRLS data for Finland and Norway (Sulkunen \& Nissinen 2013; van Daal et al. 2012) but also in the PISA 2009 study for the four Nordic countries participating in the study (Fredriksson et al. 2012; Sulkunen \& Nissinen 2012) and also in earlier PISA studies (e.g. Linnakylä, Malin \& Taube 2004, 2006; Linnakylä \& Malin 2007). The language used at home can differ from the school's language in immigrant families but also in, for instance, some Finnish-speaking families in Finland who send their children to Swedish-speaking schools (Harju-Luukkainen \& Nissinen 2011). In mathematics, also, the accumulated research evidence suggests that students' language background (home language differing from the language of instruction) and students' reading ability are related to their mathematics achievement (Brese \& Mirazchiyski 2008; Brookhart 1997; Howie 2002).

Moreover, individual students' characteristics, attitudes and practices are relevant in explaining reading performance. At Grade 4 in particular, students' basic reading skills, measured as accuracy and fluency of reading, are the most important predictors of the reading comprehension measured in the PIRLS study (Sulkunen \& Nissinen 2013; van Daal et al. 2012). However, the basic skills are relevant for reading literacy performance also at the age of 15, as shown in the Danish study on PISA 2009 data in which vocabulary knowledge was the strongest predictor of low reading performance after controlling for socio-economic status (Arnbak 2012). Student's gender is also related to reading performance. In several studies based on PISA and PIRLS data, boys are frequently overrepresented among the low performers (Linnakylä, Malin \& Taube 2004, 2006; van Daal et al. 2012; Fredriksson et al. 2012; Sulkunen \& Nissinen 2012). However, when other variables are taken into account, gender is not necessarily a significant predictor of reading performance. For instance, in the analysis of Finnish Grade 4 students' reading performance in PIRLS 2011 (Sulkunen \& Nissinen 2013), the gender effect did not appear in the predictive model. Instead, gender was replaced with variables highly cor- 
related with it, most importantly reading engagement. This suggests that it is not the male gender as such that is a risk for low reading performance but boys' lower engagement compared to that of girls. Reading engagement (enjoyment of reading, diversity of reading and time spent reading) in fact mediates more than $40 \%$ of the gender differences in reading (Chiu \& McBride-Chang 2006). OECD has estimated that if boys had the same average of reading for enjoyment in the PISA 2009 study as girls, the gender gap would be reduced significantly, and in many countries it would be reduced to less than half of the current gender gap. For instance, in Denmark it would almost disappear. (OECD 2010d.)

In mathematics, research has repeatedly suggested that mathematics attitude is a critical construct related to learning. Attitudes towards mathematics are positively and significantly associated with mathematics achievement in several countries: students with positive attitudes tend to achieve higher (Else-Quest et al. 2010; Winheller et al. 2013). Mathematics attitude includes three important dimensions (Vandecandelaere et al. 2012). Mathematics self-concept (confidence) concerns the students' capabilities to master the subject matter and to do well in mathematics. Enjoyment of mathematics involves the extent to which the student enjoys mathematics lessons and the subject matter itself. Finally, perceived value of mathematics refers to the beliefs the student holds about the importance of mathematics in every day and later life. A substantial body of research during the last three decades demonstrates that all these aspects of mathematics attitude have emerged as salient predictors of achievement in mathematics (e.g. Kupari 2006; Kupari \& Nissinen 2013; Marsh \& Hau 2004; Wilkins 2004). Earlier research on gender differences in school mathematics (e.g. Else-Quest et al. 2010; Hyde et al. 1990) reveals that differences in mathematics performance are small in many countries. However, findings seem to be dependent on the type of mathematics tasks: boys outperform girls especially on word problems, girls score higher on mental arithmetic and there are no gender differences found in computational tasks (Hyde et al. 1990; Vermeer et al. 2000). Furthermore, girls show lower levels of confidence and comfort with mathematics, experience more anxiety and consider themselves less competent. In line with this, girls have a lower mathematics self-concept, lower selfperceived math skills and lower math motivation. Girls' lower levels of 
confidence can lead to a reliance of girls on (proven) rules and procedures (such as finger counting), whereas boys seem to use more intuitive strategies (Skaalvik \& Rankin 1994).

Compared to student-level predictors, school- and class-level factors are found to play a clearly weaker role in predicting learning outcomes both in reading and mathematics (e.g. Schagen 2004 on PIRLS 2001 in the UK; Rolfsman et al. 2013). In a recent analysis of the Finnish students' reading performance in PIRLS 2011, Sulkunen and Nissinen (2013) found that not only the variation of students' outcomes, but also school and class differences were explained almost solely by student-level characteristics. This implies that the schools' and teachers' efforts and practices are not successful without engaging students in instruction - something affected also by students' characteristics. In the Norwegian analysis of PIRLS 2011, however, teachers' instructional practices and number of computers in schools proved to have impact on reading performance (van Daal et al. 2012).

\subsection{Materials and methods}

The PIRLS 2011 study assessed reading literacy - students' ability to understand and use written language forms required by the society and valued by the individual (Mullis et al. 2009a, 11) - for Grade 4 in 45 countries, including the Nordic countries Denmark, Finland, Norway and Sweden. The TIMSS 2011 study, which assessed students' learning outcomes in mathematics and science for Grade 4 and Grade 8 (Mullis et al. 2009b, 19-21) coincided with PIRLS, offering the opportunity for assessing the reading, mathematics and science performance of the same students Grade 4. Three Nordic countries, Finland, Norway and Sweden, chose this option, while Denmark decided to implement PIRLS and TIMSS studies with separate student samples. As a national option, Norway implemented PIRLS and TIMSS studies also for Grade 5 students ${ }^{2}$

\footnotetext{
${ }^{2}$ In terms of age and formal instruction in reading and writing, Grade 5 in Norway is comparable with Grade 4 in other Nordic countries.
} 
(see van Daal et al. 2012). Additionally, Finland, Norway and Sweden measured students' basic decoding skills in relation to the PIRLS test to study to what extent the basic reading skills explain performance in PIRLS reading comprehension test.

The material used in the present study consists of the Danish, Finnish and Swedish PIRLS 2011 and TIMSS 2011 Grade 4 datasets and the comparable Norwegian Grade 5 data. These data provide an opportunity to consider low and top performance especially from the perspective of early recognition and support for low performance. The datasets include the student achievement data but also a large amount of background information gathered from students and their parents, teachers and school principals. Table 1 summarises the number of students and schools in the PIRLS and TIMSS datasets considered. The Norwegian Grade 5 dataset is essentially smaller than the other countries' datasets, which reduces the power of statistical analysis of Norwegian data compared to the others. This must be kept in mind when examining the results.

The purpose of this study is to describe the characteristics of the top and low performers in reading and mathematics in the four Nordic countries. More specifically: which background variables predict low and top performance in reading and in mathematics?

Table 1: Schools and students in the PIRLS and TIMSS 2011 datasets in the Nordic countries

\begin{tabular}{lrrrr}
\hline & $\begin{array}{r}\text { Number of } \\
\text { schools partici- } \\
\text { pating in PIRLS }\end{array}$ & $\begin{array}{c}\text { Students as- } \\
\text { sessed in PIRLS }\end{array}$ & $\begin{array}{r}\text { Number of } \\
\text { schools partici- } \\
\text { pating in TIMSS }\end{array}$ & $\begin{array}{c}\text { Students as- } \\
\text { sessed in TIMSS }\end{array}$ \\
\hline Denmark Grade 4 & 232 & 4,594 & 216 & 3,987 \\
Finland Grade 4 & 145 & 4,640 & 145 & 4,638 \\
Norway Grade 5 & 53 & 1,258 & 54 & 1,270 \\
Sweden Grade 4 & 152 & 4,622 & 152 & 4,482 \\
\hline
\end{tabular}

For the purposes of this study, the low performers were defined as students below the intermediate international benchmark (475 score points) in PIRLS and in TIMSS. These students have achieved only the low international benchmark (400), if even that. Although nearly all the students in the Nordic countries reached the low international benchmark in reading, the percentage of students staying at that level (and not reaching the intermediate benchmark) varied (see Table 2 below). The top performers were defined as those achieving the advanced international benchmark 
(625 score points) in PIRLS and in TIMSS. In this article, the students with scores between 475 and 625 are called intermediate performers. In every country, the majority of students belong to this category, which is used as a reference group when examining the specific characteristics of low and top performers.

The factors affecting and predicting low and top performance were analysed by three-level ${ }^{3}$ logistic regression models. A preliminary collection of variables stemming from the PIRLS and TIMSS background questionnaires were selected in the exploratory analyses of our study. The variables were chosen to cover student, home, teaching and school characteristics that have been found important in previous research. The complete list of the variables selected for modelling is given in the appendix. The first target was to find those background variables which statistically significantly distinguish low performers from the reference group of intermediate performers. The top performers were not included in this analysis. An analysis of the top performance was then carried out correspondingly. Here, the target was to find the background variables which significantly distinguish top performers from intermediate performers. The low performers were not included in this analysis. These preliminary analyses were carried out separately for each country. Throughout the analyses, we used the conventional $5 \%$ limit as the criterion of statistical significance.

On the basis of preliminary modelling results, we then defined the final list of explanatory variables for the logistic regression model. In this final list, we included only those variables which appeared significant in at least one country. In other words, the variables which did not show statistical significance in any of the countries were not considered any longer. A similar model, containing the remaining variables, was then fitted separately for each country, whenever possible. ${ }^{4}$ The country-specific results

\footnotetext{
3 The sampling design of PIRLS and TIMSS studies produced datasets with a hierarchical structure: From each sampled school (school level) 1-4 classes were sampled (class level) and the students of these classes were then measured (student level). Valid statistical analyses thus call for method ology taking the three-level data structure into account.

4 The Danish data were lacking certain variables which were available for the other countries. This concerned especially the TIMSS data. See the appendix for details.
} 
were eventually compared to illustrate similarities and differences between the Nordic countries.

\subsection{Low and top performers in the Nordic countries}

The results of the PIRLS and TIMSS 2011 studies showed that the Nordic countries participating in the studies had many similarities in student performance in reading and mathematics. The performance level was relatively high in reading: Finland and Denmark were among the top countries, and Norway (Grade 5) and Sweden also had strong average performances. In mathematics, Finland was in the top 10 and Denmark was also very near the top. The performance level of Sweden and Norway was close to the centre point of the scale. Both in reading and in mathematics, the standard deviation was relatively small in all the countries, and in reading, the low international benchmark was achieved by nearly all the students. These similarities would be expected in countries sharing similar philosophy of educational equity (Husén 1974; Malin 2005).

In reading, the advanced international benchmark was achieved by $18 \%$ of students in Finland, which was clearly more than in the other Nordic countries (Table 2). Likewise, the proportion of low performers was smaller in Finland than in the other Nordic countries. The performance trend in Sweden seems somewhat alerting since both the average performance and the percentage of students achieving the advanced international benchmark have decreased steadily since 2001. In Denmark and Norway, the trend is quite the opposite. ${ }^{5}$ In mathematics (Table 3), the profile of Sweden differs from the other countries. The percentages of students reaching the advanced international benchmark were considerably higher in Finland (12), Norway (12) and Denmark (10) than in Sweden (3). Correspondingly, no less than one-third of students in Sweden per-

\footnotetext{
${ }^{5}$ Finland participated in the PIRLS study for the first time in 2011. Therefore, there are no trend data available.
} 
formed low, while in the other Nordic countries this proportion of students was between 13 and $18 \%$.

In reading, girls were top performers more often than boys, while in mathematics, the opposite was true. Low performance in reading was consistently more frequent among boys than among girls. Again, in mathematics, the opposite was true, but the differences between genders were slightly smaller. In reading, the advantage of girls was pronounced in Finland, and in mathematics, the gender difference in top performance was largest in Norway.

Table 2: Percentage of top and low performers in reading by gender in the Nordic countries

\begin{tabular}{lrrrrrr}
\hline & \multicolumn{2}{c}{ Low performers in reading } & \multicolumn{2}{c}{ Top performers in reading } \\
& All & Girls & Boys & All & Girls & Boys \\
\hline Denmark Grade 4 & 12 & 10 & 14 & 12 & 14 & 11 \\
Finland Grade 4 & 8 & 6 & 10 & 18 & 23 & 14 \\
Norway Grade 5 & 11 & 9 & 13 & 10 & 12 & 8 \\
Sweden Grade 4 & 15 & 13 & 17 & 9 & 11 & 7 \\
\hline
\end{tabular}

Table 3: Percentage of top and low performers in mathematics by gender in the Nordic countries

\begin{tabular}{lccccrr}
\hline & \multicolumn{3}{c}{ Low performers in mathematics } & \multicolumn{2}{c}{ Top performers in mathematics } \\
& All & Girls & Boys & All & Girls & Boys \\
\hline Denmark Grade 4 & 18 & 19 & 17 & 10 & 9 & 12 \\
Finland Grade 4 & 17 & 17 & 17 & 12 & 10 & 13 \\
Norway Grade 5 & 13 & 14 & 13 & 12 & 9 & 16 \\
Sweden Grade 4 & 33 & 34 & 32 & 3 & 2 & 4 \\
\hline
\end{tabular}

The low performers in reading are not illiterate, but students achieving no higher than the low international benchmark can only locate and reproduce explicitly stated details or information in the (literary and informational) texts. In contrast, students reaching the advanced benchmark can integrate ideas and information across texts, interpret story events to provide, for example, reasons and motivations with text-based support and interpret complex information on texts and different parts of texts as well as evaluate text features from the perspective of their function (Mullis et al. 2012). Thus, with top performance, the length and complexity of texts increases, as does the diversity of the reading processes applied. Top performers can also take a critical and evaluative stance towards the text. 
Respectively, low performers in mathematics are not totally unskilful. They demonstrate some basic mathematical knowledge, including adding and subtracting with whole numbers. In addition, they recognise familiar geometric shapes and can read and complete simple bar graphs and tables. In contrast, students reaching the advanced benchmark have facilities in several mathematics topics. These students can solve a variety of multi-step problems involving whole numbers and show an increasing understanding of fractions and decimals. They can apply geometric knowledge about a range of shapes and solve problems involving area and perimeter. Finally, they can explain their reasoning and organise, interpret and represent data to solve two-step problems. (Mullis et al. 2012.)

\subsection{Characteristics predicting low performance in reading and in mathematics}

A number of variables from the PIRLS and TIMSS background questionnaires covering student, home, teaching and school characteristics were introduced as potential predictors of student performance (see the appendix). For comparability reasons, it was chosen to fit as similar a model as possible for every country instead of finding an optimally fitting model for each national dataset separately. This led to a model with a relatively large number of explanatory variables showing statistical significance, mainly in Denmark, Finland and Sweden. In Norway, there were only a few statistically significant variables due to the smaller dataset providing less statistical power for the analysis. This was seen especially in the case of low performers in reading (Table 4), where only two variables were found statistically significant.

Table 4 summarises the results of the final model for low performance in the PIRLS reading comprehension test in the four Nordic countries. The respective results for mathematics are in Table 5. Except for binary variables like gender, the regression coefficients given in the tables are computed for standardised explanatory variables and can thus be interpreted as logarithmic odds ratios with respect to an increase of one standard deviation in the explanatory variable. For binary variables, the odds ratios are defined with respect to change from the reference category ("no event") to the op- 
posite "event category". The binary variables are indicated with (B) in the tables, and it is the event category which always is displayed (e.g. "Male gender"; the reference category is "Female gender"). Although the significant variables are not exactly the same for every country, they indicate that in all countries student performance is basically related to the same general characteristics: basic skills, home background and students' attitudes. This finding is consistent with earlier research results.

Because the Norwegian dataset was smaller than the others, thus showing fewer significant effects, we experimented with a specific model for Norway containing fewer explanatory variables. The results showed that, in addition to command of early literacy tasks and confidence in reading, three variables - liking to read, number of books at home and parents' tertiary education - also became significant in the same way as in other countries. This suggests that those factors could have been found important in Norway also, had the dataset been larger.

Overall, student- and home-related factors dominated and there were only occasional classroom- or school-related predictors of low performance. In all four countries, low performance in reading tended to coincide with students' poor basic reading skills when beginning school and still at Grade 4 as well as with relatively negative attitudes towards reading. Unfortunately, the reading accuracy and fluency test was not administered in Denmark, which slightly reduces the comparability of Danish results to the others. Low resources at home (including parents' education, number of books and other resources like availability of Internet connection and own room for the student) also tended to predict low performance in all four Nordic countries. ${ }^{6}$ Additionally, the risk for low performance increased if student's home language differed from the school's instructional language in Finland and Sweden.

\footnotetext{
${ }^{6}$ This conclusion holds for Norway with reservation since the effects appeared significant in a more parsimonious model only.
} 
Table 4: Characteristics related to low performance in reading in Denmark, Finland, Norway and Sweden

\begin{tabular}{|c|c|c|c|c|}
\hline & $\begin{array}{r}\text { Denmark } \\
\text { Grade } 4\end{array}$ & $\begin{array}{l}\text { Finland } \\
\text { Grade } 4\end{array}$ & $\begin{array}{l}\text { Norway } \\
\text { Grade } 5\end{array}$ & $\begin{array}{l}\text { Sweden } \\
\text { Grade } 4\end{array}$ \\
\hline \multicolumn{5}{|l|}{ Student } \\
\hline \multicolumn{5}{|l|}{ Basic skills } \\
\hline Command of early literacy tasks & -0.42 & -0.55 & -0.11 & -0.25 \\
\hline Reading accuracy and fluency & na & -0.31 & -0.86 & -0.58 \\
\hline Male gender (B) & 0.60 & 0.20 & 0.00 & -0.08 \\
\hline \multicolumn{5}{|l|}{ Attitudes } \\
\hline Confidence in reading & -1.33 & -0.62 & -1.01 & -0.68 \\
\hline Liking to read & -0.03 & -0.32 & -0.30 & -0.32 \\
\hline School enjoyment & 0.08 & -0.09 & -0.24 & -0.29 \\
\hline \multicolumn{5}{|l|}{ Reading activities } \\
\hline Time spent reading outside school & -0.17 & -0.24 & 0.09 & 0.02 \\
\hline Computer use at home & -0.06 & 0.23 & 0.29 & 0.04 \\
\hline Being bullied at school & 0.20 & 0.11 & 0.12 & 0.12 \\
\hline \multicolumn{5}{|l|}{ Home } \\
\hline \multicolumn{5}{|l|}{ Resources } \\
\hline Educational resources at home & -0.29 & -0.16 & 0.37 & -0.73 \\
\hline Number of books at home & -0.34 & -0.30 & -0.27 & 0.03 \\
\hline Parent has tertiary education (B) & -0.38 & -0.46 & -0.52 & -0.40 \\
\hline Language at home differs from school's language (B) & 0.24 & 0.56 & -0.30 & 0.66 \\
\hline Parental support for learning & 0.49 & 0.36 & 0.08 & 0.34 \\
\hline Early literacy activities with child & 0.04 & 0.06 & 0.01 & -0.27 \\
\hline \multicolumn{5}{|l|}{ Classroom } \\
\hline Interesting texts and tasks in class & 0.37 & 0.33 & 0.26 & 0.50 \\
\hline Use of non-fiction texts in class & -0.03 & -0.10 & -0.38 & 0.40 \\
\hline Activating students after reading & -0.15 & 0.05 & 0.12 & -0.24 \\
\hline \multicolumn{5}{|l|}{ School } \\
\hline Urban school (B) & -0.22 & -0.14 & -0.60 & 0.38 \\
\hline Percentage of students speaking other than school's language & 0.33 & 0.07 & 0.27 & 0.24 \\
\hline
\end{tabular}

Statistically significant regression coefficients are in italic. Positive coefficients indicate increased probability of low performance.

na=not administered.

Certain characteristics in Table 4 behave in a seemingly unexpected way. According to the results, parents' support for learning as well as teachers providing interesting texts and tasks to students and, in Sweden, frequently using non-fiction materials in class as part of individualised instruction increase the risk of low performance. Supposedly they indicate parents' and teachers' efforts to help a struggling student, and therefore they might be considered consequences rather than causes of low performance. Moreover, student's negative attitudes towards reading can partly be regarded as consequences of poor literacy. It is likely that negative attitudes, such as low confidence, and literacy problems have a circular relationship: 
low confidence decreases effort and motivation to read which in part results in reading problems which in turn decrease confidence.

There are, however, also differences between the Nordic countries. Boys were overrepresented among low performers in reading in all the four countries (see Table 2), but male gender itself increased the risk for low performance only in Denmark. In the other countries, gender played no role when other characteristics were controlled. This means that it is not necessarily gender that directly predicts low reading comprehension but other characteristics, such as the level of basic reading skills or reading attitudes, which are highly correlated with gender. In Sweden, teachers' actions for activating students seemed to reduce the risk of low performance.

No school-level characteristics appeared significant in Finland and Norway. In Denmark, low performance was significantly associated with school's diverse student population in terms of languages spoken at home. In Sweden, urban schools had more low performers than rural schools.

Reading activities like the reading of books, comics or magazines, which were not significant at all, or time spent reading, which was significant in Finland only, seem to play a lesser role than expected in explaining low performance. This suggests that the low performers are quite similar to the intermediate ones in regards to free-time reading activity. This is different from distinguishing the top performers from the intermediate ones, where a few characteristics related to reading activities appeared significant (Table 6). The principal difference between the low and the intermediate performers seems to lie in their basic skills, which then is related to their attitudes and activities. 
Table 5: Characteristics related to low performance in mathematics in Denmark, Finland, Norway and Sweden

\begin{tabular}{|c|c|c|c|c|}
\hline & $\begin{array}{r}\text { Denmark } \\
\text { Grade } 4\end{array}$ & $\begin{array}{l}\text { Finland } \\
\text { Grade } 4\end{array}$ & $\begin{array}{l}\text { Norway } \\
\text { Grade } 5\end{array}$ & $\begin{array}{l}\text { Sweden } \\
\text { Grade } 4\end{array}$ \\
\hline \multicolumn{5}{|l|}{ Student } \\
\hline \multicolumn{5}{|l|}{ Basic Skills } \\
\hline Command of early numeracy tasks & na & 0.28 & -0.55 & -0.20 \\
\hline Command of early literacy tasks & na & --0.17 & 0.16 & -0.43 \\
\hline Reading accuracy and fluency & na & -0.63 & -0.92 & -0.76 \\
\hline Male gender (B) & 0.04 & -0.02 & 0.52 & -0.40 \\
\hline \multicolumn{5}{|l|}{ Attitudes } \\
\hline Confidence in mathematics & -1.00 & -1.17 & -0.69 & -0.58 \\
\hline Liking mathematics & 0.18 & 0.20 & -0.41 & 0.16 \\
\hline Engagement in mathematics class & 0.16 & 0.30 & 0.50 & 0.17 \\
\hline School enjoyment & -0.05 & -0.27 & -0.02 & -0.04 \\
\hline Computer use at home & 0.03 & 0.07 & 0.05 & 0.19 \\
\hline \multicolumn{5}{|l|}{ Home } \\
\hline \multicolumn{5}{|l|}{ Resources } \\
\hline Educational resources at home & na & 0.33 & -0.20 & -0.33 \\
\hline Number of books at home & -0.58 & -0.28 & -0.51 & -0.13 \\
\hline Parent has tertiary education (B) & na & -0.26 & -1.34 & -0.62 \\
\hline Language at home differs from school's language (B) & 0.38 & 0.40 & 0.64 & 0.42 \\
\hline Parental support for learning & 0.20 & 0.61 & 0.19 & 0.41 \\
\hline \multicolumn{5}{|l|}{ Classroom } \\
\hline Percentage of students with language difficulties in class & 0.29 & 0.16 & 0.05 & 0.06 \\
\hline \multicolumn{5}{|l|}{ School } \\
\hline School size & -0.24 & 0.16 & -0.14 & -0.03 \\
\hline Urban school (B) & 0.30 & -0.06 & -0.10 & 0.32 \\
\hline Average wealth of school neighbourhood & -0.22 & -0.12 & -0.06 & -0.21 \\
\hline
\end{tabular}

Statistically significant regression coefficients are in italic. Positive coefficients indicate increased probability of low performance.

na=not administered.

The results on prediction of low performance in the TIMSS mathematics test are shown in Table 5. Unfortunately, the variables from parent questionnaires were not available for Danish TIMSS analyses. Although the choice of available predictors is somewhat narrower for mathematics than for reading, the overview of results is highly similar. Student- and homerelated factors again dominated the results. Low performance was consistently predicted by students' poor basic numeracy and literacy skills and low educational resources at home. Parents' support for learning and students' low confidence in learning mathematics were strongly associated with low performance. Also, students' engagement in mathematics learning was related to low performance. Like in reading, in mathematics it is also likely that low confidence and poor skills have a circular relation- 
ship. Parent's support and students' engagement could be seen in this context as consequences of learning difficulties because they indicate parents' efforts and repeated teacher-student interactions in helping the struggling students. Everything else being equal, students liking mathematics was also related to low mathematics performance in some countries. This is somehow an unexpected result because there is ample research evidence that strong self-concept and positive attitudes produce enhanced performance in mathematics (cf. Else-Quest et al. 2013). One possible explanation for this could be the complex and intertwined way mathematics self-concept is associated with other dimensions of mathematics attitudes (liking mathematics and importance of mathematics). In some other studies, also, mathematics self-concept has had a high positive effect on students' performance, and meanwhile, liking mathematics has had an opposite effect on performance (e.g. Kupari \& Nissinen 2013; Winheller et al. 2013; Meelissen \& Luyten 2008). An alternative explanation could be that low performing students may like mathematics activities as such, but as a consequence of much interaction with teachers, students sense that they are "in trouble" and this leads to reduced performance in mathematics (Winheller et al. 2013). Anyway, further research into the nature of the teacher-student interactions in mathematics classrooms and complex relationships between attitudinal dimensions and mathematics performance is needed to clarify this surprising result.

Additional student-related predictors of low mathematics performance were female gender (in Sweden), low school enjoyment (in Finland) and ample computer use at home (in Sweden). In all countries, the risk for low performance increased if students' home language differed from the school's instructional language.

In mathematics, no teaching-related variables appeared significant in any of the countries. The only classroom variable that had an effect here was the share of students in class having difficulties with the instruction language, and this was observed in Denmark and Finland only. Some school characteristics were again found significant in Denmark and Sweden. In Sweden, the probability of low mathematics performance was increased if the school was urban or located in a neighbourhood of relatively low wealth. In Denmark, the effect of wealth of the neighbourhood was similar. The other variable that had a significant effect in Denmark 
was school size: The probability of low mathematics performance was higher in small schools when the other variables were controlled. The school size was not found to be significant in any other Nordic country.

\subsection{Characteristics predicting top performance in reading and in mathematics}

Many of the variables which relate to top performance in reading (Table 6) or in mathematics (Table 7) have already been identified in predicting low performance. At this time, they just operate at the opposite ends of the scale. Across the four Nordic countries, the probability of top performance in the PIRLS reading comprehension test increased if students had solid basic reading skills already when beginning school. Top performers could, more likely than other students, read words and sentences and write words and some sentences when they entered school. They were accurate and fluent readers in the decoding test related to PIRLS as a Nordic option (in Finland and Sweden). The same also applied to top performers in the TIMSS mathematics test, suggesting that success in mathematics is closely related to success in reading. As expected, basic numeracy skills when beginning school were also strongly related to success in mathematics.

Students' positive attitudes towards reading significantly predicted top performance in all countries except Sweden. In Norway, the top performers in reading reported enjoying school more than the intermediate ones (although not significantly), while in Sweden, the opposite was found.

The quality and amount of reading activities also predicted top performance in reading: In Denmark, Finland, Norway (with reservation) and Sweden, low amounts of non-fiction reading predicted top performance as did avoiding excess computer use at home in Denmark and Finland. Most likely, this is a sign of reading relatively more literature and other materials and should not be interpreted as, for instance, an indication of nonfiction books' low quality or insignificance to reading development. Consistently with this finding, in Finland and Sweden, the chances of top performance increased if students read plenty of stories instead of or in addition to non-fiction books. In Finland, the reading of comics also showed a 
positive effect. In Norway and Sweden, the probability of top performance increased along with time spent reading outside school.

Table 6: Characteristics related to top performance in reading in Denmark, Finland, Norway and Sweden

\begin{tabular}{|c|c|c|c|c|}
\hline & $\begin{array}{r}\text { Denmark } \\
\text { Grade } 4\end{array}$ & $\begin{array}{l}\text { Finland } \\
\text { Grade } 4\end{array}$ & $\begin{array}{l}\text { Norway } \\
\text { Grade } 5\end{array}$ & $\begin{array}{l}\text { Sweden } \\
\text { Grade } 4\end{array}$ \\
\hline \multicolumn{5}{|l|}{ Student } \\
\hline \multicolumn{5}{|l|}{ Basic skills } \\
\hline Command of early literacy tasks & 0.39 & 0.56 & 0.53 & 0.60 \\
\hline Reading accuracy and fluency & na & 0.38 & 0.08 & 0.47 \\
\hline Male gender (B) & -0.18 & -0.34 & -0.08 & 0.08 \\
\hline \multicolumn{5}{|l|}{ Attitudes } \\
\hline Confidence in reading & 0.45 & 0.39 & -0.08 & 0.16 \\
\hline Liking to read & 0.39 & 0.24 & 0.41 & 0.22 \\
\hline School enjoyment & 0.04 & 0.09 & 0.26 & -0.42 \\
\hline \multicolumn{5}{|l|}{ Reading activities } \\
\hline Reading of stories & 0.13 & 0.31 & 0.04 & 0.54 \\
\hline Reading of comics & 0.02 & 0.16 & -0.31 & -0.17 \\
\hline Reading of non-fiction books & -0.38 & -0.38 & -0.33 & -0.22 \\
\hline Time spent reading outside school & 0.00 & 0.07 & 0.36 & 0.30 \\
\hline Computer use at home & -0.16 & -0.20 & -0.02 & -0.08 \\
\hline Being bullied at school & -0.01 & -0.02 & -0.31 & -0.36 \\
\hline \multicolumn{5}{|l|}{ Home } \\
\hline \multicolumn{5}{|l|}{ Resources } \\
\hline Educational resources at home & 0.30 & 0.28 & -0.25 & 0.04 \\
\hline Number of books at home & 0.13 & 0.25 & 0.66 & 0.48 \\
\hline Parent has tertiary education (B) & 0.20 & 0.22 & 0.52 & 0.56 \\
\hline Parent has full-time job (B) & 0.54 & 0.02 & 0.52 & 0.90 \\
\hline Language at home differs from school's language (B) & -0.42 & -0.48 & -0.76 & -0.74 \\
\hline Parental support for learning & -0.64 & -0.46 & -0.76 & -0.40 \\
\hline Early literacy activities with child & 0.15 & 0.14 & 0.40 & 0.21 \\
\hline \multicolumn{5}{|l|}{ Classroom } \\
\hline Interesting texts and tasks in class & -0.14 & -0.18 & -0.68 & 0.11 \\
\hline Understanding teacher in class & 0.06 & 0.26 & -0.12 & 0.19 \\
\hline \multicolumn{5}{|l|}{ School } \\
\hline Urban school (B) & 0.44 & 0.02 & -0.56 & -0.16 \\
\hline Average wealth of school neighbourhood & 0.26 & 0.00 & 0.42 & -0.03 \\
\hline Resources to reading instruction & 0.17 & 0.09 & 0.04 & 0.05 \\
\hline Instructional language Finnish (B) & na & 0.34 & na & na \\
\hline
\end{tabular}

Statistically significant regression coefficients are in italic. Positive coefficients indicate increased probability of top performance.

na=not administered

As for mathematics, high confidence increased the probability of top performance in all countries (Table 7). In Finland, low engagement in learning mathematics was also related to perform high. Top performers' low engagement probably suggests that the topics discussed in the class are 
too easy for them, and there is no need to be actively involved. In Finland, Norway and Sweden, boys were significantly more often top performers than girls even when other variables were controlled. In these three countries, the top performers also reported less free-time computer use than the intermediate performers.

Home-related predictors of top performance in reading and in mathematics were largely similar in the Nordic countries. The probability of top performance increased along with home resources. Remarkably, parental support for learning was negatively associated with top performance both in mathematics and reading. This may be because top performers take care of their school work independently. This finding, however, requires further research and discussion. It is also worth noting that across all four countries, the chances of a child being an excellent reader was significantly increased by parents' activities which support child's literacy development. These parents reported that they frequently did literacy activities with the child before the child began school (e.g. read books and told stories, talked with the children about books, read and played word games). In the case of poor readers, the respective effect was evident only in Sweden, which suggests that parents' early support has been particularly important to children who have reached top-level literacy.

In reading, in all countries (with reservation for Norway), top reading performance was predicted by matching languages at home and at school, suggesting that immigrant students' probability of top performance is lower than that of native students. In mathematics, the same was observed in Denmark only.

In predicting top performance in mathematics, none of the classroomor school-related factors were found significant. As for reading, a negative association between teacher giving interesting texts and tasks and students' top performance was observed in Finland and Norway (a similar association was found with low performers, also). In addition, Denmark differed from other Nordic countries in that some school-related characteristics were also found to be significant, such as school's resources for reading instruction (e.g. instructional materials, computers, computer software, library books, teachers specialized in reading). Urban and wealthy school neighbourhoods increased the probability of top performance, and the same occurred with good school resources. In Finland, the 
Finnish-speaking schools showed more top readers than the Swedishspeaking schools.

Table 7: Characteristics related to top performance in mathematics in Denmark, Finland, Norway and Sweden

\begin{tabular}{lrrrr}
\hline & $\begin{array}{r}\text { Denmark } \\
\text { Grade 4 }\end{array}$ & $\begin{array}{r}\text { Finland } \\
\text { Grade 4 }\end{array}$ & $\begin{array}{r}\text { Norway } \\
\text { Grade 5 }\end{array}$ & $\begin{array}{r}\text { Sweden } \\
\text { Grade 4 }\end{array}$ \\
\hline Student & & & & \\
Basic skills & & & & \\
$\quad$ Command of early numeracy tasks & na & 0.44 & 0.35 & 0.44 \\
Command of early literacy tasks & na & 0.48 & -0.02 & 0.73 \\
$\quad$ Reading accuracy and fluency & na & 0.17 & 0.17 & 0.44 \\
Male gender (B) & 0.08 & 0.52 & 1.00 & 1.46 \\
Attitudes & & & & \\
$\quad$ Confidence in mathematics & 0.86 & 1.00 & 1.01 & 0.79 \\
$\quad$ Engagement in mathematics class & 0.01 & -0.15 & 0.00 & -0.17 \\
Computer use at home & -0.06 & -0.15 & -0.31 & -0.38 \\
Home & & & & \\
Resources & & & & \\
$\quad$ Educational resources at home & na & 0.27 & 0.23 & 0.52 \\
Number of books at home & 0.64 & 0.15 & 0.36 & 0.21 \\
Parent has tertiary education (B) & na & 0.42 & 0.46 & 0.82 \\
Language at home differs from school's language (B) & -0.66 & -0.10 & -0.30 & 0.10 \\
Parental support for learning & -0.32 & -0.40 & -0.87 & -0.31 \\
Classroom & & & & \\
no significant effects & & & & \\
School & & & & \\
no significant effects & & & & \\
\hline
\end{tabular}

Statistically significant regression coefficients are in italic. Positive coefficients indicate increased probability of top performance.

na=not administered

\subsection{Conclusions}

\subsubsection{Reading}

Overall, the analysis presented above paints a very consistent picture of low and top performers in reading - and the picture is also consistent with previous research. Low performers have a weaker start to school work and learning to read than top performers since they have not mastered basic reading skills when they enter school, while the top performers often already know how to read at that point. Additionally, low performers' 
home environment does not support reading development to the extent that top performers' homes do. Low performers often come from home with relatively few educational resources - unlike top performers whose parents have resources (such as books and education), like reading and doing literacy-related activities with their children even before starting school. In a reading-friendly environment, top performers develop a positive attitude towards reading and engage in diverse and frequent reading activities that contribute to life-long literacy development - unlike the low performers (Brooks 2013). The crucial question remains: how to best support the students with less favourable home environments and levels of basic skills to reach their full potential?

This is a question that the European Union's High Level Group on Literacy also addressed in its report (HLG 2012) and emphasised the role of family support even at a very early age as well as high-quality early childhood education and care (ECEC) accessible to all children. To help parents particularly in the disadvantaged groups - support their children's literacy development, they should be made aware of the many ways they can support children's literacy development even starting at infancy. There are numerous awareness-raising campaigns and family literacy programs that are relatively inexpensive and have demonstrated positive gains for child literacy development (Carpentieri et al. 2011).

Since basic reading skills before beginning school are such powerful predictors of reading performance, students struggling with the first steps of learning to read should receive intensive support as early as possible provided by literacy specialists (HLG 2012, 45, 66-67). In the ideal case, children at risk of cognitive reading problems and of low performance are identified and supported even before entering school. This is where the high-quality ECEC accessible to all children plays a central role as individual learning needs can be addressed in childhood through language assessment (HLG 2012, 60-61). Alternatively, language assessment can also be implemented in a comprehensive health care system, such as the Finnish childcare clinic Neuvola, which regularly monitors children's physical and linguistic development. This requires resources for test development and carefully designed support implemented at home and in ECEC.

In literacy instruction - whether it is in a play-like environment in ECEC or at school - the first step is to acknowledge and appreciate the diverse 
backgrounds and diverse literacy practices that children bring to school. This is something that seems obvious to most educational developers and many teachers, but it is much easier said than done. Multicultural and multilingual instruction in the widest sense of the words embrace immigrant, minority and mainstream children from various social subgroups and their diverse levels and forms of literacy (Cope \& Kalantzis 1993). In practice, such instruction requires a flexible curriculum with ambitious objectives set to critical literacy and skilled teachers with an advanced understanding of literacy. Since students start their educational path at different points, individualised pedagogical solutions are also needed. Their own language and literacy resources should be used as entry points to the literacies required and appreciated at school and in the society, but the objectives of instruction should be equally ambitious for all students (Sulkunen 2013).

Another important aspect of reading literacy instruction is continuous support in developing reading comprehension strategies. In order to strengthen reading instruction, a wide range of reading strategies should be included in the reading literacy curriculum, both at the primary and secondary levels (Eurydice 2011). Reading strategies are something that can be taught in all subjects in all school years (HLG 2012; Garbe, Holle \& Weinhold 2009). In primary school years, students need instruction mainly on generic reading strategies which can be applied with all kinds of texts, but already in early adolescence they benefit from more disciplineoriented strategies in the framework of disciplinary literacy (Fang 2012; Shanahan \& Shanahan 2012). These rely on texts of different disciplines being different as then are also effective reading comprehension strategies needed (see Fang \& Coatoam 2013).

In addition to cognitive support, children at risk of low performance also need support in reading engagement: If students develop a positive relationship with reading - and frequently read diverse materials - they will have self-generated learning opportunities for reading (Guthrie \& Wigfield 2000; also Linnakylä et al. 2004, 2006). For this purpose, they need successful reading experiences which will, in turn, enhance their self-efficacy as readers (Garbe et al. 2010) and motivate them to engage in reading instead of using avoidance strategies typical for struggling readers (Guthrie \& Davis 2003). In positive and relevant reading experiences, 
the choice of texts is crucial: There is evidence that in contexts and with texts that are meaningful and interesting, perhaps even chosen by the student, struggling readers can show skilful reading (Ivey 1999; see also Sulkunen \& Arffman 2010). This requires that the gap between schools' and students' textual landscapes does not grow too wide. There is, thus, a need for a wide selection of texts used at school and also digital texts. In addition to (canonical) literary texts, magazines, newspapers, online news sites, blogs, fan-fiction and communicating through social media - the things students may frequently read and write outside school - could and should also be harnessed to the use of literacy pedagogy.

\subsubsection{Mathematics}

In mathematics, the analyses reveal quite a few factors which characterise both low and top performers in all Nordic countries. Our results are also consistent with results reported in several previous studies. Lack of confidence in learning mathematics, low educational resources at home and weak basic numeracy and reading skills are typical for low performers in mathematics. In contrast, high confidence in mathematics, a favourable home background and good skills in numeracy and reading are distinctive for top performers in mathematics. It is important to emphasise here that good reading skills are also an essential element in learning mathematics. Furthermore, in certain countries, some other factors seem to increase the chances of a child being a low performer (e.g. to be a girl; low school enjoyment) in mathematics. Like in reading, an essential question is what can be done to support students with learning difficulties in primary mathematics?

In many respects, current practices in mathematics instruction lead students to develop attitudes that value speed of computation, following the example of the teacher and correctness of answers over learning and understanding (e.g. Middleton \& Spanias 1999). Therefore, it is important to concentrate on creating a learning environment which can support all students as much as possible.

Previous research has shown that re-teaching and clarification of content usually has a significant negative effect on students' mathematics achievement (Akyüz \& Berberoğlu 2010). This may be due to the reason 
that low-performing students need re-teaching more than the high performing students. Continuous re-teaching can develop a negative perception in students about their mathematics skills and consequently the lack of positive math self-confidence can lower their level of achievement.

It is clear that attitudes towards mathematics are also a vital matter in mathematics education to low-performers (e.g. Singh et al. 2002; Middleton \& Spanias 1999). Attitudes towards mathematics are developed early, are highly stable over time and are influenced greatly by teacher actions and attitudes. Though stable, attitudes and motivation in mathematics can be affected through careful instructional design, and therefore teachers' approaches and teaching methods play an important role. Creating interesting contexts within which problems are situated stimulates students' imaginations and illustrates to them that mathematics is useful in various applications. To allow students to feel successful in mathematics, teachers must structure tasks such that they present an appropriate challenge and difficulty for students. Thus, mathematics activities must be difficult enough that students are not bored, yet tasks must allow for a high degree of success given appropriate effort by the students (Middleton \& Spanias 1999). Furthermore, the immediate opportunities for remedial instruction and extra support both in school and at home to students having learning difficulties are necessary in order to decrease the number of low performers in mathematics.

\subsubsection{Solid ground for learning at school}

Nordic countries have had a long tradition in aiming for equity in education. This has meant providing all students equally solid education but also supporting the lowest performers, reflecting the radical view of equity (Husén 1974; Malin 2005). The significant role of home resources in predicting and explaining students' learning outcomes, however, shows that even in the Nordic countries there is still lot of work to do in this area. However, equity as an educational aim is still relevant as there is plenty of evidence showing that the most successful school systems succeed in evening out the impact of students' home backgrounds on learning outcomes (OECD 2010e, 27; also Garbe et al. 2010). 
In order to further pursue educational equity as well as high average performance, schools need to have enough resources and professionals to provide individual support for the students who need it. This means students from disadvantaged families but also students whose home language differs from the school's language and students with learning disabilities. As mentioned above, support measures are most effective when provided as early as possible. In addition to proper resources for schools, this calls for active cooperation between homes, ECEC and schools.

The individualised approach provides a solid framework for learning for students with a weak start and disadvantages at school for one reason or another. However, this approach makes teaching a very demanding task. This puts a lot of pressure on teachers' education and continuous professional development in topics such as teaching materials and methods, assessment and diagnosing learning problems. And yet, in each of the Nordic countries, there is a significant number of teachers who did not participate in any kind of professional development activity related to reading and mathematics during the two-year period prior to the PIRLS/TIMSS studies. For example, in reading, the percentage of these teachers varied from $23 \%$ in Sweden to $32 \%$ in Norway, with the notable exception of Finland, where as much as $68 \%$ of teachers had not participated in professional development in the same time frame. Clearly, resources and opportunities for continuous professional development for teachers are not adequate in the Nordic countries, particularly in Finland.

Moreover, top-performers need individualised education; they need materials and tasks challenging enough to develop their competences further to the level of their full potential. In the present study, it was striking that the top students lacked support at home. It may seem that these students do not need support for their school work from parents, but they do need teachers and parents to show interest in their school work and support and challenge them to learn - not forgetting enjoyment in learning and at school. 


\subsection{References}

Akyüz, G., \& Berberoğlu, G. (2010). Teacher and classroom characteristics and their relations to mathematics achievement of the students in the TIMSS. New Horizon in Education, 58(1), 77-95.

Alatupa, S., Karppinen, K., Keltikangas-Järvinen, L., \& Savioja, H. (2007). Koulu, syrjäytyminen ja sosiaalinen pääoma. Löytyykö huono-osaisuuden syy koulusta vai oppilaasta? Sitra: Helsinki.

Alvernini, F. (2013). An exploration of the gap between highest and lowest ability readers across 20 countries. Educational Studies, 39(4), 399-417. http:// dx.doi.org/10.1080/03055698.2013.767187

Arnbak, E. (2012). To what extent do basic skills predict students' PISA reading score? In N. Egelund (Ed.), Northern Lights on PISA 2009 - focus on reading, pp. 75-90. TemaNord 2012: 501. Nordic Council of Ministers.

Brese, F., \& Mirazchiyski, P. (2010). Measuring students' family background in large-scale education studies. Paper presented in the $4^{\text {th }}$ IEA International Research Conference. July 1-3. Gothenburg, Sweden. Retrieved from http://www.iea.nl/irc-2010.html

Brookhart, S. M. (1997). Effects of the classroom assessment environment on mathematics and science achievement. Journal of Educational Research, 90, 323-330.

Brooks, G. (2013). The prerequisites for successful teaching and learning of literacy. European Journal of Education, 48(4). doi:10.1111/ejed.12049

Carpentieri, J., Fairfax-Cholmeley, K., Litster, J., \& Vorhaus, J. (2011). Family literacy in Europe: Using parental support initiatives to enhance early literacy development. London, Institute of Education.

Chiu, M. M., \& McBride-Chang, C. (2006). Gender, context, and reading: A comparison of students in 43 countries. Scientific Studies of Reading, 10, 331-362.

Cope, B., \& Kalantzis, M. (1993). The power of literacy and the literacy of power. In B. Cope \& M. Kalantzis (Eds.), The powers of literacy: A genre approach to teaching writing, pp. 63-89. London: The Falmer Press.

EC (2007). Key competencies for lifelong learning. European framework. European Communities, Education and Culture DG: Luxembourg.

Else-Quest, N. M., Hyde, J. S., \& Linn, M. C. (2010). Cross-national patterns of gender differences in mathematics: meta-analysis. Psychological Bulletin, 136(1), 103-127.

Eurydice (2011). Teaching reading in Europe: Contexts, policies and practices. Eurydice.

Fang, Z. (2012). Language correlates of disciplinary literacy. Topics in Language Disorders, 32, 19-34.

Fang, Z., \& Coatoam, S. (2013). Disciplinary literacy. What you want to know about it. Journal of Adolescent and Adult Literacy, 56, 627-632. 
Fredriksson, U., Rasmusson, M., \& Sundgren, M. (2012). Weak readers in the Nordic countries - Gender, immigrant background, socio-economic background, enjoyment of reading and school related factors. In N. Egelund (Ed.), Northern Lights on PISA 2009 - focus on reading, pp. 23-43. TemaNord 2012: 501. Nordic Council of Ministers.

Garbe, C., Gross, M., Holle, K., \& Weinhold, S. (2010). Key elements of good practice. In C. Garbe, K. Holle \& S. Weinhold (Eds.), ADORE - Teaching struggling adolescent readers in European countries, pp. 67-73. Frankfurt: Peter Lang Publishing Group.

Garbe, C., Holle, K., \& Weinhold, S. (2010). Conclusions and comments. In C. Garbe, K. Holle \& S. Weinhold (Eds.), ADORE-project. Teaching adolescent struggling readers. A comparative study of good practices in European countries. Frankfurt: Peter Lang Publishing Group.

Guthrie, J.T., \& Davis, M. H. (2003). Motivating struggling readers in middle school through an engagement model of classroom practice. Reading \& Writing Quarterly, 19(1), 59-85.

Guthrie, J. T., \& Wigfield, A. (2000). Engagement and motivation in reading. In M. L. Kamil, P. B. Mosenthal, P. D. Pearson \& R. Barr (Eds.), Handbook of reading research. Volume III. New Jersey: Lawrence Erlbaum Assoc.

Harju-Luukkainen, H., \& Nissinen, K. (2011). Finlandssvenska 15-åriga elevers resultatnivå in PISA 2009 -undersökningen. Jyväskylä universitet. Pedagogiska forskningsinstitutet.

HLG (2012). Act now! EU High Level Group of Experts on Literacy. Final report. European Union: Luxembourg.

Howie, S. J. (2002). English language proficiency and contextual factors influencing mathematics achievement of secondary school pupils in South Africa. Enschede: Doctoral dissertation, University of Twente.

Husén, T. (1974). Learning society. London: Methuen.

Hyde, J. S., Fennema, E., \& Lamon, S. (1990). Gender differences in mathematics performance: A meta-analysis. Psychological Bulletin, 107, 139-155.

Ivey, G. (1999). A multicase study in the middle school: Complexities among young adolescent readers, Reading Research Quarterly, 34, 172-192.

Jensen, T. P., \& Turmo, A. (2003). Reading literacy and home background. In S. Lie, P. Linnakylä \& A. Roe (Eds.), Nothern Lights on PISA. Unity and diversity in the Nordic countries in PISA 2000. Oslo: University of Oslo.

Kupari, P. (2006). Student and school factors affecting Finnish mathematics achievement: Results from TIMSS 1999 data. In S. J. Howie \& T. Plomp (Eds.), Contexts of learning mathematics and science, Lessons learned from TIMSS, pp. 127-140. London: Routledge.

Kupari, P., \& Nissinen, K. (2013). Background factors behind mathematics achievement in Finnish education context: Explanatory models based on TIMSS 1999 and TIMSS 2011 data. Paper presented in the $5^{\text {th }}$ IEA International Research Conference. June 26-28. Singapore. Retrieved from http://www.iea.nl/ irc-2013.html 
Lamb, S., \& Fullarton, S. (2000). Classroom and teacher effects in mathematics achievements: Results from TIMSS. In J. Bana \& S.A. Chapman (Eds.), Mathematics education beyond 2000. Volume 1, pp. 355-362. Perth, WA: Mathematics Education Research Group of Australasia Incorporated.

Linnakylä, P., \& Malin, A. (2007). Miten tukea heikkoja lukijoita? Lukuharrastukseen sitoutuminen lukutaidon vahvistajana. Finnish Educational Journal Kasvatus 38(4), 304-315.

Linnakylä, P., Malin, A., \& Taube, K. (2004). Factors behind low reading literacy achievement. Scandinavian Journal of Educational Research, 48(3), 231-249.

Linnakylä, P., Malin, A., \& Taube, K. (2006). What lies behind low reading literacy performance? A comparative analysis of the Finnish and Swedish students. In J. Mejding \& A. Roe (Eds.), Northern lights on PISA 2003 - A reflection from the Nordic countries, pp. 143-158. Copenhagen: Nordic Council of Ministers.

Malin, A. (2005). Schools differences and inequities in educational outcomes. PISA 2000 Results of Reading Literacy in Finland. Institute for Educational Research: Jyväskylä.

Marks, G. N., Cresswell, J., \& Ainley, J. (2006). Explaining socioeconomic inequalities in student achievement. The role of home and school factors. Educational Research and Evaluation, 12(2), 105-128.

Marsh, H. W., \& Hau, K-T. (2004). Explaining paradoxical relations between academic self-concept and achievements: Cross-cultural generalizability of the internal/external frame of reference predictions across 26 countries. Journal of Educational Psychology, 96, 56-67.

McConney, A., \& Perry, L. B. (2010). Socioeconomic status, self-efficacy and mathematics achievement in Australia: A secondary analysis. Educational Research for Policy and Practice, 9, 77-91.

Meelissen, M., \& Luyten, H. (2008). The Dutch gender gap in mathematics: Small for achievement, substantial for beliefs and attitudes. Studies in Educational Evaluation, 34, 82-93.

Middleton, J. A., \& Spanias, P. A. (1999). Motivation for achievement in mathematics: Findings, generalizations and criticism of the research. Journal for Research in Mathematics Education, 30, 65-88.

Mullis, I. V. S., Martin, M. O., Foy, P., \& Drucker, K. T. (2012). PIRLS 2011 international results in reading. TIMSS \& PIRLS International Study Center, Lynch School of Education, Boston College.

Mullis, I. V. S., Martin, M. O., Kennedy, A. M., Trong, K. L., \& Sainsbury, M. (2009a). PIRLS 2011 assessment framework. TIMSS \& PIRLS International Study Center, Lynch School of Education, Boston College.

Mullis, I. V. S., Martin, M. O., Ruddock, G. J., O’Sullivan, C. Y., \& Preuschoff, C. (2009b). TIMSS 2011 assessment frameworks. TIMSS \& PIRLS International Study Center, Lynch School of Education, Boston College.

Myrberg, M., \& Rosén, M. (2006). Reading achievement and social selection in independent schools in Sweden: Results from IEA PIRLS 2001. Scandinavian Journal of Educational Research, 50(2), 185-205. 
OECD 2009. PISA (2009) Assessment framework - Key competencies in reading, mathematics and science. Paris: OECD.

OECD (2010a). The high cost of low educational performance. Paris: OECD.

OECD (2010b). Pathways to success: How Knowledge and skills at age 15 shape future lives in Canada. Paris: OECD.

OECD (2010c). PISA 2009 results: Learning trends. Changes in student performance since 2000. Volume V. Paris: OECD.

OECD (2010d). PISA 2009 results: Learning to learn - Student engagement, strategies and practices. Volume III. Paris: OECD.

OECD (2010e). PISA 2009 results: What makes a school successful? Resources, policies and practices. Volume IV. Paris: OECD.

OECD (2012). Literacy, numeracy and problem solving in technology-rich environments - Framework for the OECD survey of adult skills. Paris: OECD.

OECD (2013). PISA 2012 assessment and analytical framework: Mathematics, reading, science, problem solving and financial literacy. Paris: OECD. http://dx.doi.org/10.1787/9789264190511-en.

Rolfsman, E., Wiberg, M., \& Laukaityte, I. (2013). School effectiveness in the Nordic countries in realation to PISA and TIMSS. Paper presented in the $5^{\text {th }}$ IEA International Research Conference. June 26-28. Singapore. Retrieved from http:// www.iea.nl/irc-2013.html

Schagen, I. (2004). Multilevel analysis of PIRLS data for England. Paper presented at the International Research Conference, University of Cyprus, Lefkosia, 11.13.5.2004.

Shanahan, T., \& Shanahan, C. (2012). What is disciplinary literacy and why does it matter? Topics in Language Disorders, 32, pp. 7-18.

Singh, K., Granville, M., \& Dika, S. (2002). Mathematics and science achievement: Effects of motivation, interest and academic engagement. The Journal of Educational Research, 95, 323-332.

Skaalvik, E. M., \& Rankin, R. J. (1994). Gender differences in mathematics and verbal achievement, self-perception and motivation. British Journal of Educational Psychology, 64, 419-428.

Sulkunen, S. (2013). Adolescent literacy in Europe - An urgent call for action. European Journal of Education, 48(4). doi:10.1111/ejed.12052

Sulkunen, S., \& Arffman, I. (2010). Choosing engaging reading materials. In C. Garbe, K. Holle \& S. Weinhold (Eds.), ADORE-project. Teaching adolescent struggling readers. A comparative study of good practices in European countries, pp. 102-113. Frankfurt: Peter Lang Publishing Group.

Sulkunen, S., \& Nissinen, K. (2012). Heikot lukijat Suomessa. Sulkunen, S. \& Välijärvi, J. (Eds.), 2012. Kestääkö osaamisen pohja? PISA 09, pp. 46-61. Publications of the Ministry of Education and Culture 2012: 12.

Sulkunen, S., \& Nissinen, K. (2013). Explaining $4^{\text {th }}$ grade students' reading comprehension: PIRLS 2011 in Finland. Presentation. European Reading Conference, Jönköping, 9.8.2013. 
van Daal, V., Solheim, R. G., \& Gabrielsen, N. N. (2012). Godt nok? Norske elevers leseferdighet på 4. och 5. trinn. PIRLS 2011 - norsk rapport. Universitetet i Stavanger.

Vandecandelaere, M., Speybroeck, S., Vanlaar, G., De Fraine, B., \& Van Damme, J. (2012). Learning environment and students' mathematics attitude. Studies in Educational Evaluation, 38, 107-120.

Vermeer, H. J., Boekaerts, M., \& Seegers, G. (2000). Motivational and gender differences: Sixth grade students' mathematical problem-solving behavior. Journal of Educational Psychology, 92, 308-315.

Wilkins, J. L. M. (2004). Mathematics and science self-concept: An international investigation. The Journal of Experimental Education, 72, 331-346.

Winheller, S., Hattie, J. A., \& Brown, G. T. L. (2013). Factors influencing early adolescents' mathematics achievement: High-quality teaching rather than relationships. Learning Environments Research, 16, 49-69. 


\subsection{Appendix}

Complete list of the explanatory variables employed in modeling of performance in reading and mathematics. The asterisk $\left(^{*}\right)$ indicates a variable appearing in at least one of the final models. The variables without asterisk were not found statistically significant in any of the countries.

\section{Variables common to both models for reading performance (PIRLS) and models for mathematics performance (TIMSS)}

\begin{tabular}{ll}
$\begin{array}{l}\text { Variables from student questionnaire } \\
\text { Variable }\end{array}$ & Note \\
$\begin{array}{l}\text { Gender* } \\
\text { Language at home differs from school's language* }\end{array}$ & $\begin{array}{l}\text { question G1, binary } \\
\text { binary indicator constructed from question G3 } \\
\text { qumber of books at home* } \\
\text { Educational resources at home* }\end{array}$ \\
$\begin{array}{l}\text { Computer use at home* } \\
\text { scale constructed from question G5, not available in } \\
\text { Danish TIMSS data } \\
\text { Parental support for learning* } \\
\text { School enjoyment* } \\
\text { Being bullied at school* }\end{array}$ & $\begin{array}{l}\text { question G6a } \\
\text { scale constructed from question G7 } \\
\text { scale constructed from question G8 } \\
\text { scale constructed from question G9 }\end{array}$ \\
\hline
\end{tabular}

Other student-level variables

\begin{tabular}{ll} 
Variable & Note \\
Reading accuracy and fluency* & word chain test, not administered in Denmark \\
\hline
\end{tabular}

Variables from teacher questionnaire

\begin{tabular}{|c|c|}
\hline Variable & Note \\
\hline Years worked as teacher & question G1 \\
\hline Gender & question $\mathrm{G} 2$, binary \\
\hline Level of formal education & question G4 \\
\hline Major area of formal education & question G5ab \\
\hline Percentage of students with language difficulties in class* & proportion constructed from questions G12 and G13 \\
\hline Instruction to engage students in learning & scale constructed from question G15 \\
\hline
\end{tabular}


Variables from parent questionnaire ${ }^{7}$

\begin{tabular}{|c|c|}
\hline Variable & Note \\
\hline $\begin{array}{l}\text { Command of early literacy tasks* } \\
\text { Parents' liking to read } \\
\text { Parent has tertiary education* } \\
\text { Parent has full-time job* }\end{array}$ & $\begin{array}{l}\text { scale constructed from question } 6 \\
\text { scale constructed from question } 13 \\
\text { binary indicator constructed from question } 17 \\
\text { binary indicator constructed from question } 19\end{array}$ \\
\hline Variable & Note \\
\hline School size* & question 1 \\
\hline Percentage of students speaking other than school's language* & question 4 \\
\hline School urban/rural* & binary indicator constructed from question $5 b$ \\
\hline Average wealth of school neighborhood* & question $5 c$ \\
\hline School emphasis on academic success & scale constructed from question 12 \\
\hline Discipline and safety at school & scale constructed from question 13 \\
\hline Instructional language Finnish/Swedish* & in Finland only, binary \\
\hline Instructional language Bokmål/Nynorsk & in Norway only, binary \\
\hline
\end{tabular}

\section{Variables used in models for reading performance (PIRLS) only}

\section{Variables from student questionnaire}

\begin{tabular}{ll} 
Variable & Note \\
\hline Time used for reading outside school* & question R1 \\
Reading of stories* & question R3a \\
Reading of non-fiction books* & question R3b \\
Reading of magazines & question R3c \\
Reading of comics* & question R3d \\
Borrowing books from library & question R4 \\
Interesting texts and tasks in class* & scale constructed from questions R5b and R5g \\
Understanding teacher in class* & scale constructed from questions R5c and R5e \\
Thinking of other things in class & question R5d \\
Liking to read* & scale constructed from question R7 \\
Confidence in reading* & scale constructed from question R8 \\
Motivation to read & scale constructed from question R9 \\
\hline
\end{tabular}

\section{Variables from parent questionnaire}

\begin{tabular}{ll} 
Variable & Note \\
Early literacy activities with child* & scale constructed from question 2 \\
\hline
\end{tabular}

${ }^{7}$ Only the parents of PIRLS students filled this questionnaire, which mainly concerned student's learning to read. In Finland, Norway and Sweden the same students took part in both TIMSS and PIRLS, but in Denmark this was not the case. Hence the variables from the parent question naire were not available for the Danish TIMSS analyses. 


\begin{tabular}{|c|c|}
\hline Variable & Note \\
\hline Teaching whole class simultaneously & question R3a \\
\hline Organizing students into same-ability groups & question $\mathrm{R} 3 \mathrm{~b}$ \\
\hline Organizing students into mixed-ability groups & question R3c \\
\hline Giving individualized teaching & question R3d \\
\hline Number of students who need but don't receive remedial instruction in reading & scale constructed from questions R4a and R4b \\
\hline Provision for advanced readers & question R5, binary \\
\hline Diversity of teaching material for reading & scale constructed from question R6 \\
\hline Use of fiction texts in class & scale constructed from question $\mathrm{R} 7 \mathrm{a}$ \\
\hline Use of non-fiction texts in class* & scale constructed from question $\mathrm{R} 7 \mathrm{~b}$ \\
\hline Developing students' reading strategies & scale constructed from question R9 \\
\hline Activating students after reading* & scale constructed from question R10 \\
\hline Professional help for students falling behind in reading & question R18a, binary \\
\hline Wait maturation of students falling behind in reading & question R18b, binary \\
\hline Use more time with students falling behind in reading & question R18c, binary \\
\hline Ask parents help students falling behind in reading & question R18d, binary \\
\hline Hours spent in updating education & question R21 \\
\hline
\end{tabular}

Variables from school questionnaire

\begin{tabular}{ll} 
Variable & Note \\
Resources to reading instruction* & scale constructed from question $10 \mathrm{~b}$ \\
\hline
\end{tabular}

\section{Variables used in models for mathematics performance (TIMSS) only}

Variables from student questionnaire

\begin{tabular}{|c|c|}
\hline Variable & Note \\
\hline Liking mathematics* & scale constructed from question MS1 \\
\hline Engagement in mathematics class* & scale constructed from question MS2 \\
\hline Confidence in mathematics* & scale constructed from question MS3 \\
\hline
\end{tabular}

Variables from school questionnaire

\begin{tabular}{ll} 
Variable & Note \\
Resources to mathematics instruction & scale constructed from question $10 \mathrm{c}$ \\
$\begin{array}{l}\text { Variables from parent questionnaire } \\
\text { Variable }\end{array}$ & Note \\
\hline $\begin{array}{l}\text { Early numeracy activities with child } \\
\text { Command of early numeracy tasks* }\end{array}$ & $\begin{array}{l}\text { scale constructed from question } 2 \\
\text { scale constructed from question } 7\end{array}$ \\
\hline
\end{tabular}

8 These variables were not available for the Danish TIMSS analyses. 


\section{Variables from teacher questionnaire}

Variable

Confidence in teaching mathematics

Asking students to memorize rules

Asking students to relate learned issues to daily life

Calculator allowed in class

Computers available in mathematics class

How often assign homework in mathematics
Note

scale constructed from question M2

question $\mathrm{M} 3 \mathrm{~b}$

question $\mathrm{M} 3 \mathrm{~g}$

question M5

question $\mathrm{M} 6 \mathrm{a}$

question M9a 


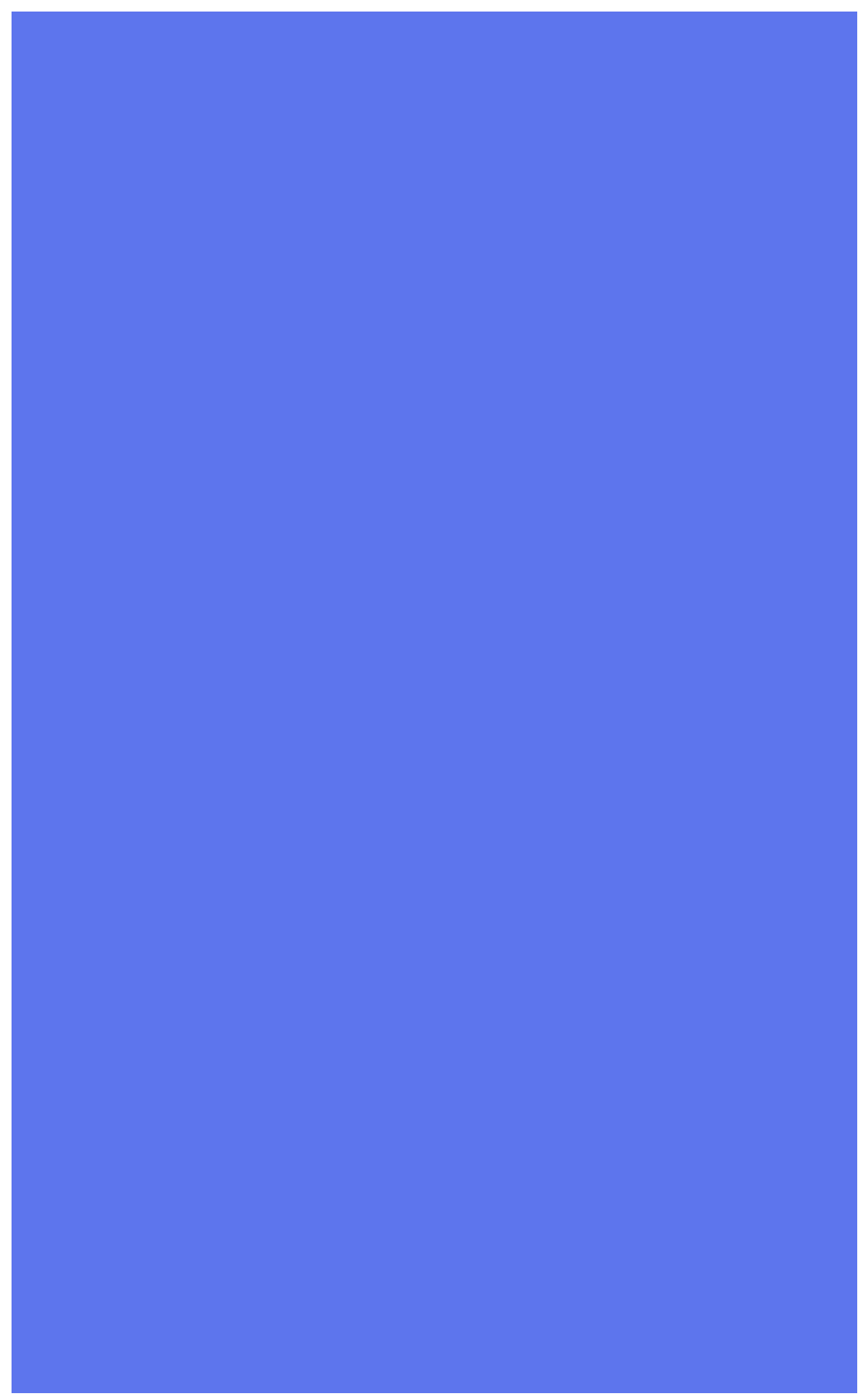




\section{Teacher attitudes and practices in international studies and their relationships to PISA performance: Nordic countries in an international context}

Ragnar F. Ólafsson and Júlíus K. Björnsson, Educational Testing Institute Reykjavik

\subsection{Summary}

Teachers' responses to PIRLS and TIMSS questionnaires regarding their teaching practices and attitudes to teaching in general, including maths, reading and science, were subjected to Multidimensional Scaling Analysis based on European or OECD country means for each of the questionnaire items. Country groups (or clusters) were identified that consisted of EastEuropean, Mediterranean, Anglo-Saxon, Germanic and Nordic countries, with some overlaps, indicating differences in teaching culture across these countries. A major dimension, engagement largely differentiated between Eastern European and Western European countries. The former showed greater engagement, which consisted, e.g., of greater teacher selfconfidence, greater use of specific teaching strategies, more test administration and home-work follow up. A correlation was found between 
engagement and progress in reading and maths literacy on PISA, indicating that more engaging teaching practices are associated with more progress. The limitations of this approach are also discussed.

\subsection{Introduction}

Stigler and Hiebert (2004) claim that "teaching is cultural; most teachers within a culture use similar methods" (p. 16). This claim is grounded in their analysis of video data from TIMSS studies. Along similar lines, Andrews (2010) points out that "teachers are proxies for an educational system's values and there is growing evidence that mathematics teachers in one country behave in ways that identify them more closely with teachers in their own country than teachers elsewhere" (Andrews, 2010, p. 21). The objective of this paper is to explore the cultural differences in teaching practices and attitudes among European countries, with a special focus on the Nordic countries. The international PIRLS and TIMSS studies provide information about teacher attitudes and practices. This data provides an excellent opportunity to explore cultural differences in the context of teaching and could be used to identify certain types of teaching practices that may be conducive to higher achievement in reading, mathematical and science literacy, which is assessed via PISA, another international OECD educational research program.

\subsection{Models of cultural differences}

One contribution to the study of cultural differences within teaching and learning comes from Hofstede (1986). He applied his classic fourdimensional model of cultural differences to speculate on what complexities could develop when teachers and students from different cultures meet and work together. 
Hofstede's model was initially based on research on 32 work-related values observed in individuals who worked at the same multinational corporation, which operated in 40 countries. Each country received a score for each of the four dimensions based on the country means for each of the values. The dimensions were individualism, power distance, uncertainty avoidance and masculinity. ${ }^{9}$ Country clusters emerged from this analysis. English-speaking countries had low power distance scores and high individualism scores. The Nordic countries and a number of other European countries also had low power distance scores, but their individualism scores were not as high. A few Mediterranean countries (e.g., France, Spain and Italy) had higher power distance scores than the other European countries. The countries with high power distance and low individualism scores included many South American and Asian countries. The Nordic countries had low uncertainly avoidance and masculinity, while Japan was situated at the other end of both dimensions, i.e., high uncertainty avoidance and masculinity.

How can these dimensions cast light on the student-teacher relationship? Contrasting countries on the collectivist-individualist dimension, Hofstede expected, for example, that individuals in collectivist societies would only speak up in small groups, while people from individualist societies would more easily speak up in large groups. He also expected students in small-power-distance societies to provide more student-centered education and expected societies with large power distances to be more teachercentred. In small-power-distance societies, students would be more likely to speak up spontaneously in class, to be allowed to contradict the teacher, to find their own path, etc. The opposite would be true in countries with large power distances. He produced some further suggestions regarding how these cultural dimensions would appear in the classroom.

Schwartz (1999) presented a theory of cultural values, another dimensional model, based on questionnaire data acquired from teachers and students in 49 nations. Schwartz chose teachers as participants because they are "key carriers of culture, and they probably reflect the mid-range

\footnotetext{
${ }^{9}$ Hofstede (1998, p. 480) later added a fifth dimension (short- vs. long-term orientation), and these dimensions have been validated in various other contexts.
} 
of prevailing value priorities in most societies" (p. 34). He was thus interested in teachers as representatives of their cultures, not in identifying cultural differences in terms of how they conducted their work or their teaching practices. He identified seven types of values, which were structured around three dimensions. Conservatism vs. intellectual and affective autonomy, hierarchy versus egalitarianism, and mastery vs. harmony. Using the co-plot technique (Goldreich and Raveh, 1993 - cited in Schwartz 1999), he observed that many Western countries sided on the intellectual and affective autonomy end, valuing the pursuit of one's "own ideas and intellectual directions (curiosity, broadmindedness and creativity)" (p. 27) and positive affective experiences "(pleasure, leading an exciting life and leading a varied life)" (p. 27), while many Eastern European countries were more on the conservative side, emphasizing "social order, respect for tradition, family security [and] wisdom)" (p. 27). Extremely conservative countries included Singapore, Nepal, Bolivia and Cyprus.

Sweden and Denmark were located close together on the side of egalitarianism and intellectual autonomy, with Finland close by but further towards the harmony section of the co-plot (p. 36). Interestingly, Schwartz (1999) identified meaningful groupings of culturally related nations, which consisted broadly of English-speaking, Western European, Eastern European, Far Eastern and Latin American groups, along with meaningful subgroups. These country characteristics are likely to be reflected in the day-today work of teachers, which is the focus of interest of the present study.

\subsection{A culture of observation, feedback and improvement}

Previous research on TALIS 2008 data indicates that certain teacher attitudes and practices at the country level are associated with greater progress on measures of PISA reading literacy between 2000 and 2009) (Ólafsson, Macdonald and Pálsdóttir, 2012). In that study, a subset of 53 items pertaining to collective teacher efficacy were analyzed with multidimensional scaling (MDS) and hierarchical cluster analysis (HCA). The main emerging dimension differentiated between countries in terms of adherence to a culture of observation, feedback and improvement. Furthermore, country scores on 
this dimension correlated positively with a measure of progress in terms of PISA reading literacy scores from 2000 to 2009.

A cluster analysis of countries was performed based on country scores for the three dimensions identified. It revealed country groups that largely reflected countries' geographical locations. This suggests that educational practices are a reflection of fundamental cultural characteristics and broader regional differences between participating countries. The Ólafsson et al. study (2012) follows the recent growth in educational studies focusing on cultural context, such as the work of Lee and Hallinger (2012), who state that "principal time use and allocation varies substantially across societies and (...) these patterns of behavior are influenced by economic, socio-cultural and institutional features of their societies" (p. 461). The analysis of PIRLS and TIMSS data undertaken here can provide further details regarding these cultural differences and their relationships to achievement outcomes.

The main dimension identified in Ólafsson et al. (2012), labelled culture of observation, feedback and improvement, distinguished mainly between the Western, Southern and Northern European country clusters on the one hand and Eastern European, Latin American and Asian countries on the other. Thus, a culture of feedback seemed to be more prominent in Eastern Europe and Asia/Latin America than in other areas. Observing the classrooms of colleagues, providing feedback about teaching, and suggesting improvements that the teacher believes to be useful are more characteristic of Eastern European practices. Western European teachers draw a more individualistic picture of their practices and appear to be more isolated in their classrooms, with less outside influence/interference.

The Nordic countries that participated in TALIS 2008 (Norway, Denmark and Iceland) formed a distinct cluster, which was similar to other Western European countries and different from Eastern European countries, as stated above.

\subsection{The link with progress}

The identification of these clusters and dimensions and more importantly their associations with measures of progress in PISA reading literacy may have important policy implications. At a conceptual level, it makes sense 
that an intensive culture of feedback should be associated with increased progress. The correlation observed between adherence to a culture of observation, feedback and improvement on the one hand and progress in reading literacy supports this notion and identifies countries where such adherence is wanting, including the Nordic countries.

The MDS approach permits the identification of dimensions at the macro-level. Links may be observed at that level that go unnoticed at the factor or item level. Another example of the fruitful use of multidimensional scaling in the context of international comparisons is the work of Smith et al. (2002).

This association between culture and improvement demands further research, however. The PIRLS and TIMSS international datasets provide an excellent opportunity to do this. If confirmed, these findings might suggest that policy makers should move away from an individualistic vision of the teacher and encourage practices with more peer and/or schoolmanagement observation of teaching practices in classrooms and more feedback, including suggestions about how to improve teaching practices.

The Nordic countries will be compared with other country groups identified via cluster analysis. There are other examples of research focusing on a subset of related countries. See, e.g., Hao and Johnson (2013), who focused on English-speaking countries. Here, however, the Nordic countries will be contrasted with other participating countries.

If Stigler and Hiebert's (2004) claim above - that "teaching is cultural" - is correct, these cultural characteristics might be persistent and observable at various school levels. Indeed, if significant variations in how teaching is conducted between countries and groups of countries are rooted in deeper cultural characteristics, it would not appear farfetched to expect correlations between teaching practices in Grade 4 and reading, mathematics and science literacy outcomes in the Grade 10.

The teacher PIRLS and TIMSS 2011 data will be analyzed at the country level. Country averages for individual items will be computed. Data from these studies is made comparable by rescaling items. Country groups and dimensions that differentiate between them will be identified using multidimensional scaling and cluster analysis. Country progress on achievement measures from the recently published PISA 2012 will then be linked to these dimensions with correlation analyses to determine 
whether cultural differences in attitudes and practices are related to country progress.

\subsection{Methods}

Participants: Teachers from 24 countries, European, Australia and Québec (Canada). Teachers from these countries participated in the combined PIRLS and TIMSS 2011 study ${ }^{10}$ and taught Grade 4 students in mathematics, science and reading. It is important to note that the teachers do not constitute representative samples of teachers. Instead, they are the teachers of representative samples of students (Foy, 2013).

Materials: the teacher questionnaires used in TIMSS and PIRLS, which contain general questions about the teacher himself or herself and his or her school, about being a teacher and about teaching a particular class. They also contain specific questions about teaching reading, computer and library resources, reading homework, assessing reading and the teacher's education in teaching reading. Similarly, questions about teaching mathematics addressed teaching mathematics to a particular class, resources for teaching mathematics, topics taught, content coverage, mathematics homework for the pupils, assessment and the teacher's preparation to teach mathematics. A section on science teaching included questions about teaching a particular science class, resources for teaching science, science topics taught, science content coverage, science homework, science assessment and the teacher's perceived preparation to teach science (link to the questionnaires: http://timssandpirls bc.edu/timss2011/international-contextual-q.html).

Procedure: The questionnaires were filled in by the teachers (further information: http://timssandpirls.bc.edu/timsspirls2011/internationaldatabase.html).

10 Denmark participated separately in PIRLS 2011 and TIMSS 2011, not in the combined TIMSS and PIRLS 2011. 


\subsection{Analysis}

A multidimensional scaling analysis (MDS) and a hierarchical cluster analysis (HCA) were computed based on the country means for each of the questionnaire items. Countries were grouped based on the similarity of their responses. Differences in teaching practices across countries were identified along one main dimension. The correlations between the dimensions of teaching practices and PISA progress scores in reading, mathematics and science were computed.

See Appendix 1 for further details on analysis.

\subsection{Results}

The outcome of the MDS can be observed in Figure 1. Two dimensions, horizontal and vertical, are displayed, with the Nordic countries appearing at the upper left extremity.

\subsubsection{Country clusters}

The model differentiates broadly between Eastern European countries (right) and Western European countries on the left, indicating that responses to the questionnaires reflect, in part, the geographical positions of the countries under study. This indicates that the major cultural differences in Europe are observed between Eastern and Western Europe. Interestingly, within the Eastern European group, Russia (RUS) and Georgia (GEO) are in close proximity, perhaps not surprisingly because these two countries were parts of the former Soviet Union. Similarly, Slovakia (SVK) and the Czech Republic (CZE) are relatively close on the graph, perhaps reflecting similarities between these countries dating from the time when they formed a single country. 
The four Nordic countries included in the study (FIN, NOR, DEN and SWE) are relatively close together in the upper left corner of the graph.11 The two Germanic countries, Germany (GER) and Austria (AUT), are also in close proximity and adjacent to the Nordic countries. Towards the lower left part, a set of largely Anglo-Saxon countries are grouped together, including Ireland (IRL); Malta (MLT); Australia (AUS); Québec (CQU), and Northern-Ireland (NIR). In the lower right part are Italy (ITA) and Portugal (PRT), with similar scores on the Dimension 1, but with Spain (ESP) being situated a bit further up on Dimension 2 .

The hierarchical cluster analysis (HCA) based on the country scores on the variables, assists in determining the groupings (Figure 2). It is largely in line with what has been described above, with the exceptions that Spain is clustered with Slovenia and Italy and Portugal are clustered with Romania.

\subsubsection{Interpreting dimensions that differentiate between country groups}

The dimensions will now be interpreted on the basis of how they correlate with the country means for each of the variables used to generate the MDS solution. Each dimension will be interpreted by exploring the correlations between the countries' coordinates on the dimension and the individual question items. It is not practical to present all the correlation coefficients. Instead, the interpretation of the dimensions is based on significant correlations and summarising and paraphrasing the content of the items that correlate significantly with the dimensions. Pearson correlations are used.

The horizontal and vertical dimensions were interpreted separately. However, their meanings were similar in that both seem to reflect different degrees of engagement. This horizontal dimension correlates significantly with two progress measures in PISA (reading and mathematics) and less well with science literacy. The vertical dimension, on the other hand, correlates with progress in science. This indicates that the high cor-

\footnotetext{
11 Iceland did not participate in PIRLS and TIMSS in 2011. Judging from a similar analysis of PIRLS data from 2006 (Ólafsson, in progress) and TALIS 2008 data (Ólafsson et al., 2012), Iceland would be expected to align closely with the other Nordic countries.
} 
relations with progress may be achieved by correlating progress with a third axis, going diagonally from the bottom right to the top left. ${ }^{12}$

Because the dimensions largely differentiate between Eastern European and Western Eurpean coutries, as well as other familiar country groups (Anglo-Saxon, Nordic and Germanic), the terminology normally used when decribing correlations (e.g., a high score for $\mathrm{x}$ is associated with a high score for y) will sometimes be put aside, and descriptions will be made in terms of differences between groups of countries, a strategy that would normally only be used when the statistical methods used to compare groups are applied (e.g., ANOVA).

The description of the dimensions largely reflects the division of the questionnaires into four sections: general, reading, mathematics and science.

By correlating the country scores for each question item with the countries' coordinates on the horizontal dimension, we are able to identify the characteristics that tend to be higher in countries on the left compared with countries on the right on the dimension. These characteristics will now be described in some detail. We will then do the same for the vertical dimension. Indications of which sections of the questionnaires the items at hand come from, should readers want to look them up on the TIMSS and PIRLS websites, appear in brackets.

The horizontal dimension (Dimension 1) will be interpreted first.

\section{Teachers' education}

Regarding the teachers' formal education in teaching reading, in countries on the right, more emphasis on studying the language itself, the pedagogy of teaching reading, educational psychology, remedial reading, reading theory, language learning and assessment methods in reading is reported by teachers (R20). However, teachers on the left end of the dimension

\footnotetext{
12 "Orientation of axes. As in factor analysis, the actual orientation of the axes in the final solution is arbitrary." For example, although a map can be rotated in any way we want, the distances between cities will remain the same. "Thus, the final orientation of axes in the plane or space is mostly the result of a subjective decision by the researcher, who will choose an orientation that can be most easily explained." (...) (W)e could have chosen an orientation of the axes other than north/south and east/west; however, that orientation is the most convenient because it "makes the most sense" (i.e., it is easily interpretable).

http://www.statsoft.com/Textbook/Multidimensional-Scaling.
} 
have placed a relatively greater emphasis on special education with regard to teaching reading. This is in line with their greater tendency to send pupils with reading problems to specialised professionals (R18).

\section{Better prepared to teach?}

Countries on the right part of the dimension report having greater confidence (S2, M2) in performing various teaching tasks. They undertake more hours of professional development (R21) and have read children's books more often as part of professional development (R22). Conversely, teachers on the left feel more "frustrated" (G11).

\section{Teachers' contact with one another}

In countries on the right, teachers collaborate more with other teachers. They plan and work together and visit one another's classes to learn from one another (G10).

\section{Assessment and homework}

Teachers in countries on the right end of the dimension accord greater importance to assessment $(\mathrm{R} 19, \mathrm{~S} 9)$ in both maths and science. They place greater emphasis on homework in reading, maths and science, expecting students to do more of it and monitoring whether it has been completed or not more frequently. They correct the homework and discuss it in class more frequently. This is the case in all three subjects: reading, maths and science.

\section{More front-loaded curriculum?}

A few topics in science and maths are taught earlier in the countries on the right. This was determined using a scale that assesses whether individual topics were taught before this year, were taught during this year or have not yet been introduced.

\section{Use of computers and books}

Computers are more accessible in the countries on the left, but teachers in countries on the right end report more frequent computer use in science lessons (S5). In a similar vein, they ask their students to read or look something up on the computer more often than countries further to the left. They also report requesting the use of textbooks on the part of their students more frequently. 
However, in the countries on the left, greater emphasis can be seen in various questionnaire sections regarding computer use. They have more computers, use software more frequently, have greater internet access and use computers more frequently in teaching preparation and classroom instruction than countries on the right.

\section{More student engagement}

Teachers of maths, science and reading were asked how often they ask pupils to perform various learning tasks. Again, teachers in the countries on the right end of the dimension present a similar picture in terms of how they conduct their teaching of maths, science or reading (S3, M3, R9 and R10). Science teachers, for example, in the countries on the right, more frequently ask pupils to relate what they are learning to their daily lives, give explanations of what they are studying, memorize facts and principles and observe natural phenomena such as the weather and describe what they see. They also more frequently ask students to watch a demonstration and read textbooks.

The pictures of mathematics and reading lessons are simliar. In mathematics, teachers more often ask pupils to explain their answers; relate what they are learning to their daily lives; memorize rules, procedures and facts; and work on problems together as a class, with direct guidance from the teacher.

In reading, teachers in countries on the right of the dimension also ask pupils to perform certain tasks more frequently in order to help them develop reading comprehension skills and strategies, e.g., locate information within text, identify the main ideas of what is read, explain or support their understanding of what they have read, compare what they have read with their own experiences or other things they have read, make predictions about what will happen next in the text, make generalizations based on what they have read, and describe the style and structure of a text and the author's intention (R9). They also more frequently ask them to write something about what they have read, answer oral questions or talk among themselves about what they have read. In reading lessons, teachers in countries on the right more frequently ask students to read aloud, teach them strategies to decode sounds and words, teach new vocabulary sytematically and teach skimming or scanning strategies (R8). 
Countries on the left are, however, more likely to give students time to read books of their own choosing and give them longer books to read. Also, pupils in these countries have more children's books available for their perusal (R6). Overall, teachers on the left complain less about a lack of teaching materials (G8).

In countries on the right, teachers' interactions with their students are also more engaging in the sense that they more frequently relate the lessons to the students' daily lives, encourage them to improve their performance, praise them, bring interesting materials to class and summarize what they should have learned from the lesson (G15).

\section{Contact with parents}

Teachers in countries on the right side of the dimension are in greater contact with parents, more frequently meet or talk individually with parents to discuss the learning progress of their offspring and more frequently send home progress reports (G17).

\section{Tests}

In all three subjects in countries on the right, great emphasis was placed on taking a written test or quiz about what the students had studied or read.

\section{When students fall behind}

When students fall behind in reading, teachers in countries on the right tend to spend more time with them, while refering them to specialised professionals is more the rule in countries on the left (R18). Teachers in countries in Western Europe more frequently complain that students lack sleep or disrupt classes.

\section{Gender and length of service}

A greater percentage of teachers on the left are males (G2). Teachers on the right had taught for longer and were older.

The vertical dimension (Dimension 2) is similar to the horizontal dimension in the sense that being lower on the dimension is associated with greater engagement of various kinds, just like the right side of the horizontal dimension. Fewer items correlate with it, however. Teachers in countries on the lower end tend to perform more professional development, report a higher level of understanding of their schools' curricular goals and spend 
more time teaching mathematics overall. They more frequently ask students to read aloud and teach strategies for decoding sounds. Also, they make greater use of some of the reading comprehension strategies, as seen in the horizontal dimension. In mathematics, pupils are more frequently asked to memorize rules and explore mathematics principles and concepts as part of computer activities. They are also asked to do more homework than students in countries toward the top.

Teachers in countries on the bottom of the dimension have higher expectations in terms of student achievement and encourage students to improve their performance more frequently. Similarly, pupils are reported to have a greater desire to do well, behave in an orderly manner, be respectful of teachers and have a high regard for school property than those in countries on the top of the dimension (G6, G7).

Teachers in countries on the top of the vertical dimension report that they have fewer pupils in class. They share what they have learned about their teaching more often, and they have greater access to teacher aid when a student has difficulties with reading.

\subsubsection{Teacher practices and progress as measured via PISA}

The country scores on the two dimensions were correlated with three measures of progress in PISA. The correlation coefficients (Table 1) indicate that high scores on the horizontal dimension (engagement) are associated with PISA progress in reading and mathematics. A high score on the dimension indicates low levels of engagement, countries on the left of the MDS solution (the Western European countries), i.e., those showing relatively little engagement in teaching activities, are making less progress in reading and mathematics. A low score on the vertical dimension is associated with more progress in science. 
Table 1: Pearson correlations between the horizontal and vertical dimensions and the three measures of PISA progress (reading, mathemics and science).

\begin{tabular}{lll}
\hline & Horizontal dimension & Vertical dimension \\
\hline Progres__PISA_Reading & $0.606^{*}$ & -0.075 \\
& $\mathrm{p}=0.013$ & $\mathrm{p}=0.782$ \\
& $\mathrm{n}=16$ & $\mathrm{n}=16$ \\
& & \\
Progress_PISA_Mathematics & $0.573^{*}$ & -0.407 \\
& $\mathrm{p}=0.026$ & $\mathrm{p}=0.132$ \\
& $\mathrm{n}=15$ & $\mathrm{n}=15$ \\
Progress_PISA_Science & 0.410 & $-0.530^{*}$ \\
& $\mathrm{p}=0.073$ & $\mathrm{p}=0.016$ \\
& $\mathrm{n}=20$ & $\mathrm{n}=20$ \\
\hline
\end{tabular}

*significant at the 0.05 level (2-tailed)

\subsection{Discussion}

The results indicate that teachers' responses to the questionnaires in the combined PIRLS and TIMSS 2011 study largely reflect the geographical positions of the countries. This indicates that the teaching practices, attitudes and conditions regarding European reading, mathematics and science teachers, as assessed in those questionnaires, are influenced by deeper cultural factors. The main dimension that differentiated between Eastern and Western European countries was interpreted to represent different degrees of engagement among teachers in those two European regions. Teachers in Western Europe reported that they more seldom use various strategies that demand engagement from their students, both in class and in terms of homework, assigning less homework and more rarely monitoring its completion, and administering fewer classroom tests. These characteristics were rather uniform across the three subjects under study.

However, the teachers in the Western European countries reported greater computer access and software and Internet use in their teaching. They complained less about a lack of instructional materials. They more often allowed pupils to read books of their own choice and had more books available for that purpose. They engaged less in interactions with other teachers regarding professional issues, had less contact with the students' parents to discuss the pupils' progress and felt more frustrated as teachers. 
The country groupings are similar to those identified by Hofstede (1986), Schwartz (1999) and Ólafsson et al. (2012). To a certain extent, their configuration can be mapped onto those identified in these studies. While the content of the questions does not allow for direct comparisons, certain parallels can be observed between the partly conservative teaching practices in the Eastern European countries and the emphasis on intellectual autonomy (Schwartz, 1999) in the Western European countries, e.g., the fact that the latter emphasize that pupils read books of their own choosing. The intellectual autonomy angle was also apparent in the TALIS data (Ólafsson et al., 2012), in which teacher collaboration and feedback were lower in the Western European countries than the Eastern European countries. The present study is consistent with the findings of Olsen (2005), who located the Nordic countries among the Western European countries in a cluster analysis. They are also consistent with with Ólafsson et al. (2012) on another level because the relative disengagement of teachers in the Nordic and Western European countries in general is consistent with the same countries' lack of interaction with other teachers, as identified via the TALIS data. The analysis of the TALIS data showed that classroom observations of colleagues, providing feedback about teaching, and suggesting improvements which the teacher considers useful, is more a characteristic of Eastern European practices. Western European teachers paint an individualistic picture of their practices and their colleagues' in which teachers appear to be isolated in the classroom, with less outside influence/interference. Following their extensive analysis of mathematics teaching culture based on the TIMSS video data for several countries, Stigler and Hiebert (2004) profess the virtues of a practice much in line with the one described by the main dimensions used in the TALIS study (Ólafsson et al. 2012) and consistent with the one identified in the analysis presented here. They claim that teaching can only change to the better "by using methods known to change culture. Primary among these methods is the analysis of practice, which brings cultural routines to awareness so that teachers can consciously evaluate and improve them" (Stigler and Hiebert, 2004, p. 17). 


\subsection{The Nordic countries}

The Nordic countries reveal themselves to be at the same extremity of the engagement dimension as many other Western European countries, and they are characterised be comparatively less engagement in their teaching and interactions with students, as the term is defined here by the correlations of the individual variables with the dimension identified by the MDS. Intuitively, these characterstics seem to not be conducive to academic progress. Indeed, the recently published PISA 2012 outcomes indicate that there is cause for concern among the Nordic countries, especially Sweden and Finland, who both dropped in performance considerably over the last PISA cycle. The findings should suggest to policy makers that these countries might consider taking up more engaging teaching practices, as described in this article. The findings must be corroborated, e.g., with EU data on the educational systems in these countries because the selfreports in questionnaires may have limitations.

A country's position on the horizontal dimension is associated with progress on PISA reading and mathematics literacy, and its position on the vertical dimension is associated with progress in science. This indicates that the practices of teachers, as assessed in PIRLS and TIMSS, can be related to the learning outcomes of students. These findings support previous findings (Ólafsson et al., 2012) showing that certain teaching practices with a focus on teacher collaboration were also related to progress in reading literacy from the year 2000 to 2009. In this study, the preferred place to be on the MDS graph is the lower right with Portugal, Italy, Romania and Russia. Being positioned there is associated with making progress on most or all three literacy domains while the Nordic top left is associated with the opposite.

As with any correlational study, causality cannot be inferred on the basis of a significant correlation. However, the association of engaging teaching practices with progress should not come as a surprise. Some of the strategies summed up under the engaging dimension have been shown to improve reading skills. The National Reading Panel in the U.S., after reviewing thousands of studies of how children learn to read, found that teaching new vocabulary or applying reading comprehension strategies is 
effective in teaching children to read. Such practices are displayed in items correlating with the engagement dimension.

Myrberg (2007), in an introduction to her own study, cites Rutter et al. (1979) and other studies that show a correlation between teacher cooperation and student achievement. Also, she cites Greenwald et al. (1996), who found that school resources, including well-educated teachers, are systematically related to student achievment (Myrberg, 2007, p. 149). As with any correlations calculation, the individual scores (scores of individual countries, in this context) may deviate from the main trend identified by a correlation. The groupings, i.e., the position of countries with regard to the MDS solution, however, reflect the overall similarities between countries in terms of how they answered the questions. Also, it is important to point out that the questions that correlate at the country level may not necessarily correlate at the individual level. As Hofstede (1998, p. 481) points out, his analyses were "a test of national culture, not of individual personality: They distinguish cultural groups or populations, not individuals" (Hofstede, 1998, p. 481).

The MDS, as a tool to summarize a great number of variables and thus identify underlying dimensions with predictive validity in relation to progress, has proved its usefulness in this analysis, as it did in that of ólafsson et al. (2012). Its weaknesses may lie in the exploratory nature of its findings. The country group differences, which are mainly between Eastern and Western Europe, must be confirmed by more direct group comparisons and by the further exploration of the TIMSS, PIRLS and TALIS data sets. The current results are based on exploratory analysis methods. Fruitful future steps will be to derive confirmatory models for the set of variables used in the present study from a theoretical basis and to compare the results with those of the exploratory analysis. Another approach would be to construct confirmatory models based on the results presented here (structural equation or confirmatory factor analytical models) and investigate how well they hold up against data from individual countries or even several countries as once (multi-level models). 
Figure 1: Multidimensional scaling of countries, displaying country groups in 2-dimensional space

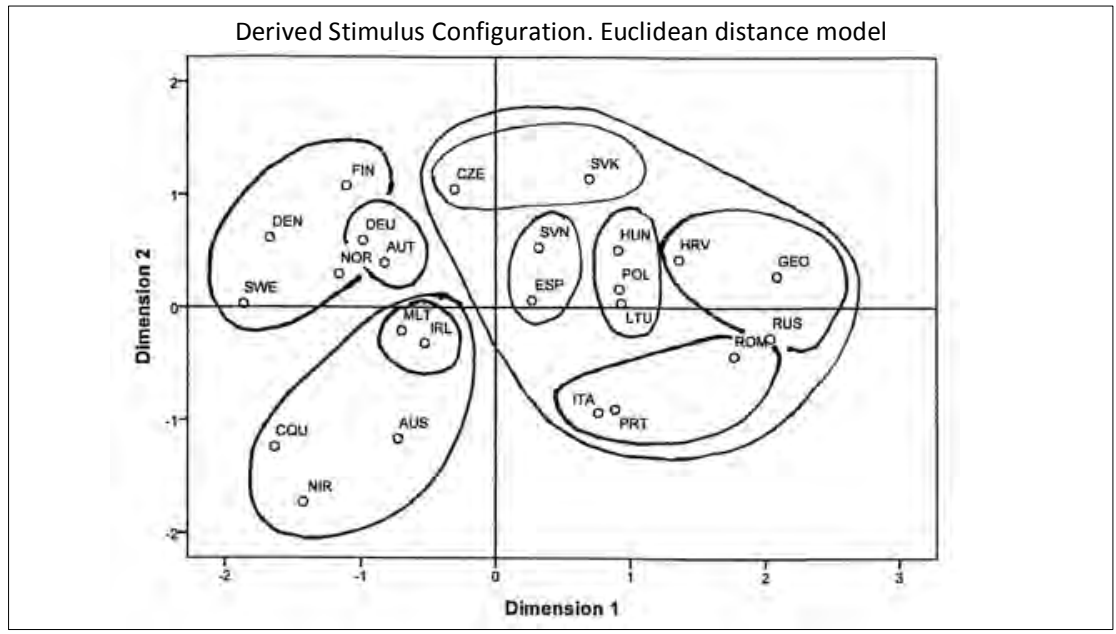

Figure 2: Hierachical cluster analysis of countries (dendrogram), grouping together countries that have similar response patterns

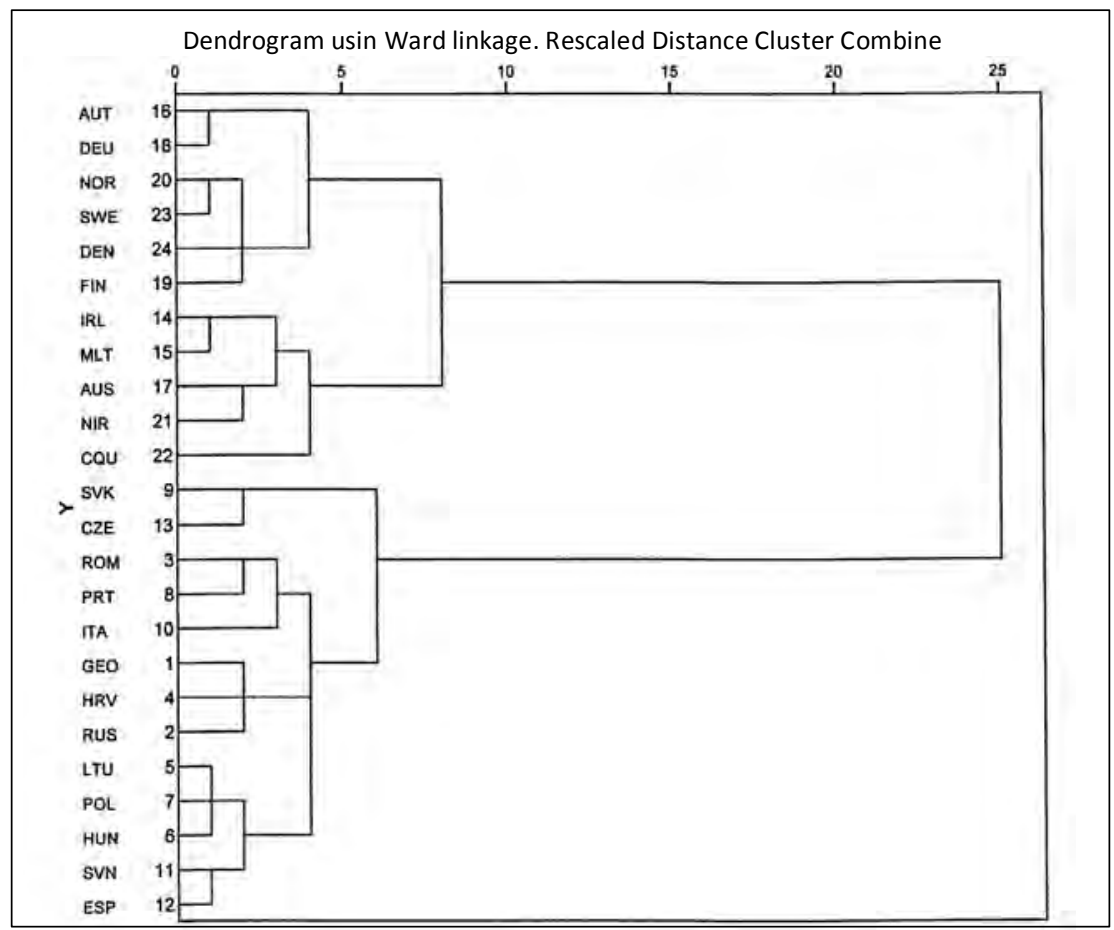




\subsection{References}

Andrews, P. (2010). Acknowledging the cultural dimension in research into mathematics teaching and learning. In Joubert, M. and Andrews, P. (Eds.) Proceedings of the British Congress for Mathematics Education. April 2010.

Foy, P. (2013). TIMSS and PIRLS 2011 User Guide for the Fourth Grade Combined International Database. TIMSS \& PIRLS International Study Center, Lynch School of Education, Boston College and International Association for the Evaluation of Educational Achievement (IEA).

Hofstede, G. (1986) Cultural differences in teaching and learning. International Journal of Intercultural Relations, 10, pp. 301-320.

Hofstede, G. (1998). Attitudes, values and organizational culture: Disentangling the concepts. Organization Studies, 19(3), pp. 477-492.

Hao, S. and Johnson, R.L. (2013). Teachers' classroom assessment practices and fourth-graders' reading literacy achievements: An international study. Teaching and Teacher Education, 29, pp. 53-63.

Lee, M. and Hallinger, P. (2012). National contexts influencing principals' time use and allocation: Economic development, societal culture, and educational system. School Effectiveness and School Improvement, 23(4), SI, pp. 461-482.

Myrberg, E. (2007). The effect of formal teacher education on reading achievement of 3rd-grade students in public and independent schools in Sweden. Educational Studies, 33(2), pp. 145-162.

National Reading Panel: http://www.nichd.nih.gov/research/supported/Pages/ nrp.aspx Retrieved March 18th, 2014.

Ólafsson, R. F., Macdonald, A. and Pálsdóttir, A. (2012). Teacher efficacy and country clusters: Some findings from the TALIS 2008 survey. Ráðstefnurit Netlu Menntakvika 2012. Menntavísindasvið Háskóla Íslands. Retrieved March 18th, 2014: http://netla.hi.is/menntakvika2012/011.pdf

Olsen, R.V. (2005): An exploration of cluster structure in scientific literacy in PISA: Evidence for a Nordic dimension? NorDiNa, 1(1), pp. 81-94. Retrieved March 18th, 2014. http://www.naturfagsenteret.no/c1515373/binfil/

download2.php?tid=1509943

Rutter, M., Maughan, B., Mortimore, P. and Ouston, J. (1979) Fifteen thousand hours: secondary schools and their effects on children. (London, Open Book).

Schwartz, S.H. (1999). A theory of cultural values and some implications for work. Applied Psychology: An International Review, 48(1), pp. 23-47.

Smith, P.K., Cowie, H., Olafsson, R.F. and Liefooghe, A.P.D. (2002). Definitions of bullying: A comparison of terms used, and age and gender differences, in a fourteen-country international comparison. Child Development, 73(4),1119-33.

StatSoft Electronic Statistics Textbook: http://www.statsoft.com/Textbook/ Multidimensional-Scaling. Retrieved March 18th, 2014.

Stigler, J.W. and Hiebert, J. (2004). Improving mathematics teaching. Educational Leadership, 61(5), pp. 12-17. Retrieved March 17th, 2014. http:// 
www.ascd.org/publications/educational-leadership/feb04/vol61/num05/ Improving-Mathematics-Teaching.aspx

\subsection{Appendix. Data Analysis}

A multidimensional scaling analysis (MDS) based on Euclidean distance was conducted on the means and percentages (rescaled) of ordinal, interval and dichotomous variables (individual items) contained in the teacher questionnaires of the PIRLS and TIMSS 2011 combined studies. The aim of the analysis is to identify groups of countries and the dimensions that differentiate between them or between these groups and individual countires. A twodimensional solution with a stress value of 0.12 , which is slightly higher than the 0.10 criterion typically used as a "fair" stress value, was chosen. The correlations between the country averages on the question items and the countries' coordinates on each dimension were then computed, which served to assist in the interpretation the dimensions.

The variables were rescaled by dividing the country average by the top score on the variable in question and multiplying by 100 . For Likert scales, the denominator is the highest possible response option (e.g., "5" on a 1-5 scale). On questions requesting the participant to record the time spent on a particular task, the denominator was equivalent to the highest time recorded. For responses expressed in percentages, the denominator was 100, regardless of whether any participant used that option or not.

A hierarchical cluster analysis (HCA) was conducted to group the 24 countries on the basis of their scores on the variables. Ward's linkage was used.

To examine whether the dimensions identified in the MDS have any validity for the prediction of performance on PISA tests, the correlations between the country scores on the dimensions on the one hand and indicators of progress on each of the three PISA literacy scores (reading literacy, mathematics literacy and science literacy) on the other hand were determined. Progress was determied by substracting the 2012 country averages on reading, maths and science from the country scores obtained the first time these topics were examined in detail in PISA. Thus, for reading, the year of reference is 2000. For maths, it is 2003. For science, it is 2006. A positive value indicates progress over the given time period. 


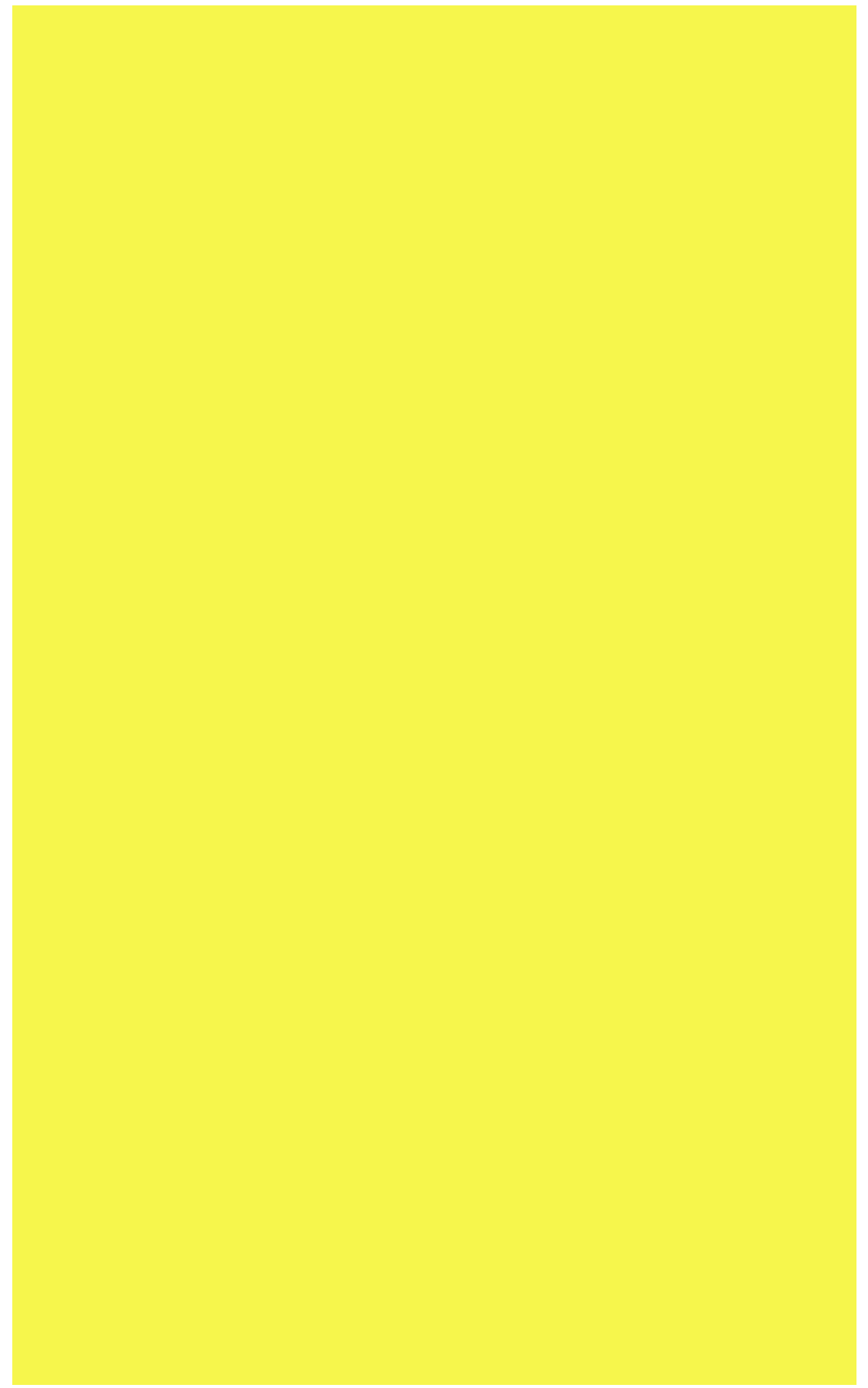




\section{Mathematics in the Nordic countries - Trends and challenges in students' achievement in Norway, Sweden, Finland and Denmark}

By Liv Sissel Grønmo, Department of Teacher Education and School Research, University of Oslo. Inger Christin Borge and Arne Hole, Department of Teacher Education and School Research and Department of Mathematics, University of Oslo

\subsection{Summary}

The aim of this article is to give an overview of important characteristics of mathematics as a school subject in the Nordic countries and to point out issues that have to be addressed to improve students' learning in mathematics. A number of analyses based on data from international comparative studies will be referred to, with the main focus of analysis based on data from the latest Trends in International Mathematics and Science Study (TIMSS). These analyses give evidence for important educational factors that can explain trends in students' achievement.

One main focus will be on mathematics for Grade 8 in Norway and Sweden, since we have the most data available for this grade level and for these two Nordic countries. Results for Finland will also be presented; but here we have to take into account limitations in available data for relevant 
comparisons and analyses. For Grade 4 there are even more limitations in available data that have to be taken into account. We have fewer data available for most of the Nordic countries at this level. Denmark will be included in the results for Grade 4 since this is the only level in the last TIMSS studies in which they participated.

From 1995 to 2003, both Norway and Sweden had a significant decrease in students' achievement in lower secondary school; the same is the case for Finland from 1999 to 2011. Since 2003, there has been a change in trends in achievement in mathematics in Norway, showing an increase in students' achievement in 2007 and 2011 in both Grade 8 and Grade 4. However, this positive trend does not apply to Sweden. In this article, we will present results from analysing several factors that may have contributed to an understanding of the trends in Norway, Sweden and Finland. This includes analyses and discussions of factors such as School Emphasis on Academic Success (SEAS) and students' Opportunity to Learn (OTL) mathematics. Results of analyses of what characterises mathematics in school in the Nordic countries will also be presented. We will also refer to results from other international comparative studies such as the Programme for International Student Assessment (PISA), TIMSS Advanced and the Teacher Education and Development Study in Mathematics (TEDS-M) to get a solid basis for discussions about how to make improvement in students' achievement in mathematics.

The article will present results both in a descriptive way and as conclusions based on secondary analyses, aiming to give both broad and indepth evidence for what characterises mathematics in the Nordic countries. Throughout the article, we try to keep to a reader friendly presentation style, visualizing the results with graphs wherever possible.

\subsection{Introduction}

A main purpose of this article is to analyse data from TIMSS to obtain information on how to improve students' achievement in mathematics in the Nordic countries. Important and foundational information for the analyses include trends and achievement levels in mathematics in all the 
Nordic countries that have participated in TIMSS, with a special focus on the last two TIMSS studies in 2007 and 2011.

Table 1: Overview of participation of Nordic countries in TIMSS from 1995 to 2011. Iceland has never participated in TIMSS

\begin{tabular}{llllll}
\hline & TIMSS 1995 & TIMSS-R 1999 & TIMSS 2003 & TIMSS 2007 & TIMSS 2011 \\
\hline Grade 8 & $\begin{array}{l}\text { Norway } \\
\text { Sweden } \\
\text { (Denmark) }\end{array}$ & Finland & Norway & Norway & Norway \\
& & & Sweden & Sweden & Fweden \\
& Norway & & & \\
Grade 4 & & Norway & Norway & Norway \\
& & & Sweden & Sweden \\
& & & Denmark & Denmark \\
& & & & Finland \\
\hline
\end{tabular}

*Sampling problems in Denmark - The Danish sampling procedure did not follow the TIMSS sampling standard for classes.

Table 1 shows that Norway and Sweden have participated regularly for Grade 8 in TIMSS from 1995 to 2011. However, these countries did not participate in TIMSS-Repeat in 1999, a study only in lower secondary school. Finland was the only Nordic country that participated in TIMSSRepeat. Denmark participated for Grade 8 in TIMSS 1995, but they did not fully follow the TIMSS procedures for sampling classes within the schools. For this reason, their data are only partially comparable with other countries (Beaton, Mullis, Martin, Gonzales, Kelly \& Smith, 1996).

Norway has participated regularly for Grade 4, while Sweden and Denmark participated at this level in 2007 and 2011. The overview in Table 1 illustrates that we have the best data coverage for Norway and Sweden for Grade 8, this being a main reason for why these countries and this grade level will be in main focus in the analyses presented in this article.

As shown in Figure 1, there is a significant decrease in students' performance in both Sweden and Norway from 1995 to 2003. After 2003, we observe an increase in students' achievement in Norway, while the negative trend continues for Swedish students. In this article, we present results of analyses aiming to get an understanding of the reasons for this. In 1995, the Danish students achieved about the same level as Norwegian students, but we have to take into account some problems with the Danish data because not all the sampling procedures for TIMSS were followed. We do not have any trend data for Denmark at this level since they participated only for 
lower secondary in 1995. Students in Finland had a significant decrease in achievement from 1999 to 2011 . The size of this decrease is about the same as was measured for Norway and Sweden from 1995 to 2003. Students in all the three Nordic countries for which we have data achieved lower in mathematics in lower secondary school after 2000 than they did in the 1990s. Possible reasons for this will be discussed in this article.

Figure 1: Trends in students' achievement in Norway, Sweden and Finland in lower secondary school for TIMSS from 1995 to 2011. The students in Norway and Finland are of the same age, while the students in Sweden are one year older

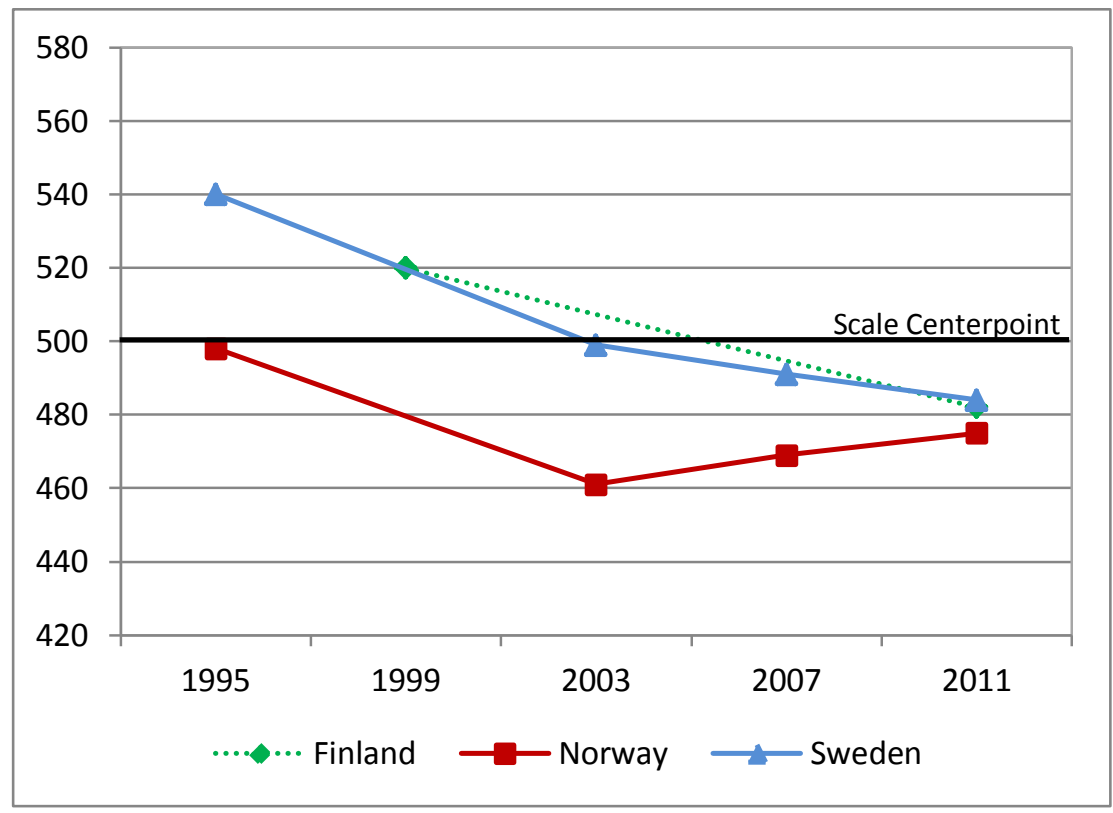

The mean achievement for Finnish students in Grade 4 in 2011 was 545 - a significantly better result than in the other Nordic countries. When reflecting on this result, we have to take into account that the Norwegian students are one year younger than those in the other Nordic countries. To be able to compare students' achievement at the same age across all the Nordic countries, Norway also tested students in Grade 5 in TIMSS 2011. The Norwegian students in Grade 5 obtained a mean achievement of 549, but the participation rate at this grade level was lower than TIMSS requires (these data are therefore not included in the international data base of TIMSS 2011). 
For this reason, we have to be careful in making conclusions based on these data. The Norwegian TIMSS report published in December 2012 concluded that this may indicate that students' achievement in mathematics in primary school for students at the same age is about the same for students in Norway, Finland and Denmark and better than for students in Sweden (Grønmo, Onstad, Nilsen, Hole, Aslaksen \& Borge, 2012).

Figure 2: Trends for grade 4 for Norway, Sweden and Denmark, the three Nordic countries for which we have these type of data. For Grade 4, we observe an increase in achievement for students both in Norway and Denmark from 2007 to 2011, while there is no change in students' achievement in Sweden. We do not have trend data for Finland since they only participated for Grade 4 in TIMSS 2011

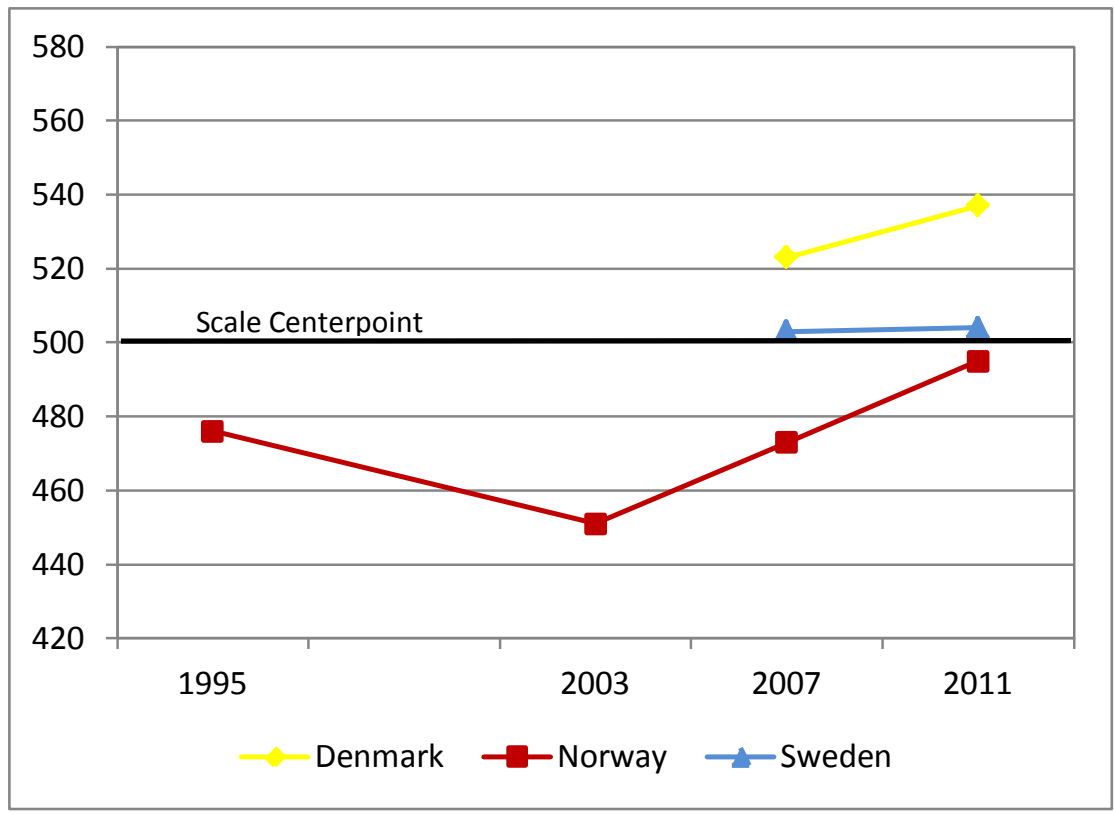

Based on this brief overview of trends and performance levels in the Nordic countries, we will concentrate on the following research questions in this article:

\section{Research questions:}

- Why has Norway had an increase in mathematics achievement level while there has been a decrease in Sweden and Finland? 
- What characterises school mathematics in the Nordic countries?

- To what degree do students in the Nordic countries have an Opportunity to Learn (OTL) mathematics?

\subsection{Mathematics Performance and School Emphasis on Academic Success (SEAS)}

Several studies of classroom and school factors affecting students' achievement in mathematics based on TIMSS data have been conducted (see e.g. Lamb \& Fullarton, 2002; Papanastasiou, 2010). Some researchers, such as Creemers \& Kyriakides (2008), have studied the influence of school leadership and school climate on students' achievement.

TIMSS data displayed a negative trend in students' performance both in Norway and Sweden from 1995 to 2003 (Grønmo, Bergem, Kjærnsli, Lie \& Turmo, 2004). In Norway, this trend moved in a positive direction in the two last TIMSS studies in 2007 and 2011 (Grønmo et al., 2012; Grønmo \& Onstad, 2013). However, this positive change has not taken place in Sweden, where the negative trend has continued. It is therefore important to investigate the factors which may have contributed to these very different developments in the two countries. As part of this investigation, an analysis of the influence of a construct labelled "læringstrykk", translated here as "School Emphasis on Academic Success" (SEAS), has been carried out (Nilsen, Grønmo \& Hole, 2013). The SEAS construct, as defined here, is related to a number of similar constructs aimed at measuring (aspects of) the emphasis on academic success and the degree of support offered by the school organisation and the school environment. Among these constructs, we find the concept of academic optimism considered in Hoy, Tarter and Hoy (2006), the concept of academic pressure (Cosmovici, Idsoe, Bru \& Munthe, 2009), the concept of academic success (McGuigan \& Hoy, 2006) and a construct called school emphasis on academic success in Martin, Mullis, Foy and Stanco (2012) (see also Nilsen \& Gustavsson, 2013). The SEAS construct is based on the seven questions presented in Textbox 1 . The construct is defined as a latent (that is, non observable) variable which can be thought of as a common underlying entity influencing the responses to the questions in Textbox 1. The analysis is based on the responses of school principals in 
Norway and Sweden, defined as a construct, and on data concerning student performance in these two countries.

\section{Textbox 1: The seven questions that measure the SEAS construct}

\section{How would you characterize each of the following within your school?}

- Teachers' understanding of the school's curricular goals

- Teachers' degree of success in implementing the school's curriculum

- Teachers' expectations for student achievement

- Parental support for student achievement

- Parental involvement in school activities

- Students' regard for school property

- Students' desire to do well in school

Principals in school were to respond to these questions on a Likert scale with five alternatives: Very high, High, Medium, Low and Very low.

The two-level analysis was carried out using Structural Equation Modelling (SEM) and Confirmatory Factor Analysis (CFA) The SEM/CFA-analyses use the Mplus software program (Muthen \& Muthen, 1998-2010). To make these analyses possible, a large amount of TIMSS data were recoded to prepare them for the analyses before data for Norway and Sweden in the last two TIMSS cycles in 2007 and 2011 were merged to investigate mediation models for the two countries. Details about the two-level SEM analysis we refer to are presented in Nilsen, Grønmo and Hole (2013).

The main findings concerning SEAS in Nilsen, Grønmo and Hole (2013) were that for Grade 8, SEAS has had a positive influence on mathematics achievement in both Norway and Sweden, and that the increase in SEAS from 2007 to 2011 in Norway can explain the observed increase in mathematics performance in Norway from 2007 to 2011, as measured by TIMSS. For Sweden, no significant change was found in SEAS from 2007 to 2011. This, of course, implies that SEAS cannot be used to explain the development in Sweden from 2007 to 2011, according to our data.

The TIMSS questionnaire results presented in figures 3, 4 and 5 illustrate the different developments in Sweden and Norway concerning SEAS. In these figures, we consider one question about students, one question about teachers and one question about parents. The figures illustrate the 
different patterns in Norway and Sweden in terms of the questions that measure the SEAS construct. In Norway, there was a positive trend in the responses to all seven questions constituting the construct and for all the actors involved. In Sweden, there were small changes - some slightly negative, some slightly positive.

Figure 3: Students' desire to do well in school in Norway and Sweden in 2007 and 2011 based on principals' answers to the related question. Data are for Grade 8

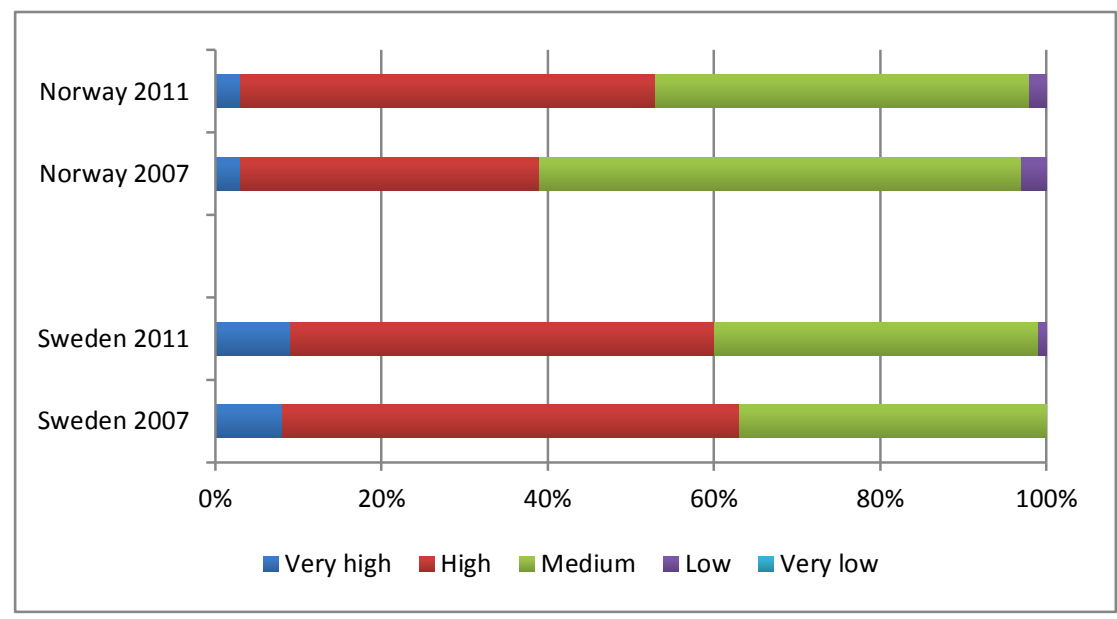

Figure 4: Teachers' degree of success in implementing the school's curriculum in Norway and Sweden in TIMSS 2003 and 2011 based on principals' answers to the related question. Data are for Grade 8

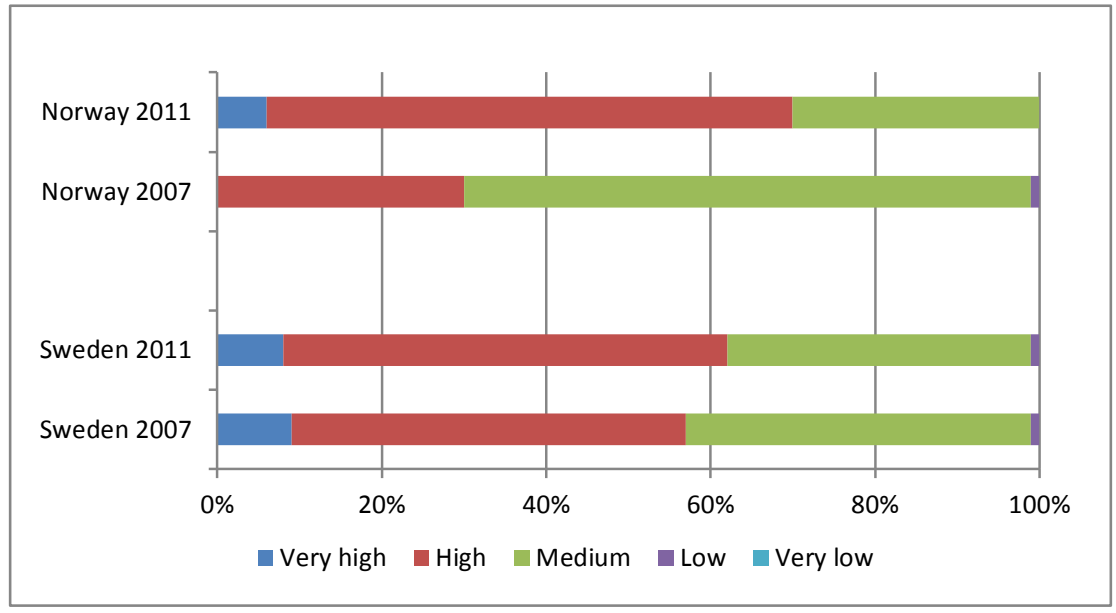


Figure 5: Parental involvement in school activities for Norway and Sweden in TIMSS 2007 and 2011 based on principals' answers to the related question.

Data are for Grade 8

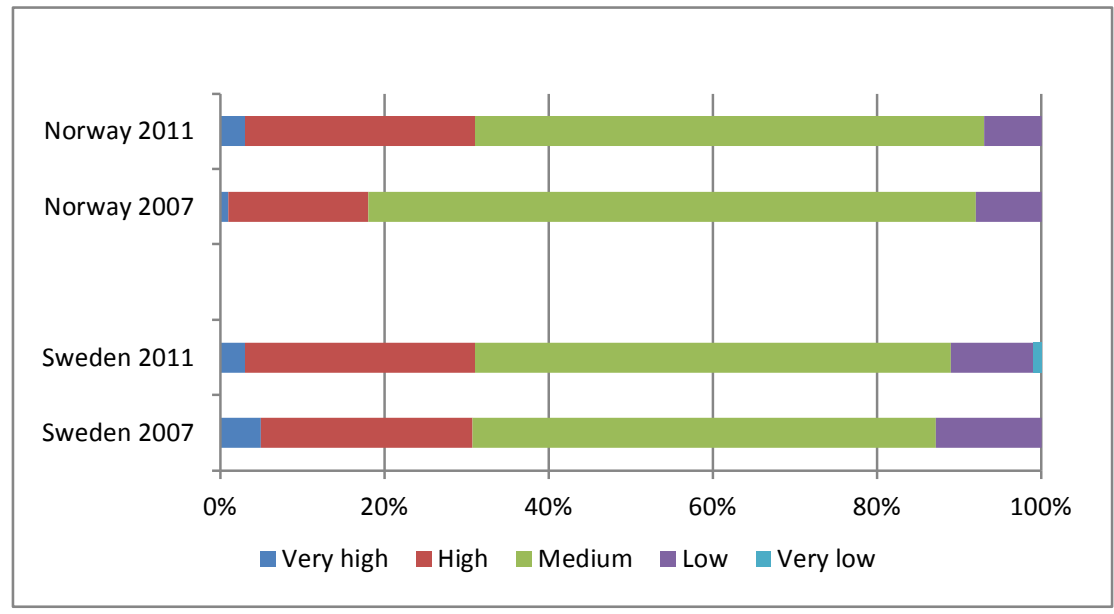

Two-level SEM analyses of this kind were also carried out for Grade 4 (Nilsen, Grønmo \& Hole, 2013). However, for Grade 4, the results were not as conclusive as they were for Grade 8. The positive trend found for Grade 8 in Norway on all questions measuring the SEAS construct was not found for Grade 4. On some questions, there was a positive trend in Norway; on other questions, the trend was negative. The same was the case for Sweden. A possible reason for the analysis not being conclusive regarding the influence of the SEAS factor for Grade 4 may be that there has not been the same collective improvement in the SEAS factor in any of these countries for Grade 4 as was found for Grade 8 in Norway. Researchers have underlined that the collective aspect of the SEAS factor (and related constructs) is important: A positive influence on student achievement is dependent on the collective behaviour of all actors in school, including teachers, students and parents (Cosmovici et al., 2009; McGuigan \& Hoy, 2006).

For Grade 8, the Norwegian TIMSS data indicate a pronounced emphasis on collective aspects in the span from 2007 to 2011; there was movement in a positive direction concerning virtually all SEAS-related questions answered by teachers, students and parents. Since this was not the case for Grade 4, neither in Norway or in Sweden, the increase in achievement for Grade 4 in Norway may be due to other factors. One factor that may have been positively influencing students' achievement for 
Grade 4 in Norway is that with the new curriculum in Norway in 2006 (LK06), the government allocated one hour of additional time to primary school mathematics. The new curriculum was called "Kunnskapsløftet" in Norwegian, which can be translated as "The Knowledge Promotion Curriculum" (Udir, 2012). This name clearly indicates that schools are to put more emphasis on students' academic success. Thus, it is reasonable to assume that the LK06 reform itself contributed significantly to the increase in SEAS observed in Norway for Grade 8 from 2007 to 2011. For Grade 4, the observed lack of increase in Norwegian SEAS indicates that other aspects of the reform, such as the above-mentioned increase in the time resource, may have been more important.

When discussing possible reasons for trends in achievement in Norway and Sweden, it is also interesting to discuss the development in students' achievement in Finland. We do not have data available to do the same in-depth analysis for Finland as we have for Norway and Sweden. Nevertheless, the case of Finland is worth reflecting upon. The high performance of Finnish students in PISA has received a lot of attention. At the same time, more than 200 mathematicians working in the Finnish education system warned in 2005 that the PISA results only tell part of the story about the actual mathematical skills of Finnish children:

\begin{abstract}
One reason for the increase of poor standards in the matriculation exam and in the beginning of university studies is, und oubtedly, the weakness of the foundation received in the comprehensive school. New, more difficult concepts are hard to learn because still in upper secondary school much energy is spent in reviewing concepts that should have been learned in the comprehensive school. This vicious circle continues in tertiary education: the high-school concepts are not properly learned, and further learning becomes more difficult. The PISA survey provides us with useful information regarding the mathematical literacy needed in everyday life and the ability to solve simple problems. These skills are simply not enough in a world which uses and utilizes mathematics more and more. (Astala et al., 2005, retrieved 24.03.2014)
\end{abstract}

Norway and Sweden participated in TIMSS Advanced in 2008 and a similar problem was revealed. A main reason pointed out for the significant decrease in performance from the mid-1990s to 2008 was that too much emphasis in compulsory school had been placed on the type of mathematics 
tested in PISA and too little on the type of mathematics students need in further education and professions. While the main focus in PISA is the mathematical competences one needs in order to function as a citizen in daily life, TIMSS, and especially TIMSS Advanced, is more directed towards mathematics as an ingredient in a professional education. This difference between TIMSS and PISA underscores the complementary aspect of these studies and the need for more of the Nordic countries to participate more regularly in TIMSS at different levels, including TIMSS Advanced in upper secondary school. This is important to obtain adequate information about how to improve the educational system in a country. Mathematics is a hierarchical subject; what students learn at lower levels in school will influence what students are prepared to and can learn at higher levels in school.

It is important to remember that School Emphasis on Academic Success (SEAS) is quite a general factor and that it says little about the content taught or the methods used in school. Also, there are several ways of interpreting what it actually means to say that schools put more effort into emphasizing the academic success of students (Grønmo, Borge \& Onstad, 2013). The questions used in the SEAS definition indicate that teachers emphasizing students' academic success tend to have a better understanding of the curriculum goals and that they tend to be more successful in implementing the curriculum goals in their teaching. Parents emphasizing the academic success of their children also can reasonably be assumed to give good support to their children's schoolwork as well as to the school in general. In particular, it is reasonable to assume that such parents will encourage their children to work hard at learning mathematics. It is interesting to link this to the mathematical content students are expected to learn in school and to discuss the role of teachers, students and parents in that context. In the next sections, we deal with analyses based on TIMSS data regarding the mathematical content students are supposed to learn in school and the students' actual opportunity to learn it. 


\subsection{What Characterises Mathematics Performance in the Nordic countries?}

As background for discussing what characterises mathematics in the Nordic countries, we present data showing students' performance in different domains in mathematics (numbers, algebra, geometry and statistics) for Grade 8 in TIMSS 2011. On the left side of Figure 6, we display the results for Norway, Sweden and Finland. On the right side of the figure 6, we display the results for Norway compared with other countries. Each country represents a different profile in mathematics education, based on earlier cluster analysis results of the so-called "item-by-country interactions" aimed at investigating similarities and differences between countries or groups of countries across cognitive items based on data from TIMSS and PISA studies. (For more about cluster analyses, see Olsen, 2006 and Grønmo, 2010). It has to be recognised that these analyses are based on relative performance. This cluster analysis displays groupings of countries according to similarities in relative response patterns across items. Countries placed in the same group tend to have relative strengths and weaknesses in the same items. In the discussion of the grouping of countries, the focus is on groups that are meaningful from a geographical, cultural or political point of view. These analyses revealed four different profiles that were stable over time and in different studies a Nordic profile, an English speaking profile, an Eastern European profile and an Eastern Asian profile. Typical for students in the Nordic countries was that they performed relatively low on items in pure mathematics, such as algebra, and better on items in applied mathematics that had a daily life context (Grønmo, 2010; Olsen \& Grønmo, 2006). In Figure 6, we see that the most pronounced characteristic regarding students' performance in mathematics in the Nordic countries compared to other countries in TIMSS 2011 is that students in all the Nordic countries perform low in algebra, a result consistent with results in earlier cluster analysis. Norwegian and Finnish students perform lowest in algebra, while Swedish students perform about equally low in both algebra and geometry.

The earlier cluster analyses based on data from TIMSS and PISA displayed consistent results for students at Grade 8 in TIMSS and grade 8 in PISA, despite the fact that these studies have different frameworks for describing the mathematical performance they measure. For more about 
the different frameworks in TIMSS and PISA, see Olsen \& Grønmo (2006) and Grønmo (2010). In addition, analyses of data from TIMSS Advanced in upper secondary school (Grønmo \& Pedersen, to be published) and data from TEDS-M regarding teachers' education (Blömecke, 2012) support the conclusions that the Nordic profile in mathematics education is characterised by little emphasis on pure mathematics such as algebra. This gives solid support for the conclusions about what characterises the Nordic profile in mathematics.

Figure 6: Left: Students' performance in different domains in mathematics (numbers, algebra, geometry and statistics) for grade 8 in TIMSS 2011 for Norway, Sweden and Finland in lower secondary school. Right: A comparison of countries representing different profiles in mathematics education
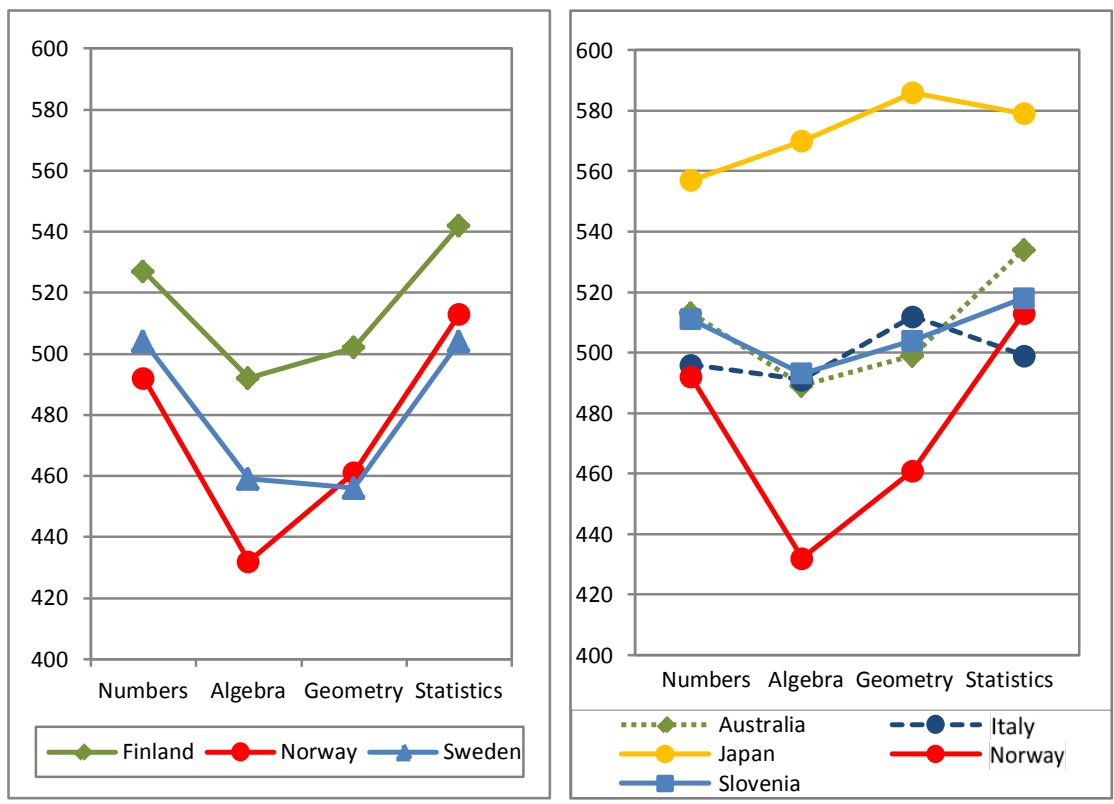

Olsen and Grønmo (2006) also looked for characteristics of the Nordic profile by contrasting it with profiles for other groups of countries based on data from PISA 2003. They developed a specific classification system for their analysis in which the items in PISA were re-classified according to how close they were to "real-world" or "daily-life" mathematics. The profile for the Nordic countries was strongly characterised by relatively high performance on items involving some sort of real-world mathemat- 
ics, and the same was true for the English-speaking countries. The East Asian and East European countries, however, achieved relatively lower on items categorised as kind of real-world mathematics. This result, consistent with Grønmo et al.'s (2004) findings, made it reasonable to conclude that real-world mathematics has been a driving force in school mathematics in the Nordic and English-speaking countries, in contrast to countries in Eastern Europe and East Asia. Different aspects of school curricula are discussed later in this article, with special attention given to students' opportunity to learn mathematics.

Figure 7 shows students' performance for Grade 4 in different domains in mathematics for all the four Nordic countries that participated in TIMSS 2011. In Grade 4, there is a tendency that students in the Nordic countries do not perform very well in numbers, but this is not at all pronounced in the same way as it is with algebra for Grade 8. As shown in Figure 7, Norwegian and Danish students perform best in geometry, while this is not the case for Swedish and Finnish students.

Figure 7: Left: Students' performance in different domains in mathematics (numbers, geometry and statistics) for grade 4 in TIMSS 2011 for Norway, Sweden, Denmark and Finland in primary school. Right: A comparison of countries representing different profiles in mathematics education
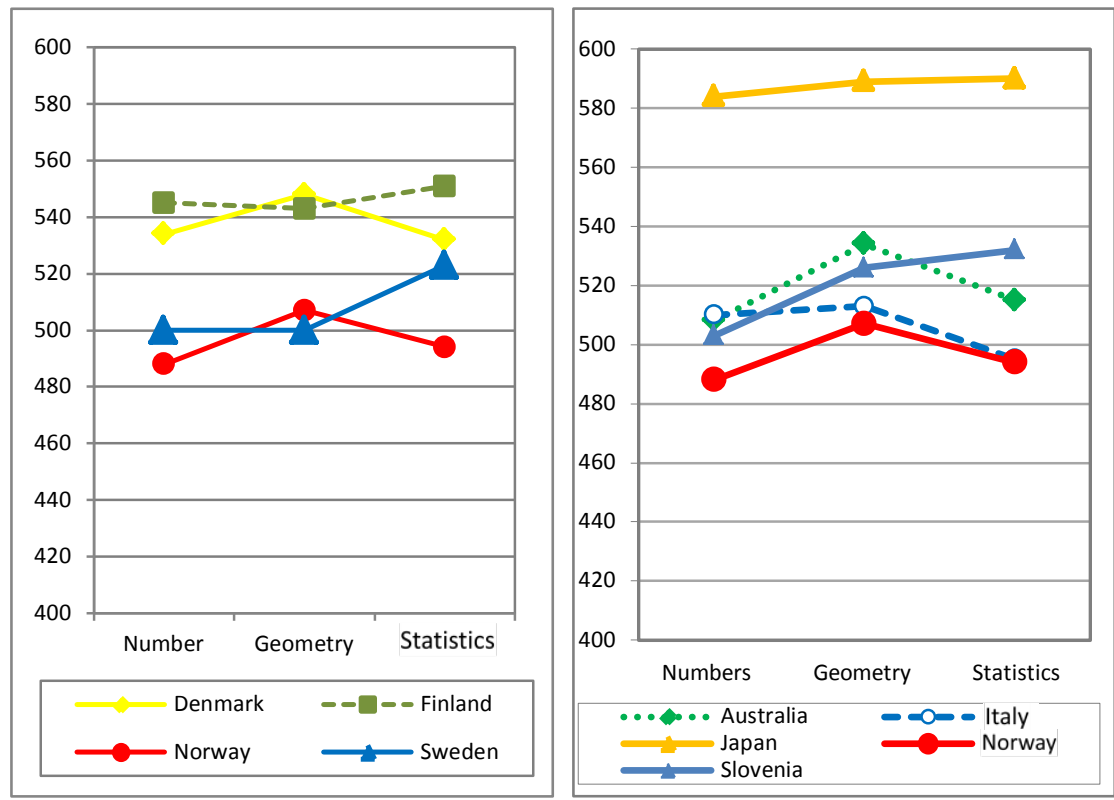
The most pronounced and common problem in the Nordic countries seems to be students' low achievement in algebra. However, as earlier research has pointed out, students' learning of algebra is depending on whether they have a good basis in the mathematical domain of numbers (Brekke, Grønmo \& Rosèn, 2000). From this point of view, the results for grade 4 students are also important when discussing the Nordic profile in mathematics. We also have to take into account that a critical factor for improving students' competence in algebra is teachers' competence in mathematics, and the international comparative study TEDS-M showed that Norwegian teacher students in all types of teacher education performed low in algebra compared with teacher students in other countries (Grønmo \& Onstad, 2012). So even if there is more focus on algebra in the Norwegian curriculum after a revision in 2013, this is still an issue that needs to be addressed.

\subsection{Students' Opportunity to Learn (OTL) Mathematics}

The use of the concept Opportunity to Learn (OTL) varies. Some use it to cover a broad range of factors influencing the learning process, whereas others use it to study a few well defined factors that earlier research has shown are central to students' opportunity to learn (Carroll, 1963; McDonnell, 1995; Stevens, 1996). An important aspect of OTL is what content knowledge students have been taught. We may say that the more intensively students have been taught a particular domain in mathematics (or a subdomain), the higher the OTL factor is for that content knowledge. A high or low OTL factor is related to school curriculum, both the intended curriculum (the written curriculum) and the implemented curriculum (to what extent the written curriculum has been implemented in the school). Both these aspects of the curriculum will be analysed and discussed in this article. In a number of international studies, OTL is often defined as consisting of two components: allocated learning time and content covered (Carroll, 1963; Husén, 1967). Both these aspect of OTL are essential in our presentation and discussions of results. 
Figures 8 and 9 present the teachers' report on time allocated - how much instructional time they have spent on the various content domains including "other topics", as percentage of the total instructional time in mathematics in Grades 8 and 4, respectively. The total instructional time in mathematics for Grade 8, as reported in TIMSS 2011, is as follows for the Nordic countries (in hours per year): Norway: 125, Sweden: 97 andFinland: 105 . The international mean is 138 . For grade 4 , the numbers are: Norway: 157, Sweden: 138, Finland: 139 and Denmark: 124. The international mean is 162 . We see that the Nordic countries are below the international mean for both Grades 8 and 4 when it comes to instructional time in mathematics, with Norway being closest to the international mean.

Figure 8: The teachers' report for the Nordic countries and the international mean on regarding how much instructional time they have spent on the various content domains in mathematics. The data are from TIMSS 2011, Grade 8

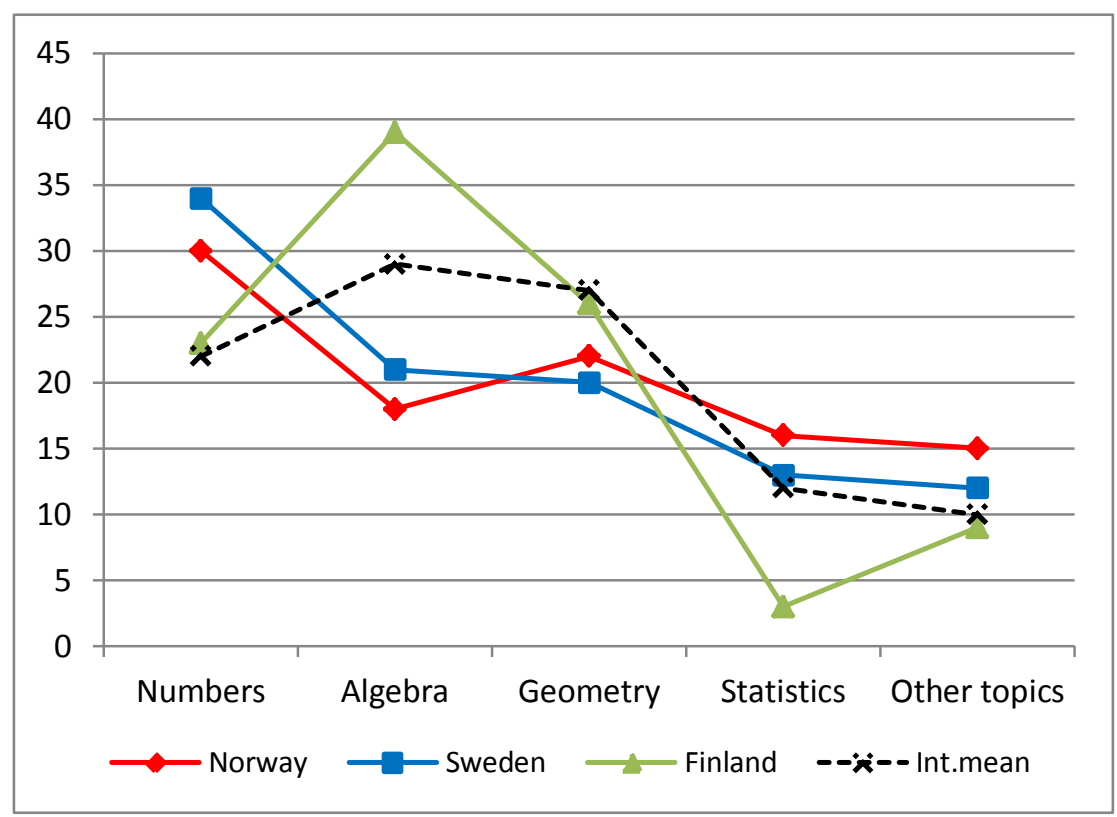


Figure 9: The teachers' report for the Nordic countries and the international mean regarding how much instructional time they have spent on the various content domains in mathematics. The data are from TIMSS 2011, Grade 4

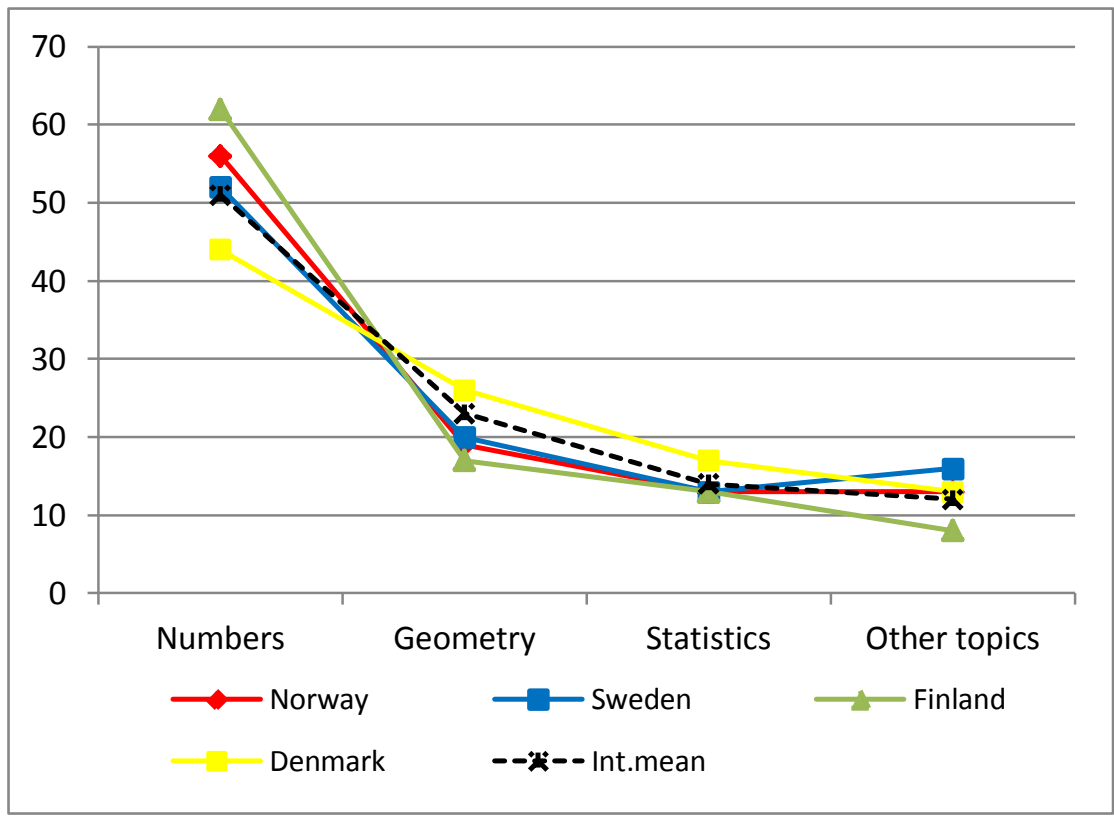

For Grade 4, there is general agreement when it comes to time allocated; there is small difference between all the Nordic countries and the international mean in all domains. The greatest difference is found for numbers, where Finland and Denmark spend more time than the international mean. For Grade 8 in Norway and Sweden, the teachers report less time spent on algebra and geometry and more time spent on numbers than the international mean, whereas Finland reports more time spent on algebra and less time spent on statistics than the international mean. This indicates disagreement about content to be taught at in school.

If we compare Figure 8 with Figure 6 (students' performance in Grade 8), we see that Norway and Sweden show consistency in numbers, algebra, and geometry. Finnish students are given more instructional time in algebra, and they also perform better than Norwegian and Swedish students in algebra but, nevertheless, Finnish students perform below the international mean in algebra. In Grade 8, a lot of the time in Norway and Sweden is used to give students instruction in numbers, while less time is allocated to giving them 
instruction in algebra. It is important that students are learning a lot in numbers, but it would probably be a better use of time if more of this content knowledge were implemented earlier in school. Finland gives, for example, more instruction in numbers than Norway and Sweden in Grade 4, and less in Grade 8. Emphasizing numbers earlier may leave more time for instruction in algebra at higher school levels in Norway and Sweden.

We now consider content covered. Figures 10 and 11 present the teachers' reports on the TIMSS' mathematics content domains, presented as percentages of the total number of topics in each domain for Grades 8 and 4, respectively. For Grade 8, all three countries report that they have covered all domains in numbers, and that they have covered fewer domains than the international mean in algebra. In geometry, Finland has a higher coverage than Norway and Sweden, while the opposite is true in statistics. For grade 4, about $90 \%$ of numbers is covered in Finland, while the percentage is only about 60 in Norway and Sweden. This result also contributes to the discussion about what type of content should be emphasised at different levels in school. It seems that both in Norway and in Sweden, there is little emphasis on numbers at the lower levels and more at the higher levels compared to other countries.

Figure 10: The teachers' reports in the Nordic countries and the international mean in TIMSS 2011 on the TIMSS' mathematics content domains, presented as percentages of the total number of topics in each domain for Grade 8

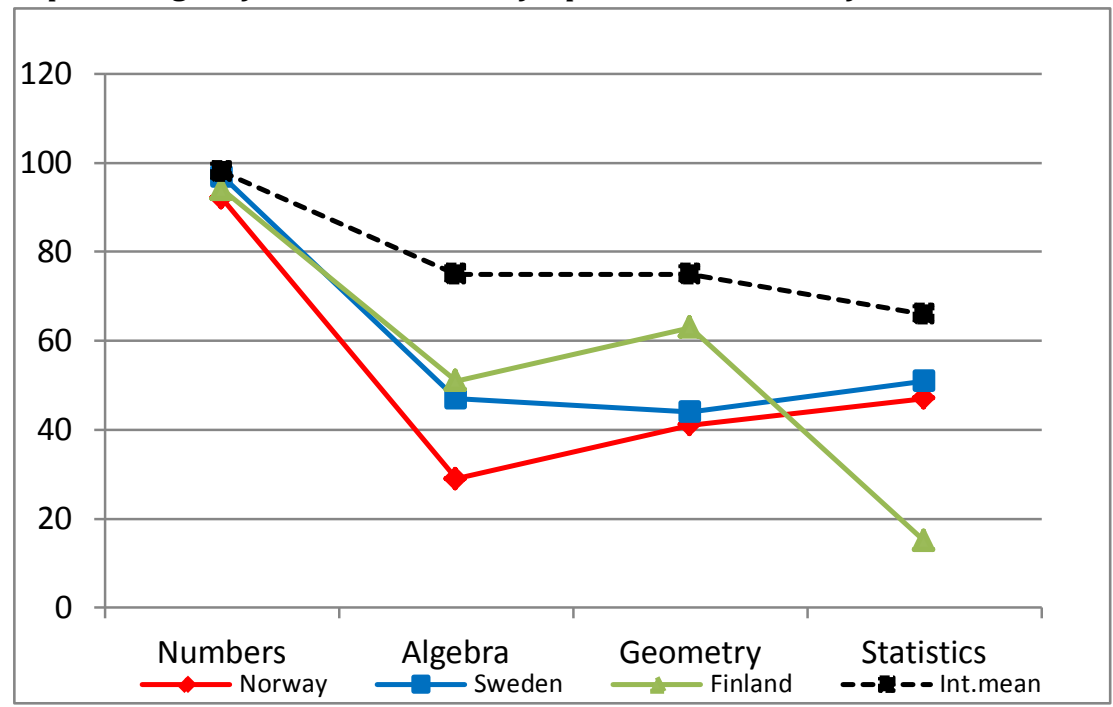


Figure 11: The teachers' reports in the Nordic countries and the international mean in TIMSS 2011 on the TIMSS' mathematics content domains, presented as percentages of the total number of topics in each domain for Grade 4

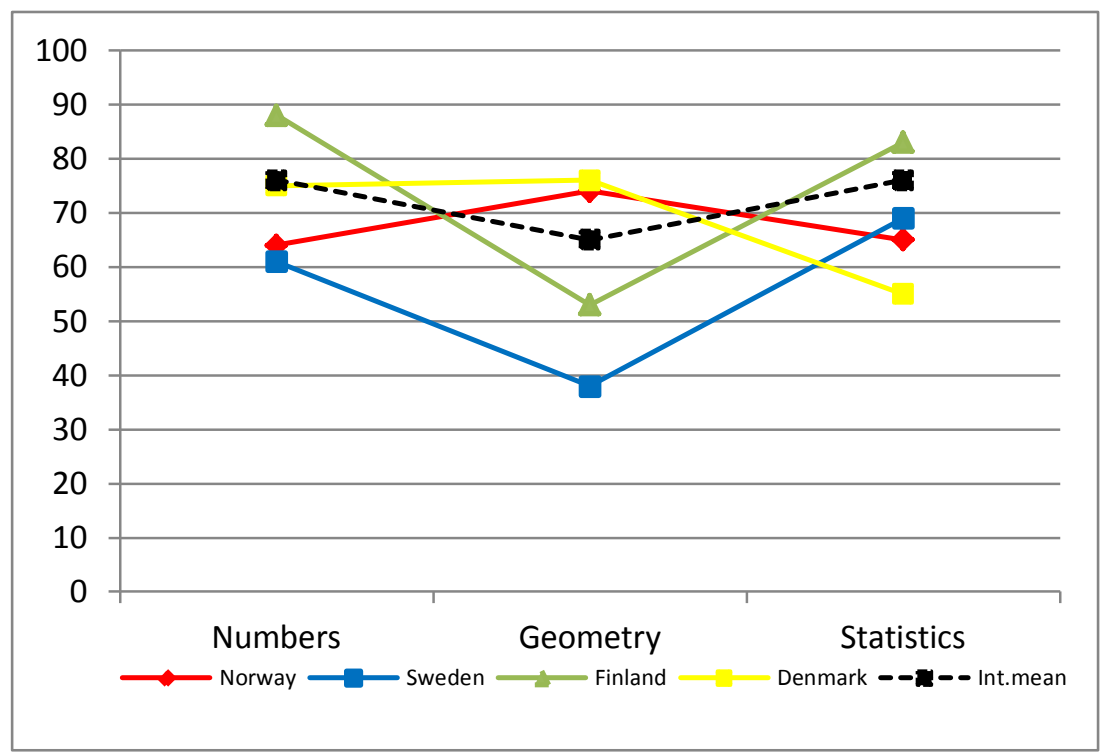

The fact that Norwegian, Swedish and Finnish students' achievement in Grade 8 is low in algebra compared to other countries is consistent with the teachers' answers about how many subdomains they have implemented in their teaching (implemented curriculum). This result is also consistent with earlier analyses of what characterises the Nordic profile in mathematics (Grønmo, 2010, Olsen \& Grønmo, 2006). The National Research Coordinators (NRC) reported on similar questions regarding content covered in the various content domains based on each country's official curriculum (intended curriculum). Figures 12, 13 and 14 present the NRCs' reports for Grade 8 compared to the teachers' reports in Figure 10 for Norway, Sweden and Finland, respectively. 
Figure 12: Comparing teachers' (implemented curriculum) and NRCs' (intended curriculum) reports in TIMSS 2011 on the mathematics content domains, presented as percentages of the total number of topics in each domain in Norway for Grade 8

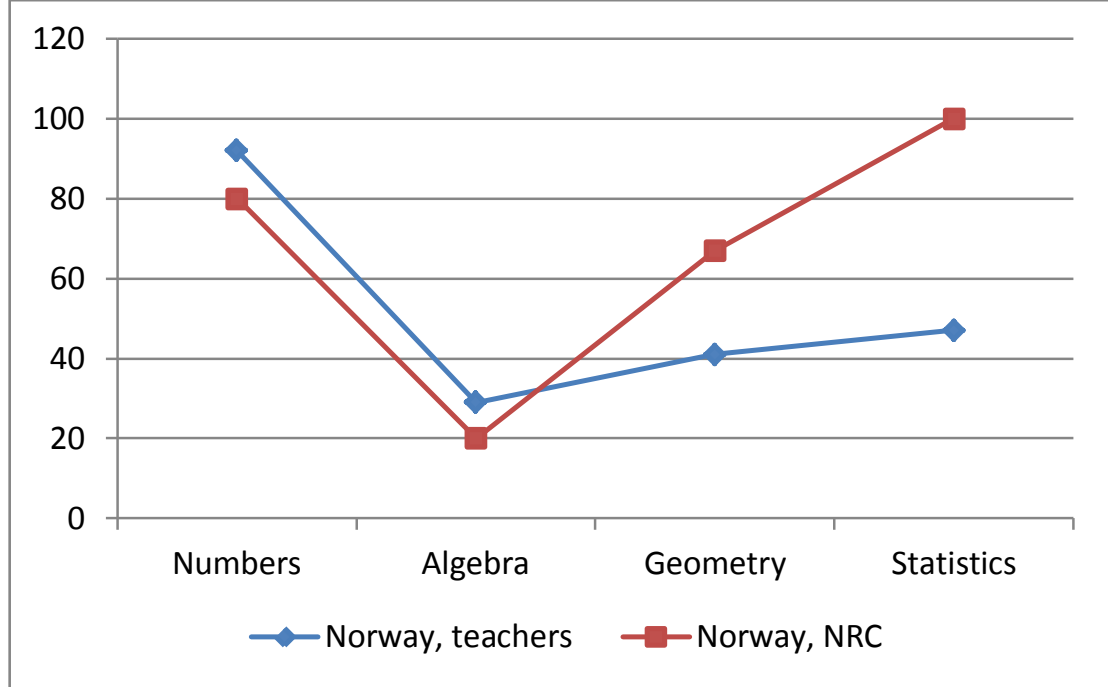

Figure 13: Comparing teachers' (implemented curriculum) and NRCs' (intended curriculum) reports in TIMSS 2011 on the mathematics content domains, presented as percentages of the total number of topics in each domain in Sweden for Grade 8

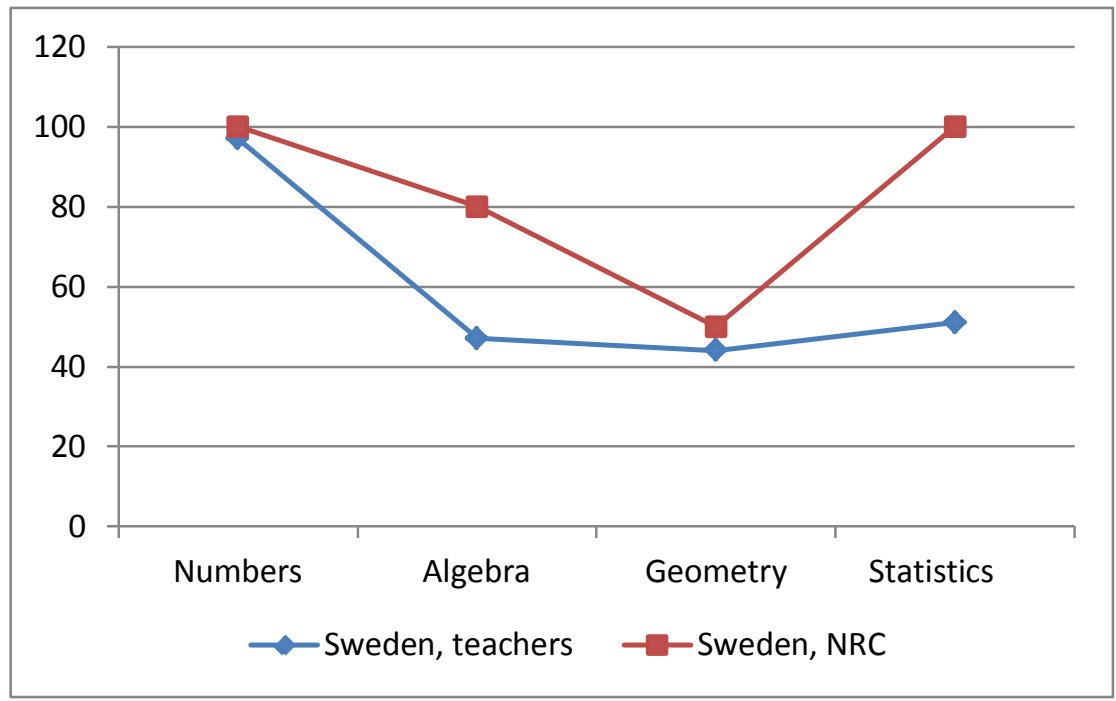


Figure 14: Comparing teachers' (implemented curriculum) and NRCs' (intended curriculum) reports in TIMSS 2011 on the mathematics content domains, presented as percentages of the total number of topics in each domain in Finland for Grade 8

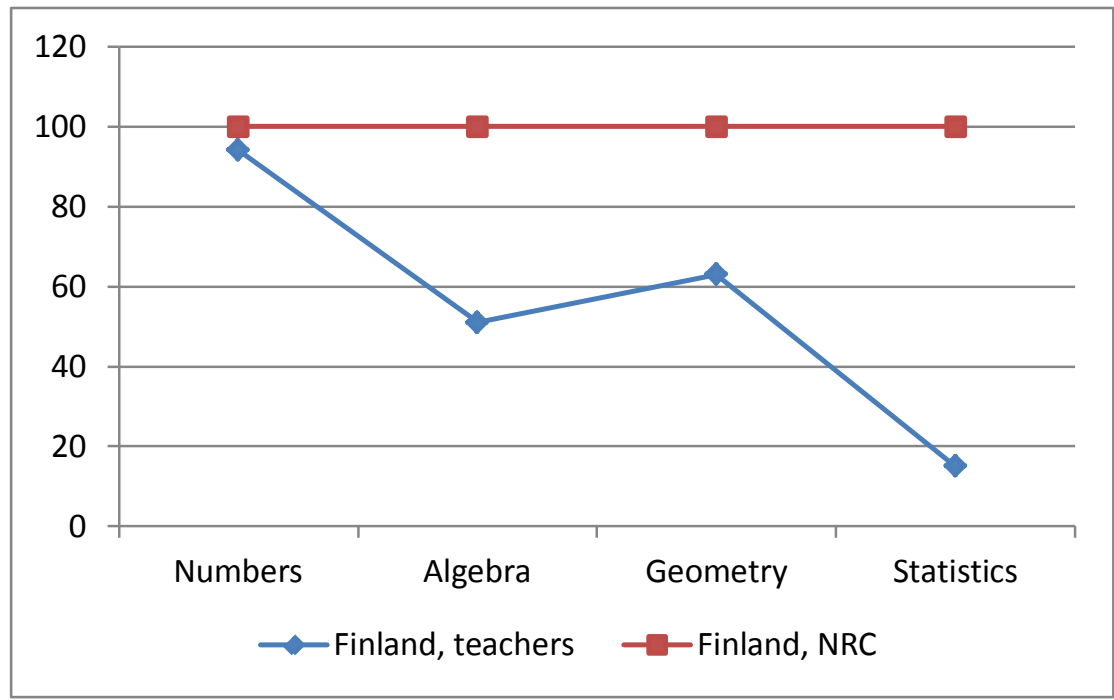

Figure 15: Comparing the international means for teachers' (implemented curriculum) and NRCs' (intended curriculum) reports in TIMSS 2011 on the mathematics content domains, presented as percentages of the total number of topics in each domain for Grade 8

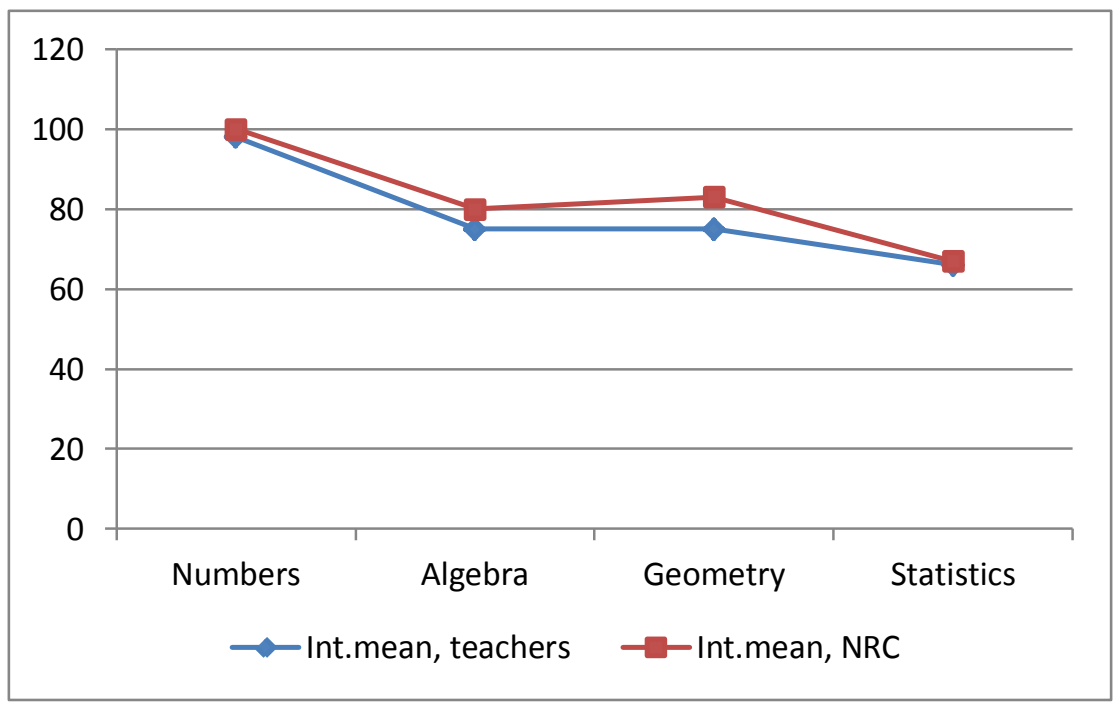


We see that Norway, Sweden and Finland show much inconsistency between intended and implemented curriculum (figures 12, 13 and 14) compared to the international mean (Figure 15). There are several possible explanations for this inconsistency. One possible explanation is that neither Norwegian, Swedish or Finnish curricula specify core objectives of mathematics instruction for each school year after Grade 8. In Norway, goals are specified only collectively for Grades 8-10. Similarly, goals are specified collectively for Grades 6-9 in Sweden and for Grades 6-9 in Finland (TIMSS, 2012). In what way the curriculum goals given for the three or four year period are actually distributed in each grade level will depend on a number of factors. We will discuss this more in the last section of this article. This issue was also discussed in a book published in 2013, where more details from a number of analyses of OTL and performances focusing on Norway and Sweden were given (Grønmo, Borge \& Rosèn, 2013).

\subsection{Summary and Conclusions - Discussions on How to Improve Students' Achievement in Mathematics in the Nordic Countries}

We have presented the results of research examining issues such as School Emphasis on Academic Success (SEAS), Characteristics of Mathematics Education in the Nordic countries and Students' Opportunity to Learn (OTL) mathematics; the two latter issues focus on the mathematical content domains of numbers, algebra, geometry and statistics. We will now discuss the results regarding these three critical issues, with a main focus on the relations between them.

School Emphasis on Academic Success (SEAS) turned out to be an important factor in understanding students' mathematics performance in Norway and Sweden in Grade 8. The analyses showed that this factor has a positive influence on mathematics achievement in both Norway and Sweden, and that the Norwegian increase in SEAS from 2007 to 2011 explained the observed increase in mathematics performance in Grade 8 during this period. However, this does not imply that this is the one and only plausible explanation for the increase in mathematics performance. The positive changes in the SEAS factor in Norway are likely to reflect 
changes in educational policy and curriculum in Norway, such as a new curriculum with an increased emphasis on students' performance in 2006 (LK06). This new educational policy with more emphasis on academic success was enacted partly due to the attention and discussion resulting from the negative results in large-scale surveys such as the TIMSS and PISA results presented in 2004.

It should be added that SEAS is a general factor which tells little about important factors such as the content taught and the teaching methods used in school. The questions used in the definition of the SEAS construct include questions about the teachers' understanding of curriculum goals and about the degree of success teachers have in implementing these goals in their own teaching. A critical question related to this is: What mathematical content and goals do teachers emphasise when teaching mathematics in the Nordic countries?

Analyses based on data from a number of earlier international comparative studies (TIMSS, PISA, TIMSS Advanced and TEDS-M) have all indicated that mathematics in the Nordic countries is characterised by little emphasis on pure mathematics such as algebra - a conclusion highly consistent with students' performance in the last TIMSS and PISA studies. Providing a generalisation of numerical, geometric and other patterns, algebra is the language of modern mathematics and is essential for all further study programs leading to professions using advanced mathematics. The low emphasis on algebra in the Nordic countries in Grade 8 is likely to influence students' possibility for pursuing such studies or professions - a conclusion supported by analyses of data from TIMSS Advanced in both mathematics (Grønmo, Onstad \& Pedersen, 2010) and physics (Lie, Angell \& Rohatgi, 2010). A high dropout rate from Nordic engineering programs has also been explained by students' lack of elementary algebra when entering the study programs (NOKUT, 2008). The next issue of concern is therefore: Why is there so little emphasis on algebra in the Nordic countries?

We have presented results of analyses of students' Opportunity to Learn mathematics in the Nordic countries in Grade 8 related to both the intended and the implemented curriculum. These analyses showed that the implemented curriculum (what teachers actually implemented in their own teaching) in all the Nordic countries participating in TIMSS 2011 was 
on a significantly lower level than the international mean in algebra. Norway, Sweden and Finland all have an intended curriculum where educational aims are explicitly given for only three to four year periods, not for each single year. This organisation is based on the assumption that it will promote students' learning if teachers in schools (or communities) discuss and negotiate to make local plans for each year. According to data from TIMSS 2011, textbooks were used as a basis for instruction in mathematics more in Norway and Sweden than was the international mean for this factor. This indicates that it is the publishers of textbooks for schools who, to a great extent, decide what should be the objectives for mathematics each year in school, not local cooperation among teachers. Taken together with the fact that there may be no system for evaluating or selecting textbooks for schools, this forms a critical issue that must be addressed. Our research does not explain how to solve this problem, but it gives convincing evidence that the issue has to be taken seriously. The problem is likely to be a significant factor influencing the low performance of students in algebra, with serious consequences for students' possibility to pursue further education and professions using mathematics.

Earlier analyses of data from TIMSS and PISA have concluded that applied mathematics, which some have referred to as "real-world mathematics", has been a driving force in school mathematics in the Nordic and English-speaking countries, in contrast to the situation in countries in Eastern Europe and East Asia (Olsen \& Grønmo, 2006; Grønmo \& Olsen, 2006). A critical issue here is how the content of "real-world mathematics" is defined, as well as how we perceive the relationship between pure and applied mathematics. Real-world mathematics may be interpreted as mathematical content knowledge all students in school need to learn in compulsory school to be able to use mathematics to solve daily life problems. In daily life, a good basis in numbers is likely to be what all students need the most. However, a significant percentage of students will need a good basis in algebra to pursue their educational goals. The needs of these students do not seem to have been taken seriously enough in compulsory school in the Nordic countries. The low emphasis on algebra illustrates this. Even in Norway, with a positive trend for Grade 8 after 2003, there is a lower percentage of students at the highest competence levels in mathematics in 2011 than there was in 1995. To give talented students in 
mathematics the basis they need for further education and professions, we conclude that more emphasis must be placed on the learning of algebra in Nordic schools (Grønmo, 2014).

The ability to apply mathematics to solve problems in the real world in daily life as well as in further education and professions depends on students' competence in pure mathematics. The wording itself makes this a reasonable interpretation of the relation between pure and applied mathematics. Students' competence in pure mathematics is the basis for all types of applied mathematics, a fact illustrated in the mathematical cycle of applied mathematics defined in the US Standards from 1989 as well as in the PISA framework. Nevertheless, in English-speaking and Nordic countries, this has, to some extent, been misunderstood in the way that applied mathematics has been seen as an alternative to pure mathematics (Gardiner, 2004).

We know that a lot of teachers in lower secondary school in Norway themselves have low competence in algebra (Grønmo \& Onstad, 2012). It is reasonable to assume that the situation in Sweden is similar. This may be another factor negatively influencing students' performance. It may contribute to teachers "pushing" algebra to the end of upper secondary school - an opportunity they have since there is no national curriculum objectives for mathematics specified for each individual year. This is an understandable choice based on the fact that teachers themselves do not have a solid basis in this mathematical domain. Both Norway and Sweden are currently starting a process aimed at giving teachers in school further education in mathematics and mathematics teaching. A critical issue to be discussed here is the content in this type of further education as well as who shall give it and how it shall be organised.

The positive influence of the SEAS factor on students' performance found for Grade 8 in Norway was not found for Grade 4. One reason for this may be that there has not been the same collective emphasis on the SEAS factor in Grade 4 as in Grade 8. There might be other reasons for the increase in Norwegian students' performance in Grade 4 - for example, the extra time resource in mathematics given to primary schools after 2006. When it comes to emphasis on mathematical content, Grade 4 teachers in both Norway and Sweden report that they have exposed their students to fewer topics in numbers than the international mean for 
teachers in all participating countries. In Grade 8, however, teachers report that they spend more time on numbers than the international mean. Numbers and algebra are likely to be the two mathematical domains where it is most important for students to have a solid basis. This may indicate that to improve students' competence in mathematics, it might be a good idea to put more emphasis on numbers in primary school as a basis for applying mathematics to daily life problems as well as a necessary basis for further learning in algebra. This may also allow more time in lower secondary school (or at higher levels) for algebra. We do not claim that we have unambiguous proof for this, but as before, we point to some issues that need to be addressed.

In 2015, TIMSS for both primary school and the beginning of lower secondary school, TIMSS Advanced for mathematics last year of upper secondary school (http://timss.bc.edu/), and PISA for the last year of lower secondary school (www.oecd.org/pisa/home/) will all be conducted. This gives countries all over the world a unique opportunity to get a picture of mathematics (and science) education throughout their school systems. Norway and Sweden will both participate in all these studies, but this is not the case for the other Nordic countries. Participation on a regular basis from all the Nordic countries in international comparative studies in mathematics at different levels in school is likely to significantly improve our possibility for further research into factors that positively influence students' performance in mathematics and would prove a good investment in educational improvement. Taking this article as an example, most of the analyses presented are based on data for Grade 8 in Norway and Sweden, simply because we have the most data available for this grade level and for these two Nordic countries. Limitations in data availability for Finland and Denmark significantly limited the possibility to conduct a number of analyses and comparisons with these two Nordic countries.

Norway's regular participation in TIMSS has provided a lot of information about the educational system, information that has received much attention in the media and among politicians - first to the negative results and then to the positive changes in the last studies. If the increased emphasis on academic success in Norway, at least partly, was caused by the attention and discussion arising from the negative results in large-scale surveys, one may ask whether other countries could benefit from having more sub- 
stantial public discussions of results from studies such as TIMSS and PISA. In the Nordic perspective, this point may seem especially relevant for Sweden and Finland, which have both measured a significant decrease in students' mathematical performance in TIMSS 2011 as well as in PISA 2012.

\subsection{References}

Astala, K., Kivelä, S. K., Koskela, P., Martio, O., Näätänen, M., \& Tarvainen, K. (2005). The PISA survey tells only a partial truth of Finnish children's mathematical skills. http://solmu.math.helsinki.fi/2005/erik/PisaEng.html

Beaton, A. E., Mullis, I. V. S., Martin, M. O., Gonzales, E. J., Kelly, D. L., \& Smith, T. A. (1996). Mathematics achievement in the middle school years: IEA's Third International Mathematics and Science Study (TIMSS): TIMSS International Study Center, Boston College.

Blömeke, S. (2012). Assessing strengths and weaknesses of teacher knowledge in Asia, Eastern Europe and Western countries: Differential item functioning in TEDSM. Paper presented at the Improving Skills Conference, Limassol, Cyprus. http:// ec.europa.eu/education/lifelong-learning-policy/doc/skills/blomeke_en.pdf

Brekke, G., Grønmo, L. S., \& Rosén, B. (2000). KIM (Kvalitet i matematikkundervisningen): Veiledning til algebra. Oslo: Nasjonalt læremiddelsenter.

Carroll, J. B. (1963). A Model of School Learning. Teachers College Record, 64(8), 723-733.

Cosmovici, E. M., Idsoe, T., Bru, E., \& Munthe, E. (2009). Perceptions of Learning Environment and On-Task Orientation Among Students Reporting Different Achievement Levels: A Study Conducted Among Norwegian Secondary School Students. Scandinavian Journal of Educational Research, 53(4), 379-396.

Creemers, B., \& Kyriakides, L. (2008). The dynamics of educational effectiveness: a contribution to policy, practice and theory in contemporary schools. . Abingdon: Routledge. .

Gardiner, A. (2004). What is Mathematical Literacy? Paper presented at the ICME10, Copenhagen, Danmark.

Grønmo, L. S. (2010). Low Achievement in Mathematics in Compulsory School as Evidenced by TIMSS and PISA. In B. Sriraman, C. Bergsten, S. Goodchild, G. Pálsdóttir, B. Dahl \& L. Haapasalo (Eds.), The First Sourcebook on Nordic Research in Mathematics Education (pp. 49-69). Charlotte, NC: Information Age Publishing.

Grønmo, L.S., 2014. Svikter skolen de flinke elevene? In Grønmo, L.S; Jahr, E.; Skogen, K.; Wistedt, I. Matematikktalenter i skolen - hva me dem? (pp. 9- 35). Oslo: Cappelen Damm Akademiske. 
Grønmo, L. S., Bergem, O. K., Kjærnsli, M., Lie, S., \& Turmo, A. (2004). Hva i all verden har skjedd i realfagene? Norske elevers prestasjoner i matematikk og naturfag i TIMSS 2003. Oslo: Institutt for lærerutdanning og skoleutvikling, Universitetet i Oslo.

Grønmo, L. S., Borge, I. C., \& Onstad, T. (2013). Hvor står vi - hvor går vi? In L. S. Grønmo \& T. Onstad (Eds.), Opptur og nedtur. Analyser av TIMSS-data for Norge og Sverige (pp. 163-169). Oslo: Akademika forlag.

Grønmo, L. S., Borge, I. C., \& Rosén, M. (2013). Læringsmuligheter og prestasjoner i matematikk på 8.trinn. . In L. S. Grønmo \& T. Onstad (Eds.), Opptur og nedtur. Analyser av TIMSS-data for Norge og Sverige (pp. 73-96). Oslo: Akademika forlag

Grønmo, L. S., Kjærnsli, M., \& Lie, S. (2004). Looking for Cultural and Geographical Factors in Patterns of Responses to TIMSS Items. Paper presented at the 1st IEA International Research Conference, Lefkosia.

Grønmo, L. S., \& Olsen, R. V. (2006a). Matematikkprestasjoner i TIMSS og PISA: ren og anvendt matematikk. In B. Brock-Utne \& L. Bøyesen (Eds.), Å greie seg i utdanningssystemet i nord og sør (pp. 160-173). Bergen: Fagbokforlaget.

Grønmo, L. S., \& Olsen, R. V. (2006b). TIMSS VERSUS PISA: The Case of Pure and Applied Mathematics. Paper presented at the 2nd IEA International Research Conference, Washington D.C. http://www.timss.no/publications/IRC2006_ Gronmo\%260lsen.pdf

Grønmo, L. S., Onstad, T., Nilsen, T., Hole, A., Aslaksen, H., \& Borge, I. C. (2012). Framgang, men langt fram. Norske elevers prestasjoner i matematikk og naturfag i TIMSS 2011. Oslo: Akademika forlag.

Grønmo, L. S., \& Onstad, T. (2012). Mange og store utfordringer. Et nasjonalt og internasjonalt perspektiv på utdanning av lærere i matematikk basert på data fra TEDS-M 2008. Oslo: Unipub.

Grønmo, L. S., \& Onstad, T. (2013). Opptur og nedtur. Analyser av TIMSS-data for Norge og Sverige. Oslo: Akademika forlag.

Grønmo, L. S., \& Pedersen, I. (Til publisering). Do analyses of TIMSS Advanced data confirm that countries have a similar cultural profile in mathematics at all levels in school?

Grønmo, L. S., Onstad, T., \& Pedersen, I. F. (2010). Matematikk i motvind. TIMSS Advanced 2008 i videregående skole. Oslo: Unipub.

Hoy, W. K., Tarter, C. J., \& Hoy, A. W. (2006). Academic optimism of schools: A force for student achievement. American Educational Research Journal, 43(3), 425-446.

Husén, T. (1967). International Study of Achievement in Mathematics: a Comparison of Twelve Countries. New York, NY: Wiley \& sons.

Kjærnsli, M., \& Olsen, R. V. (2013). Fortsatt en vei å gå. Norske elevers kompetanse i matematikk, naturfag og lesing i PISA 2012 Universitetsforlaget

Lamb, S., \& Fullarton, S. (2001). Classroom and School Factors Affecting Mathematics Achievement: A Comparative Study of the US and Australia Using TIMSS TIMSS Australia Monograph Series (Vol. 4): Australian Council for Educational Research ACEReSearch.

Lie, S., Angell, C., \& Rohatgi, A. (2010). Fysikk i fritt fall? TIMSS Advanced 2008 i videregående skole. Oslo: Unipub. 
Martin, M. O., Mullis, I. V. S., Foy, P., \& Stanco, G. M. (2012). TIMSS 2011 International Results in Science. Chestnut Hill, MA: TIMSS \& PIRLS International Study Center, Lynch School of Education, Boston College.

McDonnell, L. M. (1995). Opportunity to learn as a research concept and policy instrument. Educational Evaluation and Policy Analysis, 17(3), 305-322.

McGuigan, L., \& Hoy, W. K. (2006). Principal Leadership: Creating a Culture of Academic Optimism to Improve Achievement for All Students. Leadership and Policy in Schools, 5(3), 203-229. doi: 10.1080/15700760600805816

Nilsen, T., Grønmo, L. S., \& Hole, A. (2013). Læringstrykk og prestasjoner i matematikk og naturfag In L. S. Grønmo \& T. Onstad (Eds.), Opptur og nedtur. Analyser av TIMSS-data for Norge og Sverige (pp. 19 - 51). Oslo: Akademika forlag

Nilsen, T., \& Gustafsson, J.-E. (2013). School Emphasis on Academic Success. Exploring Changes in Performance Employing Two-level SEM. Paper presented at the IRC, Singapore.

NOKUT. (2008). Evaluering av ingeniørutdanningen i Norge 2008. Sammendrag av viktige konklusjoner og anbefalinger.

Muthén, L. K., \& Muthén, B. O. (1998-2010). Mplus User's Guide (6th ed.). Los Angeles: Muthén \& Muthén.

Olsen, R. V., \& Grønmo, L. S. (2006). What are the Characteristics of the Nordic Profile in Mathematical Literacy? In J. Mejding \& A. Roe (Eds.), Northern Lights on PISA 2003 - A Reflection from the Nordic Countries (pp. 47-57). Copenhagen: Nordic Council of Ministers.

Onstad, T., Grønmo, L. S., \& Nilsen, T. (2013). Om TIMSS og forskningsmetoder In L. S. Grønmo \& T. Onstad (Eds.), Opptur og nedtur. Analyser av TIMSS-data for Norge og Sverige (pp. 171 - 192). Oslo: Akademika forlag

Stevens, F. I. (1996). The need to expand the opportunity to learn conceptual framework: should students, parents, and school resources be included? Paper presented at the The annual meeting of the American Educational Research Association.

TIMSS. (2012). TIMSS Encyclopedia. Education Policy and Curriculum in Mathematics and Science. In I. V. S. Mullis, M. O. Martin, C. A. Minnich, G. M. Stanco, A. Arora, V. A. S. Centurino \& C. E. Castle (Eds.), (Vol. 1: A-K). Chestnut Hill, MA: TIMSS \& PIRLS International Study Center, Boston College, Lynch School of Education, Boston College.

Udir. (2012). Curriculum "Knowledge Promotion" in English. Oslo: Utdanningsdirektoratet Retrieved 2.2.2014 from http://www.udir.no/Stottemeny/English/Curriculumin-English/. 


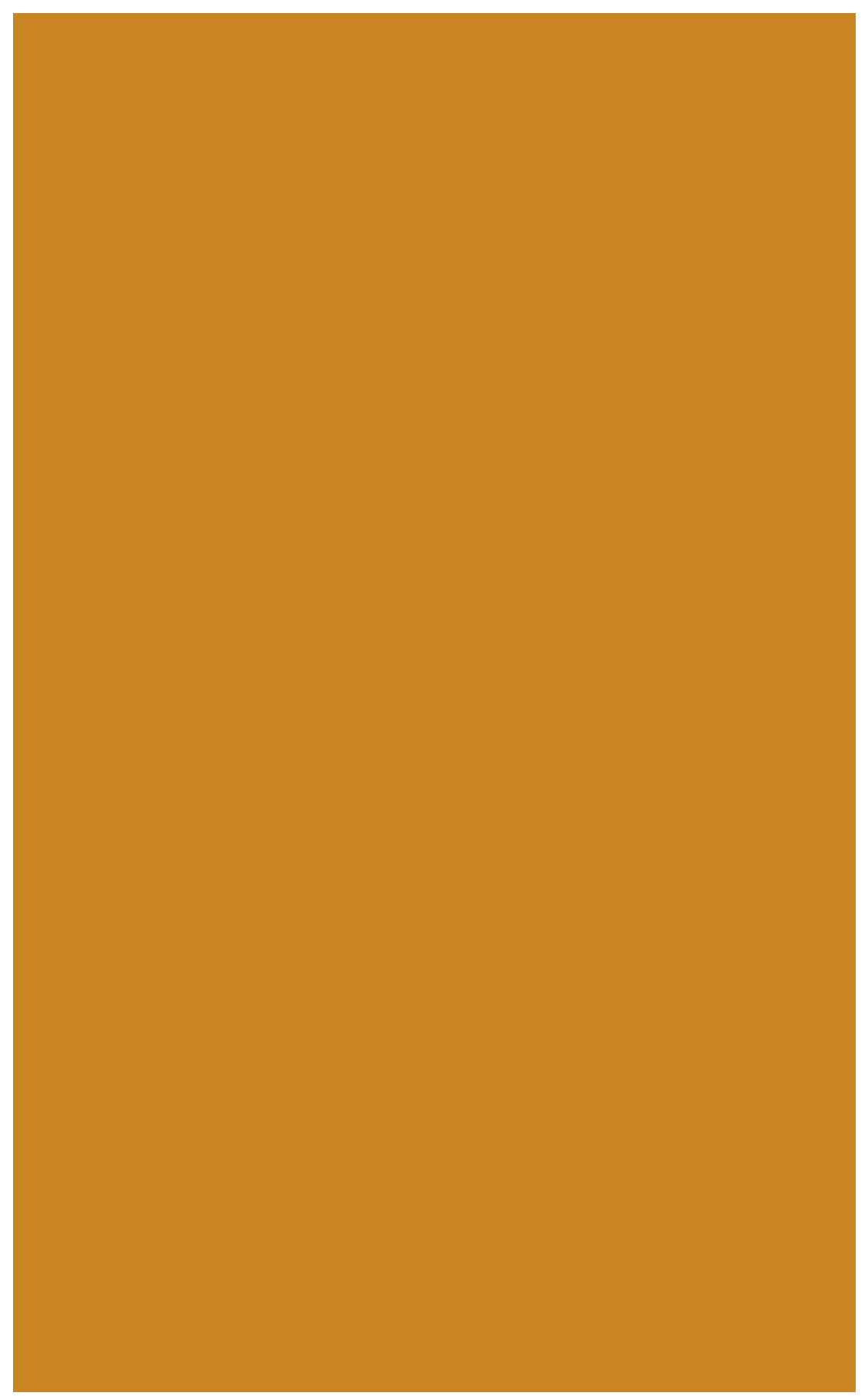




\section{A Nordic comparison of national objectives for reading instruction and teachers' responses about actual reading practice}

By Louise Rønberg and Jan Mejding, Aarhus University, Department of Education (DPU)

\subsection{Summary}

This article presents a comparison of the Nordic countries' official objectives for reading and analyses of 1005 Nordic teachers' responses regarding their reading instruction. The specificity and transparency vary greatly in the objectives, from broad outlines in Norway to more specific and functional goals in Finland. It appears that the Finnish descriptions are more aligned with current empirical research on reading comprehension.

Swedish and Norwegian teachers have the most varied used of both literary and informational text types during a week, whereas Finnish teachers give informational texts a higher priority than literary texts - and the opposite is apparent for Danish teachers. The Finnish and Norwegian teachers prioritise activities that enhance students' oral reading fluency, which is important for reading comprehension development, to a greater extent than teachers in Denmark and Sweden do. The Nordic teachers in general appear to prioritise advanced comprehension activities to a lesser extent than teachers in the English-speaking countries do. Furthermore, 
Danish teachers put the least emphasis on formative assessments compared to the other Nordic countries.

It is important that national objectives correspond with empirical research on reading instruction and that they are functional and transparent as they set the stage for the actual instruction in class.

\subsection{Introduction}

The Nordic countries share similarities in many areas of their educational system, such as free education for all and equality in the relationship between teacher and students. However, when students' reading achievement is evaluated through the lens of international studies - the Progress in International Reading Literacy Study (PIRLS) (Grade 4) and the Programme for International Student Assessment (PISA) (15 year olds) - the Nordic countries differ from each other.

Finland is consistently among the top four achieving countries in both PIRLS and PISA, whereas the ranking of the other Nordic countries is significantly below that of Finland (Mullis, Martin, Foy, \& Drucker, 2012; Arnbak \& Mejding, 2013). Moreover, the students in Denmark, Sweden and Norway do not do equally well in PISA and in PIRLS.

In PISA 2012, Norwegian students achieved just above the international mean in reading, Danish students at the international mean, and Swedish students somewhat below.

In PIRLS 2011, the Danish students achieved significantly above the achievement of both Swedish and Norwegian students, and the Norwegian 4th graders achieved significantly below all the Nordic countries (see figure A). However, Norway also participated with a sample of 5th graders, who achieved just below the Danish 4th graders. The Norwegian 5th Graders are comparable in age to the 4th Graders in the other Nordic countries. 
Figure A: Nordic reading literacy mean scores on Rasch scales in PISA 2012 and PIRLS 2011. When the confidence intervals (the vertical lines) overlap, the mean score between the countries cannot be said to be significantly different

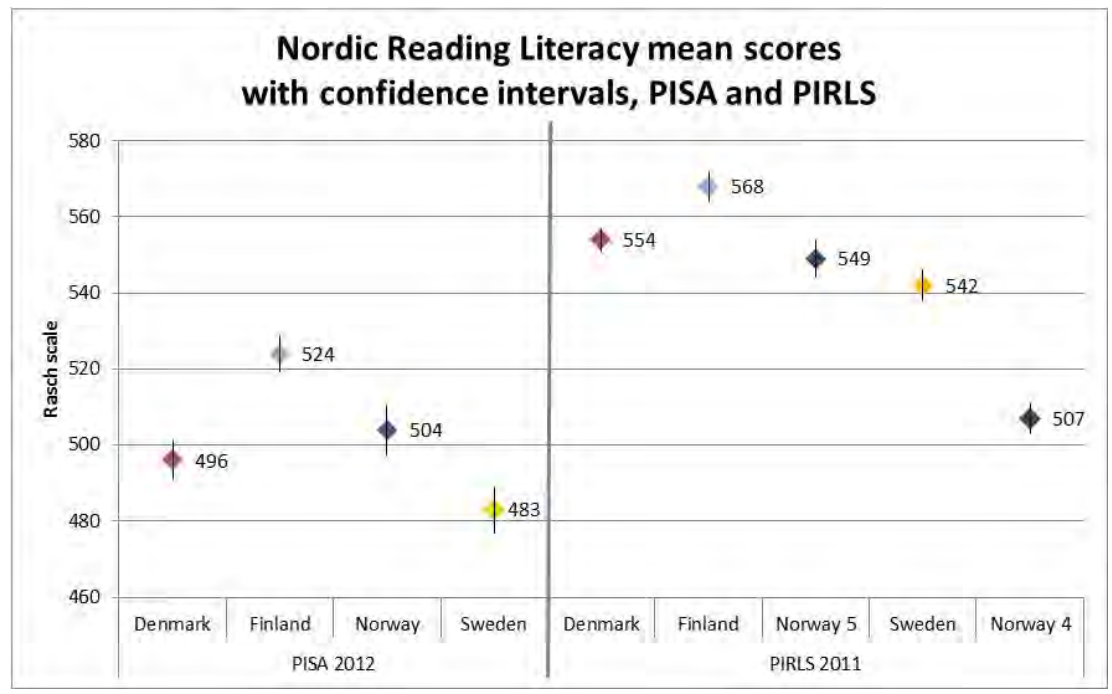

Note: The international means in the two studies are based on different country selections, and they are not centred on the same Rasch scale. The mean scores are not comparable between the PISA and PIRLS studies, but the relative position of the countries within each study is. PIRLS students are thus not better readers than PISA students.

In the present paper, we are interested in detecting differences in the national documents that lie behind reading instruction, which may be elements in explaining the differences in achievement between the Nordic countries. We present a comparison of the national objectives for teaching reading in the Nordic countries as they are presented in formal documents and relate these to research-based evidence about reading instruction.

Furthermore, we are interested in detecting differences in the teachers' actual practice as it is reflected through the PIRLS 2011 survey. The teachers are asked to respond to several questions about their classroom practices. This gives insight into the actual priorities in the classroom according to the 1,005 responding Nordic teachers. 
PIRLS is not designed to answer questions about what works in the classroom as all data are gathered at one single point in time and not longitudinally. To answer those sorts of questions, controlled intervention studies are needed. However, the data from PIRLS are very important in order to answer questions about how the nation's school systems perform compared to each other, and how they are similar or how they differ. Together with evidence from a synthesis of findings in controlled intervention studies, we gain valuable insight into the reading teaching practices of the participating teachers.

\section{Policy points}

- The national objectives for the teaching of reading must correspond with sound empirical research on reading instruction and development.

- Reading comprehension abilities may vary with text type and challenge of text. The national objectives must ensure that a variety of text types and also challenging texts are prioritised in reading instruction at the 4 th grade level and beyond.

- Reading takes place in all subjects in school; however, reading comprehension is not a general ability. Each specific subject area needs to work with students' reading comprehension of subject-related texts, e.g. by teaching text structure, vocabulary, and comprehension strategies.

- Formative assessment of students' progress is necessary as a means to monitor learning and adjust teaching strategies.

\subsubsection{Theoretical and scientific framework for reading comprehension instruction}

Reading comprehension is here understood as an active process, where readers extract and construct meaning simultaneously while interacting and involving with written language (Snow, 2002; Mullis, Martin, Kennedy, Trong, \& Sainsbury, 2009). According to modern theoretical frameworks, reading comprehension is the process of integrating text-based information with prior knowledge to construct a deeper understanding of text (Kintsch \& Rawson, 2005). Text-based information refers to the content of the text i.e., the specific words, phrases, and relations between 
them, as well as the structure of text in terms of phrase ordering and graphic organisation (Goldman \& Rakestraw, 2000). Basically, to allow reading comprehension to happen, the reader must be able to read the words and understand the language in which the text is written (Perfetti \& Stafura, 2014).

The past $20+$ years of reading research have resulted in a voluminous amount of knowledge about reading development and instruction. A landmark report is the National Reading Panel's Report from 2000, which has also been a cornerstone in the US literacy policy (e.g. Shanahan, 2006, p. 5; NICHD, 2000). The report gives a comprehensive synthesis of research on effective methods for teaching reading. It reveals that the greatest chance of reading success is present when the following five areas are systematically and directly taught: Phonemic Awareness, Phonics, Fluency, Vocabulary and Comprehension Strategies.

All elements are relevant at all levels of instruction. However, instruction in Phonological Awareness and Phonics is primarily crucial in the initial years of reading instruction, whereas the last three, Fluency, Vocabulary and Comprehension Strategies, continue as elements of high importance for further reading comprehension development after the initial years of instruction. Moreover, reading comprehension ability may vary with the text type, genre, and the language of a specific text (Snow, 2002). This makes it urgent that students during reading instruction are exposed to a variety of literary and informational texts as well as digital texts and directly instructed in recognising the structure and features of these texts.

Furthermore, formative assessment together with quality feedback is considered one of the most effective mechanisms for improving students' learning, which is also true for reading development (Sharon, 2010). Quality feedbacks is feedback that helps the student set goals and monitor his or her own learning progress (Andreassen, Bjerresgaard, Bråten, Hattie, Hermansen, Nerheim et al., 2013). 


\subsection{The present study}

The aim of the present paper is twofold: firstly, to analyse the Nordic countries' formal objectives for reading as they appear in the countries' written documents $^{13}$ and secondly, to analyse the Nordic teachers' instructional practise as displayed through the PIRLS 2011 teacher questionnaire.

The analysis of the official documents will focus on:

- The definition of reading ability.

- The objectives for reading comprehension strategies.

- The objectives for developing students' reading fluency.

- The objectives for the use of text types.

The analyses of the teacher responses in the PIRLS 2011 survey will focus on:

- Materials and text genres (literary and informational) applied during instruction.

- Activities during and after reading instruction that enhance reading fluency and comprehension strategies.

- Emphasis on formative assessment of reading.

In the following section, the analysis of the national objectives for reading in the Nordic countries will be presented.

\footnotetext{
${ }^{13}$ It should be noted that the official objectives in the different Nordic countries have been supplemented by national guidelines or syllabi, where the background for the objectives have been described and explained in more detail. However, it should be expected that the objectives are perceived as more binding for teaching than the broader guidelines, and they should therefore contain the necessary information needed for structuring the teaching of reading literacy.
} 


\subsection{Formal objectives of reading in the Nordic countries}

\subsubsection{Comparison of objectives}

Table 1 shows a comparison of the objectives as described in the countries' current curricula for reading instruction in the Nordic countries. Some interesting contrasts appear and will be pointed out in the following. It should be noted that the Norwegian curricula presented here have been revised since the PIRLS 2011 data were collected. Moreover, the curricula are currently under revision in both Denmark and Finland. The Danish revision will be launched in 2014/2015, whereas the Finnish will be launched in 2016.

There is slight variation between the countries regarding the grade level to which the objectives apply, which must be taken into account when the objectives are presented in Table 1, and when contrasts are further discussed. One of the differences between the Nordic countries is the way they organise school entry. In Denmark, Finland, and Sweden, a Kindergarten Class ("förskoleklass" or "børnehaveklasse") is included and described as a part of the school curricula and is intended to be a transition between prescool and school. In Finland and Sweden, this class is voluntary, and in Denmark it is obligatory. In Norway, the voluntary Kindergarten Class was made the obligatory Grade 1 when the school entry age was changed in 1997 from seven to six years of age. However, the curriculum in Grade 1 remained more or less the same as what was expected in the kindergarten classes in the other Nordic countries. This means that the Norwegian $4^{\text {th }}$ graders correspond to the age of third graders in the other Nordic countries.

In Denmark and Norway, the objectives are described as goals after Grade 4, in Finland, the objectives are goals and core content that are meant to be achieved and covered in Grades 3-5. In Sweden, the objectives presented in Table 1 are specified as acceptable skills developed by the end of Grade 3, and furthermore, specific descriptions of core content in grade levels 4-6 are presented. The specific Swedish objectives after Grade 6 are specified at five different grading levels, which made it too voluminous to include here. As the Grade 4 students in Norway are one 
year younger than the other Nordic countries' students, the Norwegian objectives and goals after Grade 4 can more readily be compared to the Swedish objectives by the end of Grade 3.

Table 1: Review of the current curriculum descriptions of objectives for reading around Grades 3-5 translated and summarised by the authors using the Swedish and Norwegian versions and an English version of the Finnish curriculum (Finnish National Board of Education, 2004;

Skolverket, 2011; Utdanningsdirektoratet, 2013; Undervisningsministeriet, 2013)

\begin{tabular}{|c|c|}
\hline Country & Objectives \\
\hline Denmark & $\begin{array}{l}\text { Objective Grade } 4 \text { Written Language - Reading } \\
\text { - The students should acquire knowledge and skills that enables them to: } \\
\text { - Apply efficient strategies for decoding known and unknown words in age-appropriate texts } \\
\text { - Read texts that aid and support language development and apply different reading com } \\
\text { prehension strategies } \\
\text { - Search for explanations of words and concepts } \\
\text { - Know different ways of reading } \\
\text { - Adjust reading speed, accuracy and reading technique to match purpose, genre and diffi } \\
\text { culty of text } \\
\text { - Express an understanding of what is read orally and in writing } \\
\text { - Read age-appropriate literary and informational and digital texts with good comprehend } \\
\text { sion } \\
\text { - Read for disciplinary knowledge in Danish } \\
\text { - Conscious monitoring of their understanding of what they read } \\
\text { - Develop and maintain appropriate reading routines } \\
\text { - Browse and choose literary and informational texts at the library and in digital media } \\
\text { - Read easy Norwegian and Swedish texts }\end{array}$ \\
\hline Finland & $\begin{array}{l}\text { Grades 3-5: } \\
\text { Objectives Grades 3-5 The student's skills in interpreting and utilising various texts will } \\
\text { develop } \\
\text { The student will: } \\
\text { - Learn to read various texts fluently and will become accustomed to observing and evaluat } \\
\text { ing themselves as readers } \\
\text { - Gain an introduction to various ways of reading; they will become practised in using strat } \\
\text { egies to improve text comprehension } \\
\text { - Learn to choose appropriate reading for different purposes; they will become accustomed } \\
\text { both to considering and expressing ideas awakened by texts and to connecting them with } \\
\text { their own lives and environment } \\
\text { - Learn to look for information from different types of age-appropriate sources } \\
\text { Core content Text comprehension } \\
\text { - Practise in listening with comprehension and concentration } \\
\text { - Skimming, reading to search, literal reading and inferential reading } \\
\text { - Anticipating the content and structure of texts on the basis of illustrations, headings and } \\
\text { prior knowledge and reading experiences. } \\
\text { - Distinguishing main issues from secondary ones, summarising, using intermediate head } \\
\text { ings, posing questions, taking notes, drawing conclusions and evaluating things read and } \\
\text { heard } \\
\text { - Preparing outlines and schematics, considering a text's idea and comparing texts }\end{array}$ \\
\hline
\end{tabular}


- Read texts in different genres in bokmål and in nynorsk with coherence and understanding

- Find information by combining words and illustrations in texts on screen and paper

- Recognise and use linguistic traits like repeated events, contrasts and simple metaphors

- Make reflections and talk about one's own texts and the texts of others' part, the student is able to apply well-functioning reading strategies. The student shows basic comprehension of what is read through his or her commenting and summarising of the main content. Moreover, the student is able to make simple arguments about evident main messages of the texts as well as relate this to his or her own experiences.

Core content grades 4-6 Reading (and Writing)

Reading strategies for comprehension and interpretation of texts from various media. Reading strategies for identifying the message of the text, the explicitly stated as well as the message between the lines.

Narrative texts and informational texts

Narrative texts and poetic texts for children and adolescents, old and new literature, from Sweden, the Nordic countries and other parts of the world. Literary texts like lyric, drama, tall tales and myths that reflect life conditions, questions of identity and questions of life of human beings.

The message, language, and structure of narrative texts with parallel action and flashbacks, descriptions of environment, characters and dialogues.

Some important authors of children's and youth literary books and their work.

Descriptive, explanatory, instructive, and argumentative texts, such as informational texts, work descriptions, advertisings, and letters to the editor. The content, structure, and typical language of the texts.

Texts that integrate word, illustration, and sound, for example, web texts, interactive games, and television programs. The content, structure, and typical language of the texts.

\subsection{The Nordic countries' definition of reading ability}

In the following, we are looking for ways in which the countries specify the kind of reading ability that the students around Grade 4 are expected to attain (see Table 1).

In the Finnish curriculum for the primary years (Grades 1-2), the descriptions of the objectives for reading and writing are found under the heading Reading and writing skills. However, from Grades 3-5, this changes to the functional headings The students' skills interpreting and utilising various texts and Text comprehension.

In contrast, neither Denmark, Norway nor Sweden use headings that summarise the functional aspects of reading, and they only sparsely make clear what kinds of reading abilities define good comprehension. In the Danish curriculum, a broad heading, The Written language - reading (Det 
skrevne sprog - læsning), is used throughout the grades when describing objectives for reading. In Norway, the heading Written communication (Skriftlig kommunikation), which includes objectives for both reading and writing, is applied and in Sweden, the heading Reading and writing (Läsa och skriva) is applied.

It is noteworthy that the functional approach in Finland to the description of the act of reading is not restricted to the headings. It is present throughout the Finnish curriculum. The objectives are specified in core content descriptions with functional verbs that mirror how text comprehension is viewed such as anticipating content and structure, distinguishing main issues from secondary ones, drawing conclusions and evaluating things read and heard. The Swedish documents also make use of some functional wording in the descriptions however, not to the same extent. The kind of reading ability the Swedish students are expected to achieve by the end of Grade 3 is described as basic comprehension, which will be reflected in the student's commenting and summarising of the main content. Moreover, the acceptable reading ability by the end of Grade 3 is described as being able to make simple arguments about evident main messages and making relations to own experiences.

Norway and Denmark have chosen a broad and unspecific way of describing their objectives of reading. In the Norwegian objectives after Grade 4, the students are expected to be able to read, reflect, and find information, and they are expected to be able to do so in different text genres. What it means to read and reflect at this grade level is not made explicit. Compared to the Norwegian objectives, the Danish objectives have more words. Nevertheless, they are not more specific regarding the definition of reading ability. After Grade 4, the Danish students are expected to be able to express an understanding, read age-appropriate literary and informational and digital texts with good comprehension. What is meant by expressing an understanding and good comprehension is not made explicit. 


\subsection{Research-based elements in the national objectives}

In the following, we are interested in detecting signs of research-based elements in the objectives. We particularly search for the explicit mentioning of reading comprehension strategies, reading fluency and the priority of various text types in the curricula.

\subsubsection{Reading comprehension strategies}

Research synthesized by the United States' National Reading Panel (NRP) has clearly shown that teaching students to use comprehension strategies to guide their own meaningful interactions with text is important for reading achievement (NICHD, 2000). The National Reading Panel (NRP) was established in 1997 in the United States in order to evaluate existing research and evidence to find the best ways of teaching children to read (NICHD, 2014).

The NRP report showed that all the following strategies make an impact on students' learning of content when taught independently as well as in combination with other strategies: monitoring understanding, generating and answering questions, summarisation of text, story mapping, and graphic organisers (NICHD, 2002). The strongest scientific evidence has been found for the effectiveness of asking readers to generate questions during reading (NICHD, 2000; p. 4-45). Moreover, the instructional activity reciprocal teaching in which students become the teacher in small group reading sessions has proven effective (NICHD,2000; Oczuks, 2003). The teacher models and helps students learn to guide group discussions using four strategies: predicting, clarifying, generating questions, and summarising.

Reading comprehension strategies are targeted differently in the Nordic countries' opbjectives for reading. In the Norwegian objectives, comprehension strategies are not mentioned at all. In the Danish objectives, it is stated that the students will have acquired knowledge and skills that enable them to apply different reading comprehension strategies. However, specific kinds of strategies are not mentioned. The same is apparent in the Swedish descriptions. However, even though no specific strategies are mentioned, the Swedish descriptions emphasise the purpose of strategy 
instruction. It says that reading strategies for comprehension and interpreting texts from various media must be emphasised, as well as strategies for identifying the explicitly stated text message and the implicit message. The Finnish objectives actually mention activities that fit in to a research-based framework for reading comprehension instruction. It is specified that the students will become practised in using strategies to improve text comprehension, and in the descriptions of core content a wide array of strategy activities are mentioned: anticipating the content and structure of texts on the basis of illustrations, headings, prior knowledge, and reading experiences (i.e., predicting, story mapping); taking notes, drawing conclusions, evalutating things read (i.e., summarising); posing questions (i.e., generating questions, clarifying); preparing outlines and schematics (i.e., graphic organisers).

\subsubsection{Fluency}

Fluent reading is a critical element in skilled reading. When fluent reading is established, cognitive energy may be devoted directly to the comprehension of text (NICHD, 2000; Rasinski, Rikli, \& Johnston, 2009). This makes it relevant to identify whether reading fluency is mentioned as an objective in the Nordic countries' descriptions.

As shown in table 1, both Sweden and Finland explicitly mention fluent reading as an objective at the level around Grade 4, however, without further definition of what that is. In the Norwegian text, an objective is "coherent reading", which may be interpreted as a way to mention fluent reading. In the Danish text, fluent reading is not explicitly stated as a goal after the $4^{\text {th }}$ Grade level. However, the Danish document states the ability to "apply efficient strategies for decoding known and unknown words" as an objective and furthermore the ability to "adjust reading speed, accuracy and reading technique to match purpose, genre, and difficulty of text." Both are related to fluency development. The first is a prerequisite for developing automatic recognition of words, and the second is a consequence of having developed fluent reading. Thus all Nordic countries have a mention of elements that may be interpreted as fluent reading, but it is only an explicitly stated goal in Sweden and in Finland. 


\subsubsection{Priority of text types in the countries' objectives}

In contrast to the other Nordic countries' descriptions, the Swedish descriptions of the core content for Grades 4-6 are detailed regarding the specific literary and informational text genres with which students are expected to be acquainted, such as tales, myths, advertisings and letters to the editor. Finland mentions the reading of various texts, Norway mentions texts in different genres and Denmark mentions literary, information$a l$ and digital texts.

In addition to genre or text type, a specific focus on challenging texts in the teaching of English Language Arts has been launched with the Common Core State Standards in the United States (CCSS, 2012). The idea is that in order to develop a high proficiency in reading, one must be guided in processing challenging texts (Shanahan, 2013). The objectives in a curriculum may seem ambitious, but the argument is that if the challenge level of the texts is ignored, then the goals may be reached at an embarrassingly low performance level (Shanahan, 2013, p. 6). In the Nordic countries' documents, there are no specific mentions of challenging texts. Age-appropriate texts are mentioned in the Danish, Swedish, and Finnish documents. However, the Swedish document also mentions a variety of specific text types, old and new literature, as well as texts for children and adolescents, which indicates that the difficulty level of texts is varied.

\subsubsection{Hypotheses based on the analysis of official documents}

In the following, the Nordic teachers' instructional practice will be explored through analyses of the PIRLS 2011 survey data. Based on the preceeding observations, it is expected that:

- Sweden will use a variety of text genres. Denmark and Sweden will give literary and informational texts equal priority during reading instruction. The priority of text types in Finland and Norway is not clear from the countries' objectives.

- The teachers in Finland and Sweden will prioritise reading activities that enhance reading fluency, whereas reading fluency will be less prioritised in Denmark and Norway. 
- The teaching of reading comprehension strategies will have a higher priority in Finland compared to the other Nordic countries.

- Formative assessment of students' progress in reading will be most present in Finland, where core content are clearer as to what kind of processing is expected of the students.

\subsection{Analysis of Nordic teachers' reading instruction based on data from PIRLS 2011}

The following results are based on survey data from Grade 4 teachers in Denmark, Finland, Norway, and Sweden participating in PIRLS 2011 (see Table 2).

The Norwegian students start Grade 1 one year before the other Nordic countries, which means that they are one year younger than the other Nordic students in Grade 4. Even though the Norwegian Grade 5 sample was somewhat smaller than the main sample of Grade 4 students, the results from the Norwegian 5th Grade teachers have been included for a comparison, as the level of teaching here should be more on the level of Grade 4 classrooms in the other Nordic countries. When reporting statistically significant differences between the participating Grade 4 teachers' responses, Chi-Square Tests have been applied.

Table 2: Participating Grade 4 teachers in the Nordic countries

\begin{tabular}{lrrr}
\hline Country & Female teachers & Male teachers & Total \\
\hline Denmark & $206(88 \%)$ & $28(12 \%)$ & 232 \\
Finland & $210(77 \%)$ & $62(23 \%)$ & 272 \\
Norway & $164(84.5 \%)$ & $30(15.5 \%)$ & 194 \\
Norway Grade 5 & $54(69 \%)$ & $24(31 \%)$ & 78 \\
Sweden & $190(83 \%)$ & $39(17 \%)$ & 229 \\
& & & 1,005 \\
\hline
\end{tabular}




\subsection{Materials and genres as a basis or supplement for reading instruction}

The teachers were asked about the kind of materials that serve as a basis and supplement for reading instruction; the responses included textbooks, children's books, newspaper articles, and computer software. Furthermore, the teachers were asked specifically about how often they use particular literary and informational materials during reading instruction. The teachers were not asked about their use of digital texts during reading instruction in PIRLS 2011. In the following, the results will be presented in text and in tables.

Textbooks used as a basis for instruction in Grade 4 apply to more than $80 \%$ of the teachers in Norway and Finland, whereas this only applies to $50 \%$ and $46 \%$ of the teachers in Denmark and Sweden, respectively, ${ }^{14}$ $p<.001$.

\subsubsection{Children's books (e.g. novels, collections of stories)}

More than $50 \%$ of the Swedish and Danish teachers use a variety of children's books as a basis for instruction, whereas this only applies to $25 \%$ and $20 \%$ of the teachers in Norway and Finland (see Table 3 ).

Table 3: Question from the PIRLS teacher questionnaire: When you have reading instruction and/or do reading activities with the students, how do you use a variety of children's books (e.g., novels, collections of stories, nonfiction)?

\begin{tabular}{lccc}
\hline Country & Basis & Supplement & Not used \\
\hline Denmark & $55 \%$ & $44 \%$ & $0.9 \%$ \\
Finland & $20 \%$ & $78 \%$ & $1.1 \%$ \\
Norway & $25 \%$ & $74 \%$ & $1.1 \%$ \\
Norway Grade 5 & $29 \%$ & $72 \%$ & $0.0 \%$ \\
Sweden & $57 \%$ & $43 \%$ & $0.5 \%$ \\
\hline
\end{tabular}

\footnotetext{
14 (However, for the sake of the Danish results this is a major shift from the teachers' report in 2006, where the proportion was similar to the Norwegian and Finnish 2011 results. Possibly this has to do with a slightly change in the wording of the 2011 questionnaire compared to the 2006).
} 


\subsubsection{Newspaper articles and magazines}

Newspaper articles are used as a basis of instruction by very few Nordic teachers. As supplementary material, they are used by $70-78 \%$ of the teachers in Finland, Norway and Sweden, whereas this is less common in Denmark. Only 36\% of the Danish teachers replied they use newspaper articles as a supplement, and $62 \%$ replied that they never or almost never use newspaper articles (see Table 4).

Table 4: Question from the PIRLS teacher questionnaire: When you have reading instruction and/or do reading activities with the students, how do you use children's newspapers and/or magazines?

\begin{tabular}{lccc}
\hline Country & Basis & Supplement & Not used \\
\hline Denmark & $1.7 \%$ & $36 \%$ & $62 \%$ \\
Finland & $2.3 \%$ & $78 \%$ & $20 \%$ \\
Norway & $2.6 \%$ & $69 \%$ & $28 \%$ \\
Norway Grade 5 & $2.6 \%$ & $70 \%$ & $28 \%$ \\
Sweden & $8.4 \%$ & $76 \%$ & $15 \%$ \\
\hline
\end{tabular}

\subsubsection{Computer software}

Computer software is used as a basis for instruction by less than $10 \%$ of the Nordic teachers. However, most of the Nordic teachers (60-70\%) agree that they use computer software as a supplement during reading instruction.

\subsection{The use of literary and informational text types during reading instruction}

Knowledge of how literary and informational texts are structured is helpful for comprehension. With regards to the knowledge of structure and features of informational texts, it may be argued that this takes longer to develop as exposure to informational texts are limited as read-alouds in the preschool years and also as a text type used in the primary years of instruction (Duke, 2000). In the United States, there has been a shift towards more informational reading during reading instruction since the adoption of the Common Core State Standards. 
In the following, we will compare the Nordic teachers' answers regarding the kinds of literary and informational text types they have their students read during reading instruction, and how often they have them do so.

\subsubsection{Literary short stories and longer fiction}

It appears that around $30 \%$ of the Danish and Norwegian teachers have their students read literary short stories during reading instruction almost every day (see Figure 1a). This is more frequently than the practice of Swedish and Finnish teachers, $p<.001$. On the other hand, it appears that Swedish teachers more often prefer longer literary fiction books as part of reading instruction, $p<.001$. Reading longer fiction books almost every day applies to $66 \%$ of the Swedish teachers, whereas this only applies to around $35 \%$ of the Norwegian and Danish teachers and only $7 \%$ of the Finnish teachers (see Figure 1b).

Only a very small part of the Nordic teachers $(<5 \%)$ have their students read literary plays on a daily basis. However, more Finnish and Norwegian teachers (around 45\%) compared to Danish and Swedish teachers (around $25 \%$ ) reply that it happens at least once a month, $p<.001$. 
Figure 1a-1b: Question from the PIRLS teacher questionnaire: When you have reading instruction and/or do reading activities with the students, how often do you have the students read: short stories (e.g. fables, fairy tales, action stories, science fiction and detective stories)? Or longer fiction books with chapters?

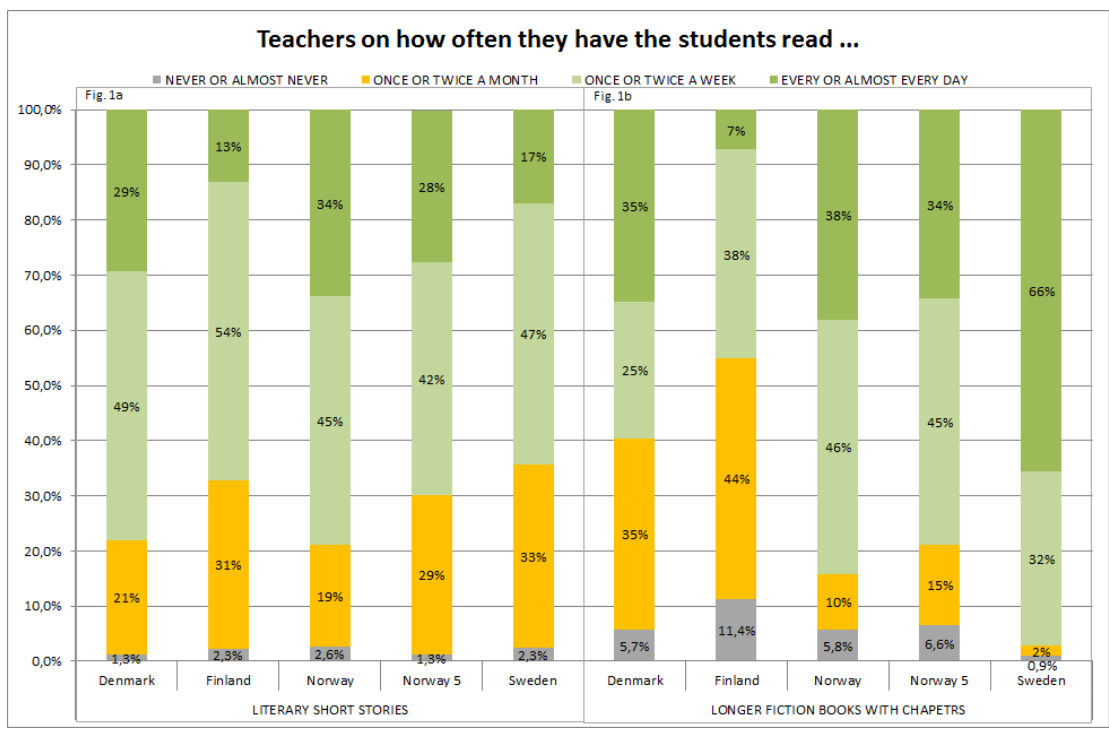

\subsubsection{Informational reading - informational books and informational articles}

In the previous section, it was shown that the majority of Danish teachers did not use newspaper articles at all during reading instruction. This was in contrast to the other Nordic teachers, where the majority replied that they used newspaper articles as a supplement. The following is about how often the teachers use informational books and informational articles. During reading instruction. Informational articles refer to articles that describe and explain things, persons, events and how things work.

Informational books appear to be particularly much less prioritised by Danish teachers compared to the other Nordic teachers, $p<.001$. Only $14 \%$ of the Danish teachers have their students read non-fiction books every day, whereas this applies to $71 \%$ of the Finnish teachers (see Figure 1c). On a weekly basis, this means that only $47 \%$ of the Danish teachers compared to $87 \%$ of the Finnish, $89 \%$ of the Norwegian, and $95 \%$ of the Swedish teachers prioritise informational books. 
Less than $10 \%$ of all the Nordic teachers use informational articles, such as descriptions, and explanations on a daily basis (see Figure 1d). On a weekly basis, more than $30 \%$ of the Danish and Norwegian teachers and $42 \%$ of the Swedish teachers prioritise informational articles, whereas this only applies to $11 \%$ of the Finnish teachers, $p<.001$.

Figure 1c-1d: Question from the PIRLS teacher questionnaire: When you have reading instruction and/or do reading activities with the students, how often do you have the students read: nonfiction subject area books or textbooks? Or nonfiction articles that describe and explain about things, people, events or how things work?

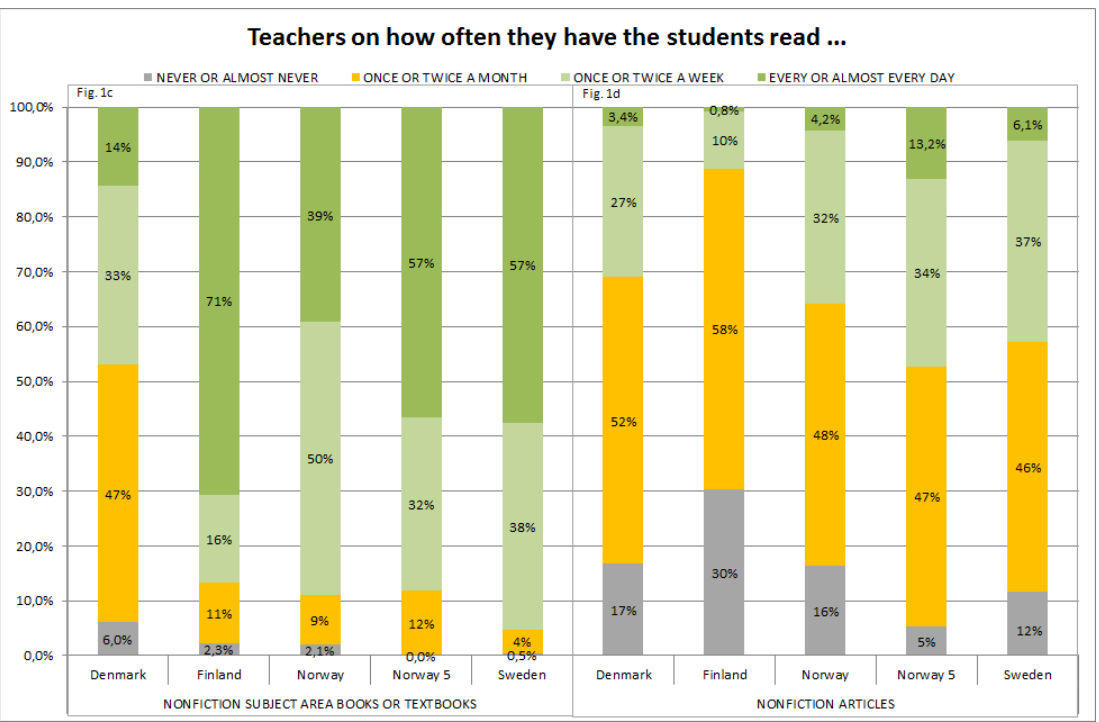

\subsubsection{Summing up}

The reading of fiction seem to be highly prioritised in Denmark, Sweden, and Norway, and less prioritised in Finland.

Even though informational reading is mentioned in the Danish objectives for Grade 4, Danish teachers seem in general to give informational texts less priority during reading instruction and a higher priority to the reading of fiction. The only exception is nonfiction articles that are used almost as frequently as in Norway and Sweden. Informational reading seems to have a higher priority than the reading of fiction in Finland. The 
Finnish objectives are not specific regarding the kinds of text types to be used; they just state that the text types are to be varied and ageappropriate. Swedish teachers appear to prioritise longer literacy fiction books more frequently than the other Nordic teachers. The reading of plays as part of instruction is less prioritised in all Nordic countries at the Grade 4 level, although it is more prioritised in Finland and Norway.

Sweden has the most detailed mentioning of specific text types in their documents. Norway only specifies that the students are expected to read in different genres and in both the main languages in Norway. Norwegian and Swedish teachers appear on a weekly basis to be more varied in their choices of texts compared to the Danish and Finnish teachers, who on the other hand give a higher priority to one or the other of the two text types.

\subsection{Activities during and after reading instruction}

\subsubsection{Activities that enhance reading fluency}

When teachers read aloud to classes, students get an adult model of how fluent reading sounds. Furthermore, reading aloud to students gives rise to the encounter of new vocabulary and knowledge. The data from the Nordic teachers reveal that significantly less instructional time in Denmark and in Finland is spent on teachers' reading aloud to class compared to the teachers' reading practices in Sweden and Norway, $p<.001$ (see Table 5).

However, students have to read on their own to become fluent readers themselves (NICHD, 2000). One way is to encourage students to read silently on their own, which may improve reading fluency, vocabulary development and motivation for reading. In all the Nordic countries, the majority of the teachers have their students read independently almost daily as a part of reading instruction. However, research has clearly shown that not all students develop a proficient level of fluency and vocabulary during unguided practice (NICHD, 2000). Research has shown that reading fluency, which is a foundation for comprehension development, is most efficiently improved when reading instructors prioritise that students read aloud (in pairs or small groups) (NICHD, 2000). 
The majority of Finnish and Norwegian teachers have their students read aloud in class almost every day, whereas this applies only to $21 \%$ and $24 \%$ of the students in Denmark and Sweden, respectively. The difference between the countries is significant, $p<.001$.

Table 5: Nordic teachers' replies about oral and silent reading in class

\begin{tabular}{lrrr}
\hline & $\begin{array}{c}\text { Teacher reads aloud } \\
\text { every day or almost }\end{array}$ & $\begin{array}{r}\text { Students read aloud every } \\
\text { day or almost }\end{array}$ & $\begin{array}{r}\text { Students read silently } \\
\text { every day or almost }\end{array}$ \\
\hline Denmark & $19 \%$ & $21 \%$ & $60 \%$ \\
Finland & $32 \%$ & $68 \%$ & $62 \%$ \\
Norway Grade 4 & $68 \%$ & $50 \%$ & $70 \%$ \\
Norway Grade 5 & $65 \%$ & $62 \%$ & $65 \%$ \\
Sweden & $63 \%$ & $24 \%$ & $77 \%$ \\
\hline
\end{tabular}

\subsubsection{Activities in order to develop reading comprehension strategies and skills}

The teachers were asked how often they engage students in specific reading activities in order to develop strategies and skills that may enhance their reading comprehension. The majority of Nordic teachers have their students do basic comprehension activities (see Table 6a) on a weekly basis like locating information, eliciting main ideas, giving explanations, and finding evidence in the text that supports their understanding (Mejding \& Rønberg, 2012, p. 127).

On the other hand, when compared to the English-speaking countries, the Nordic teachers appear to focus less on advanced activities (see Table $6 \mathrm{~b})$, like making predictions of what will happen next, making generalisations and drawing inferences based on the information in text, describing the style or structure of the texts they read as well as determining the author's perspective or intention.

Even though the Finnish national documents were more explicit about reading comprehension strategies, the data from PIRLS 2011 do not show that Finnish teachers give the areas the areas mentioned in tables $6 \mathrm{a}$ and $6 \mathrm{~b}$ a higher priority than the other Nordic countries' teachers do. Actually, more Danish teachers than the other Nordic teachers seem to focus on advanced comprehension activities, $p<.001$. 
Table 6a: Percentage of students whose teachers weekly have the students do basic comprehension activities ${ }^{15}$

\begin{tabular}{|c|c|c|c|c|c|}
\hline \multirow[t]{2}{*}{ Country } & \multicolumn{5}{|c|}{ Percent of Students Whose Teachers Ask Them to Do the Following At Least Weekly } \\
\hline & $\begin{array}{r}\text { Locate } \\
\text { Information } \\
\text { Within the } \\
\text { Text }\end{array}$ & $\begin{array}{r}\text { Identify the } \\
\text { Main Ideas of } \\
\text { What They Have } \\
\text { Read }\end{array}$ & $\begin{array}{r}\text { Explain or Support } \\
\text { Their Understand- } \\
\text { ing of What They } \\
\text { Have Read }\end{array}$ & $\begin{array}{r}\text { Compare What } \\
\text { They Have Read } \\
\text { with Experiences } \\
\text { They Have Had }\end{array}$ & $\begin{array}{r}\text { Compare What } \\
\text { They Have Read } \\
\text { with Other Things } \\
\text { They Have Read }\end{array}$ \\
\hline Australia* & 96 & 95 & 96 & 87 & 72 \\
\hline England & 97 & 97 & 95 & 78 & 74 \\
\hline New Zealand & 99 & 98 & 97 & 89 & 74 \\
\hline Northern Ireland* & 99 & 94 & 98 & 67 & 59 \\
\hline United States* & 99 & 99 & 99 & 95 & 90 \\
\hline Denmark & 86 & 86 & 86 & 65 & 51 \\
\hline Finland & 86 & 88 & 80 & 67 & 39 \\
\hline Norway & 98 & 90 & 91 & 65 & 49 \\
\hline Norway 5th & 92 & 88 & 91 & 77 & 51 \\
\hline Sweden* & 96 & 78 & 77 & 56 & 27 \\
\hline International Avg. & 96 & 95 & 95 & 81 & 70 \\
\hline English Speaking Avg. & 98 & 97 & 97 & 83 & 74 \\
\hline Nordic Avg & 92 & 86 & 85 & 66 & 43 \\
\hline
\end{tabular}

Table 6b: Percentage of students whose teachers weekly have the students do more advanced comprehension activities

\begin{tabular}{|c|c|c|c|c|}
\hline \multirow[t]{2}{*}{ Country } & \multicolumn{4}{|c|}{ Percent of Students Whose Teachers Ask Them to Do the Following At Least Weekly } \\
\hline & $\begin{array}{r}\text { Make Predictions about } \\
\text { What Will Happen Next } \\
\text { in the Text }\end{array}$ & $\begin{array}{r}\text { Make Generaliza- } \\
\text { tions and Draw } \\
\text { Inferences }\end{array}$ & $\begin{array}{r}\text { Describe the Style } \\
\text { or Structure of the } \\
\text { Text }\end{array}$ & $\begin{array}{r}\text { Determine the } \\
\text { Author's Perspective } \\
\text { or Intention }\end{array}$ \\
\hline Australia* & 92 & 92 & 84 & 73 \\
\hline England & 96 & 93 & 82 & 72 \\
\hline New Zealand & 94 & 94 & 72 & 72 \\
\hline Northern Ireland* & 84 & 82 & 64 & 50 \\
\hline United States* & 98 & 98 & 81 & 84 \\
\hline Denmark & 50 & 54 & 41 & 40 \\
\hline Finland & 44 & 66 & 24 & 15 \\
\hline Norway & 33 & 52 & 29 & 19 \\
\hline Norway 5th & 29 & 58 & 21 & 12 \\
\hline Sweden* & 38 & 53 & 19 & 12 \\
\hline International Avg. & 74 & 80 & 66 & 63 \\
\hline English Speaking Avg. & 93 & 92 & 77 & 70 \\
\hline Nordic Avg & 39 & 57 & 27 & 20 \\
\hline
\end{tabular}

* indicates data are available for at least $70 \%$ but less than $85 \%$ of the students in the country sample. SOURCE: IEA's Progress in International Reading Literacy Study - PIRLS 2011.

15 The data in tables $6 \mathrm{a}$ and $6 \mathrm{~b}$ come from a table in the international report, and tables $6 \mathrm{a}$ and $6 \mathrm{~b}$ show the percentage of students whose teachers do something. In the remaining figures and tables in this chapter, it is the percentage of teachers who do something regardless of the number of students they are teaching. 


\subsection{Emphasis on the evaluation of students' progress in reading}

\subsubsection{Formative assessment}

Finnish, Norwegian and Swedish teachers appear to emphasise ongoing evaluation and monitoring of students' development of reading more than Danish teachers do, $p<.001$. The teachers were asked how much emphasis they place on the evaluation of students' ongoing work (see Figure 2a) as well as emphasis on classroom tests (see Figure $2 b$ ). There is no national testing in Finland, which may explain the lack of major emphasis on that (see Figure 2c). It appears that Norwegian and Swedish teachers put more emphasis on national and regional testing than Danish teachers do $p<.001$.

Figure 2a-2c: Question from the PIRLS teacher questionnaire: How much emphasis do you place on the evaluation of students' ongoing work, classroom tests and national tests as a source to monitor students' progress in reading?

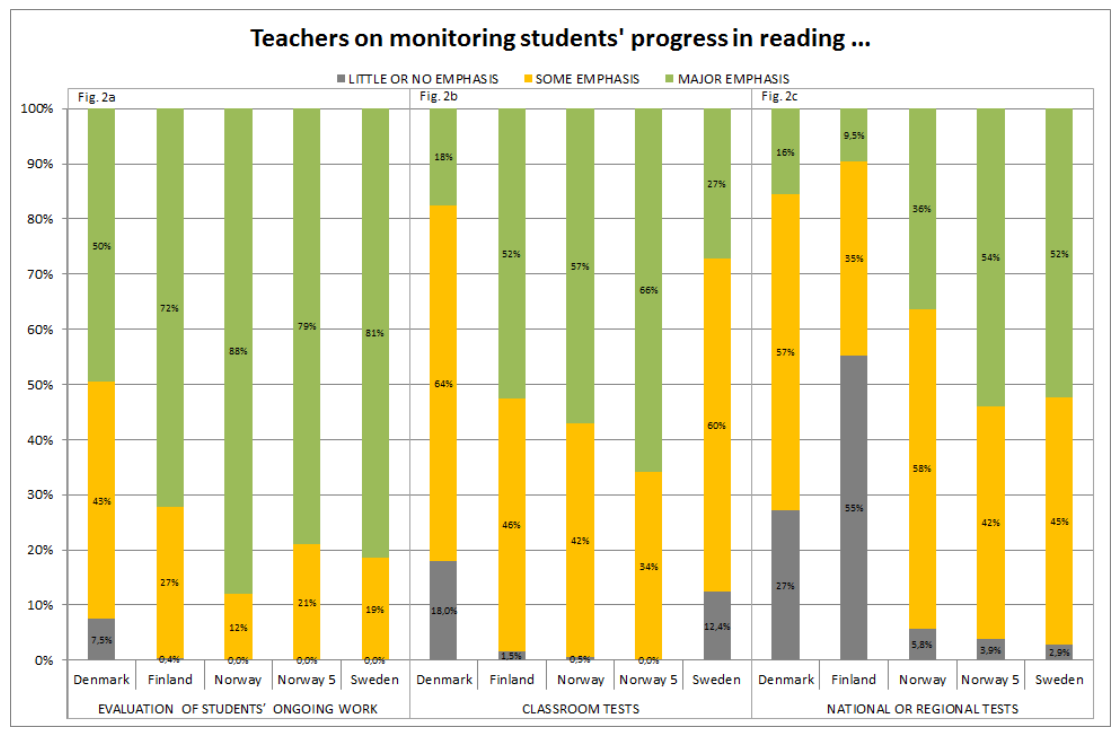

Specifically, the teachers were asked what kind of after reading activities they use when the students have read something which may be regarded as specific kinds of formative assessment. 
On a weekly basis, it appears that around $60 \%$ of the Nordic teachers have their students write something in response to what they have read. However, more Finnish teachers reply that they use this as a daily practice compared to the other Nordic countries, especially Denmark and Norway, $p<.001$ (see Figure 3a).

Figure 3a-3b: Question from the PIRLS teacher questionnaire: After students have read something, how often do you ask them to write something about what they have read? Or answer oral questions or summarise what they have read?

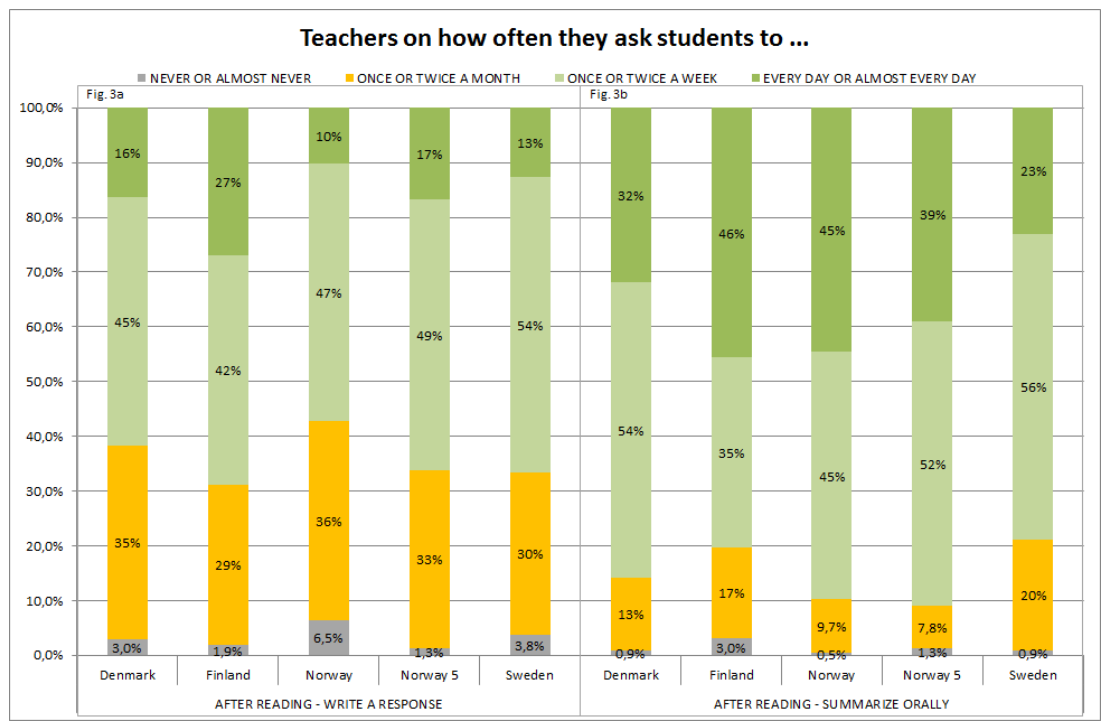

The majority of the Nordic teachers use oral summarisation or question answering about what has been read as a weekly activity after reading (see Figure 3b). This applies to $79 \%$ of the Swedish teachers and above $80 \%$ of the Danish, Finnish and Norwegian teachers. However, it appears that more Finnish and Norwegian teachers use this as a daily practice compared to Sweden and Denmark, $p<.001$. Asking students to summarise what they have read may also help students to use summarisation as a strategy in improving their own comprehension.

It appears that having the students talk to each other about what they have just read is a typical after-reading activity in Denmark compared to the other Nordic countries, $p<.001$. On a weekly basis, this applies to $74 \%$ of the 
Danish teachers and only $41 \%$ of the Finnish, $58 \%$ of the Norwegian and $57 \%$ of the Swedish teachers (see Figure 3c).

Figure 3c-3d: Question from the PIRLS teacher questionnaire: After students have read something, how often do you ask them to talk with each other about what they have read? Or take a written quiz or test about what they have read?

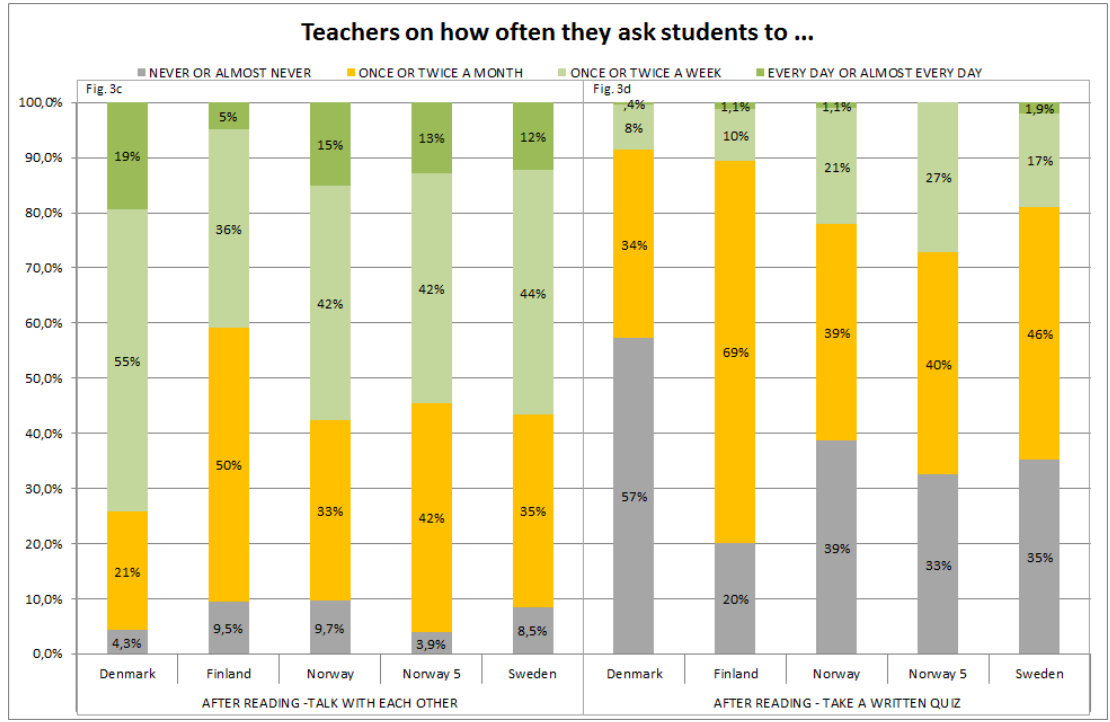

Furthermore, it appears that Finnish, Norwegian and Swedish teachers more often make use of written quizzes as a formative assessment of the students' reading comprehension than their Danish colleagues, $p<.001$. At least once a month, $79 \%$ of the Finnish teachers, $61-67 \%$ of the Norwegian teachers and $65 \%$ of the Swedish teachers have their students take a written quiz about what they have read, whereas this only applies to $43 \%$ of the Danish teachers of Grade 4 (see Figure 3d).

\subsection{Discussion}

In this paper, the Nordic countries' official objectives for reading and the teachers responses regarding reading comprehension instruction have been analysed and discussed. The results have been evaluated in relation to the scientific evidence about reading comprehension instruction. 
The countries vary regarding how they describe objectives, from very broad outlines in Norway to more specific and clear goals in Finland. In addition to having Grade 4 students reading at the top end of the scale, Finland tends to have the most research-based objectives and core content for reading instruction.

The national objectives set the stage for the instruction in a given subject; however, the actual instruction in class may not reflect these objectives very well. Through the PIRLS 2011 survey, the teachers responded to several questions about their reading instruction practice in class. Naturally, there is always a risk that respondents in surveys may give answers that are not a precise reflection of actual practice. However, this is a well known source of error in survey data, and the large amount of respondents in the PIRLS data should minimize this kind of error.

Based on the analyses of the national objectives, we stated four expectations of the PIRLS analyses of teacher responses.

Firstly, based on the national objectives, we expected that Sweden and Denmark would place a high priority on both literary and informational texts in reading instruction. No specific predictions on choice of text types were possible through the Finnish and Norwegian descriptions. This expectation was met only for Sweden. Furthermore, Norway also appeared to present students with a variety of texts on a weekly basis. On the other hand, the Finnish teachers seem to give informational reading a higher priority than literary reading, whereas the opposite seems true for the Danish teachers. The most specific details regarding text types were found in the Swedish documents, and this was also reflected in the Swedish teachers' responses.

Obviously, one has to consider the differences regarding the Nordic teachers' teaching responsibilities. In Finland and Sweden, the teacher is responsible for teaching the class in most of the disciplines in Grade 4, whereas Denmark and Norway have a system with basically one teacher per discipline. However, the questionnaire refers to reading instruction and not to reading in other subjects. This means that the priority of more informational texts in Finland should not be due to the fact that the teachers include reading in the disciplines, such as science and history. However, being the teacher in those subjects may make them more aware of the difficulties of reading informational texts. 
Secondly, based on the national objectives, we expected that teachers in Finland and Sweden would place a higher priority on reading activities that enhance reading fluency, whereas reading fluency activities would be of less priority in Denmark and Norway.

Based on the teachers' actual responses regarding their instructional practice, it appeared that Finnish and Norwegian teachers prioritise students' oral reading more than the teachers in Sweden and Denmark. Having the students reading aloud frequently is more effective for the development of reading fluency and reading comprehension than having students reading silently on their own (NICHD, 2000). Student silent reading is the only fluency activity which seems to be prioritised by the majority of Danish teachers on a daily basis. The majority of Norwegian and Swedish teachers also read aloud for their students almost every day, which is less common in Finland and Denmark.

Thirdly, based on the national objectives, we expected that the teaching of reading comprehension strategies might have a higher priority in Finland compared to the other Nordic countries. However, the data on the teachers' prioritization of reading comprehension strategies during instruction did not reveal remarkable differences between the Nordic countries. Furthermore, based on the information in Table 6a-6b, it appeared that the Nordic countries focused less on the development of more advanced skills and strategies compared to English-speaking countries.

This may be a sign of less advanced reading comprehension instruction in the Nordic countries. However, it may also be a sign of an international disciplinary vocabulary regarding specific teaching practices which is not applied by the Nordic teachers.

Fourthly, based on Finland's more explicit core content in the national objectives and based on Finland's position as one of the top scoring countries in both PIRLS and PISA, we expected that formative assessment of students' progress in reading would be most present in Finland. Nevertheless, the data analyses revealed that all Nordic teachers except the Danish appeared to place strong emphasis on formative assessment. This may indicate that even though evaluation is a buzz word in the Danish school system, many teachers do not know how to apply it in their daily practice. Knowledge of the strengths and weaknesses of each student should influence the teachers' goal-setting and expectations for students' learning. 
However, it is essential that, based on that, the teacher knows how to provide timely and relevant feedback that actually helps students grow (Andreassen, Bjerresgaard, Bråten, Hattie, Hermansen, Nerheim et al., 2013).

As mentioned, the Finnish and the Danish national objectives are currently being revised. In Denmark, this has given rise to a debate regarding measurability. Critics of the revision fear that the new national objectives will be made more specific in order to make them easy measurement goals and not learning goals. However, as can be inferred from the Finnish descriptions, objectives may be specific in the verbalisation of what kind of reading ability is expected, but this does not ensure that they are easy to measure. They require that the teacher considers what it means to, for example, distinguish main points from secondary points in a text, and summarise and anticipate text content at grade level 4. Moreover, if one ignores the challenge level of the texts that the students work with during instruction, the goals may seem ambitious - but in reality only reflect low performance.

Even though we do not in all cases find that the objectives stated in the national guidelines are reflected in the teachers' actual practices, they do play a role in shaping teacher behaviour and activities in the classroom. It is therefore very important, when revising the official objectives for reading, that an effort is made to give clear and adequate descriptions based on scientific knowledge about the teaching of reading that can easily be transformed by the teachers into daily practices.

\subsection{References}

Andreassen, R., Bjerresgaard, H., Bråten, I., Hattie, J., Hermansen, M., Nerheim, T. et al. (2013). Feedback og vurdering for læring, Dafolo.

Arnbak, Elisabeth, \& Jan Mejding (2013). Læsning, in Egelund (ed): PISA 2012 danske unge $i$ en international sammenligning, KORA.

CCSS (2012). English Language Arts Standards. Retrieved 4.3.2013, from http:// www.corestandards.org/ELA-Literacy

Duke, N. K. (2000). 3.6 minutes per day: The scarcity of informational text in first grade. Reading Research Quarterly, 35(2), 202-202.

Finnish National Board of Education (2004). National Core Curriculum for Basic Education 2004 - chapter 7. Retrieved from http://www.oph.fi/english/ curricula_and_qualifications/basic_education 
Goldman, S. R., \& Rakestraw, J. (2000). Structural aspects of constructing meaning from text. In M. L. Kamil, P. B. Mosenthal, P. D. Pearson \& R. Barr (Eds.), Handbook of Reading Research (Vol. III, pp. 311-335). Mahway, NJ: Erlbaum.

Kintsch, W., \& Rawson, K. A. (2005). Comprehension. In M. J. Snowling \& C. Hulme (Eds.), The Science of Reading: A Handbook. Oxford: Blackwell Publishing.

Mejding, J., \& Rønberg, L. (2012). PIRLS 2011 - En international undersøgelse om læsekompetence i 4. klasse: Institut for Uddannelse og Pædagogik (DPU), Aarhus Universitet.

Mullis, I. V. S., Martin, M. O., Foy, P., \& Drucker, K. T. (2012). PIRLS 2011 International results in reading. Chestnut Hill, MA: TIMSS \& PIRLS International Study Center, Boston College.

Mullis, I. V.S., Martin, M. O., Kennedy, A. M., Trong, K. L., \& Sainsbury, M. (2009). PIRLS 2011 Assessment Framework. Retrieved from http:// timssandpirls.bc.edu/pirls2011/downloads/PIRLS2011_Framework.pdf

NICHD (2000). Report of the National Reading Panel. Teaching children to read: An evidence-based assessment of the scientific research literature on reading and its implications for reading instruction NIH Publication. Washington, DC: National Institute of Child Health and Human Development.

NICHD (2014) Retreived from http://www.nichd.nih.gov/research/supported/ Pages/nrp.aspx/

Oczuks, L. (2003). Reciprocal teaching at work: Strategies for improving reading comprehension. Newark, DE: International Reading Association.

Perfetti, C., \& Stafura, J. (2014). Word knowledge in a theory of reading comprehension. Scientific Studies of Reading, 18(1), 22-37.

Rasinski, T., Rikli, A., \& Johnston, S. (2009). Reading fluency: More than automaticity? More than a concern for the primary grades? Literacy Research and Instruction, 48, 350-361.

Shanahan, T. (2006). The National Reading Panel Report: Practical Advice for Teachers. Naperville: Learning Point Associates.

Sharon, G (2010). Formative assessment and feedback: A review. Planet, Issue 23, 40-45.

Shanahan, T. (2013) Letting the text take center stage. How the Common Core State Standards will transform English Language Arts instruction. American Educator 37(3).

Skolverket (2011) Kursplan Svenska http://www.skolverket.se/laroplaneramnen-och-kurser/grundskoleutbildning/grundskola/svenska

Snow, C. (2002). Reading for understanding: Toward a Research and Development program in reading comprehension. Santa Monica, CA: RAND Reading Study Group.

Undervisningsministeriet (2009). Fælles Mål Dansk http://www.uvm.dk/Service/ Publikationer/Publikationer/Folkeskolen/2009/Faelles-Maal-2009-Dansk/

Utdanningsdirektoratet (2013). Læreplan i norsk - kompetansemål http:// www.udir.no/kl06/NOR1-05/Kompetansemaal/?arst=372029322\&kmsn= 424125164 


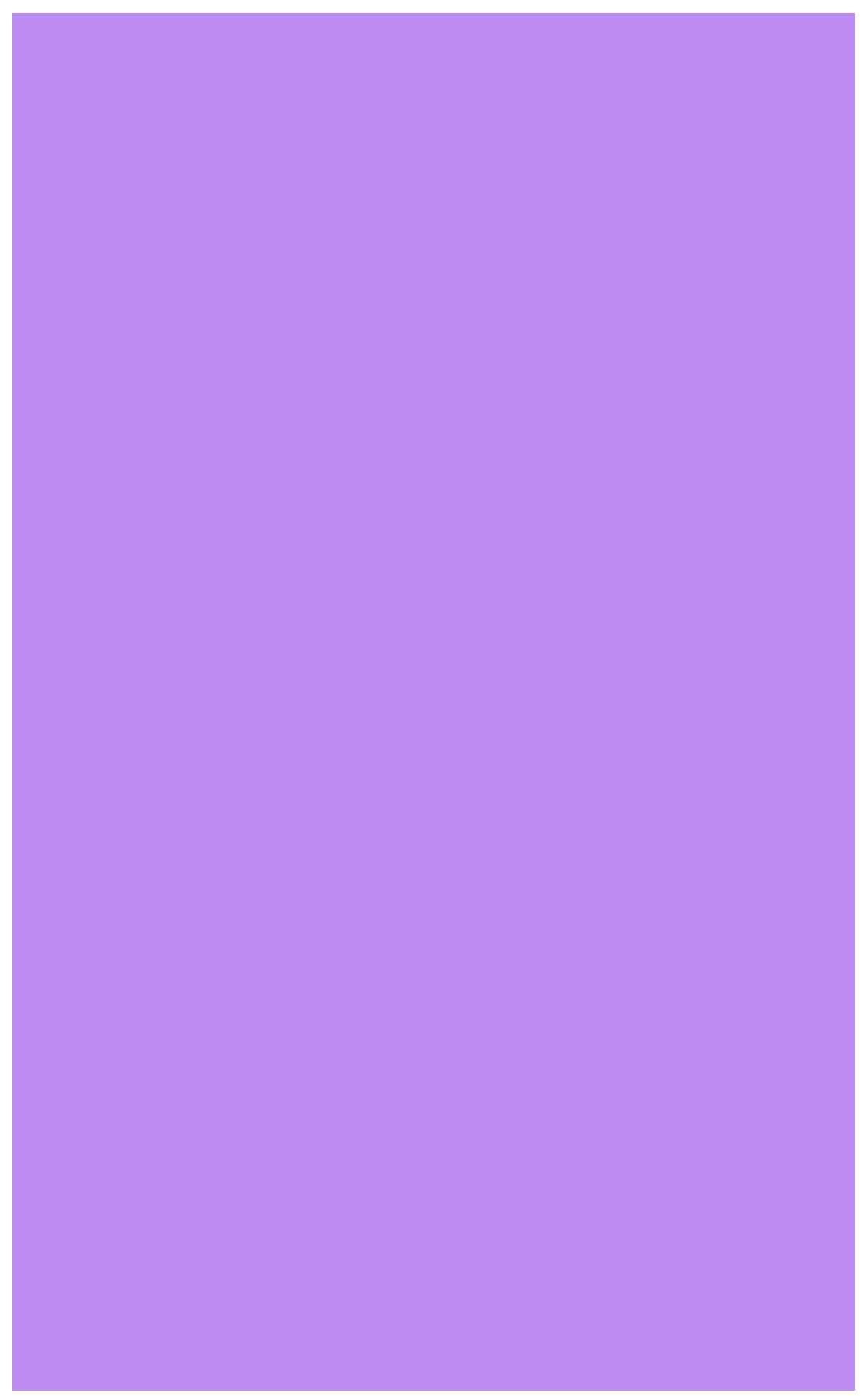




\section{Sammendrag}

I denne rapporten har forskere fra alle nordiske land brukt de internasjonale undersøkelsene Trends in Mathematics and Science Study (TIMSS) og Progress in Reading Literacy Study (PIRLS) til å undersøke forskjeller og likheter i de nordiske landenes utdanningssystemer. Både TIMSS og PIRLS er studier fra International Association for the Evaluation of Educational Achievement (IEA). Dette er den første rapporten i Northern Lights-serien som bruker TIMSS og PIRLS som datagrunnlag. De tidligere utgavene i serien har hovedsakelig sett på PISA-studien.

Sentrale spørsmål som blir besvart i rapporten er:

- Hvordan foregår leseopplæringen i nordiske klasserom og hvordan er leseopplæringen påvirket av læreplanverkene?

- Hvordan kan vi forbedre matematikkopplæringen i Norden?

- Hvilken sammenheng er det mellom skoleprestasjoner og ulike utdanningspolicyer i Norden?

- Hvordan påvirker lærernes holdninger, oppfatninger og praksis elevenes læringsutbytte?

- Hva kjennetegner de elevene som presterer best og dårligst, og hvordan kan vi få flere til å prestere på det høyeste nivået?

De nordiske landene deler i stor grad den samme kulturelle bakgrunnen og dette gir en unik mulighet til å analysere utdanningssystemer på tvers av landegrensene. Målet med denne rapporten er å gi relevant kunnskap til å videreutvikle nasjonal utdanningspolitikk. Vi ønsker også å gi et grunnlag for felles nordiske satsinger og videre forskning på utdanning $\mathrm{i}$ Norden.

Rapporten består av fem ulike artikler. Her er et kort sammendrag av problemstillinger og noen konklusjoner. 


\section{School performance differences and policy variations in Finland, Norway and Sweden}

Kajsa Yang Hansen, Jan-Eric Gustafsson og Monica Rosén, University of Gothenburg

Denne artikkelen undersøker forskjeller i læringsutbytte mellom skoler og mellom klasserom på fjerde og åttende trinn i Norge, Finland og Sverige. Store forskjeller mellom skoler kan være en indikasjon på segregerte skolesystemer, hvor elever blir sortert på skoler etter nivå og prestasjoner. Forskjeller mellom skoler kan også være en indikasjon på kvalitetsforskjeller mellom skolene. Derfor er det viktig å undersøke både forskjellen mellom skolene og bestemme hva disse forskjellene kommer av. For å gjøre dette undersøker forskerne forskjeller på klasseromsnivå.

Forskerne finner at det er relativt store prestasjonsforskjeller mellom skoler i både Norge og i Sverige. Disse forskjellene kan skyldes bostedssegregering og fritt skolevalg. I Finland ser forskerne små forskjeller mellom skolene, men de finner en overraskende stor forskjell på klasseromsnivå.

\section{Characteristics of low and top performers in reading and mathematics. Exploratory analysis of Grade 4 PIRLS and TIMSS data in the Nordic countries}

Sari Sulkunen, Kari Nissinen og Pekka Kupari, University of Jyväskylä

Hva kjennetegner elevene som presterer på de høyeste og laveste nivåene i PIRLS og TIMSS? Ved å skaffe mer kunnskap om disse gruppene vil vi i større grad kunne tilpasse utdanningssystemene til elevenes individuelle behov.

Forskerne finner at de som presterer på de laveste nivåene i lesing har svake ferdigheter i lesing når de begynner på skolen. De har ikke like god støtte fra hjemmet som de høyest presterende elevene. De sterkeste elevene kommer også fra hjem med god tilgang til resurser, som bøker og høyt utdannende foreldre. De beste elevene har også mer positive holdninger til lesing og liker å drive med leseaktiviteter.

Det samme mønsteret viser seg også for matematikkprestasjoner. Lav selvtillit for læring av matematikk, svake resurser i hjemmet og dårlige 
tallferdigheter ved skolestart er typiske kjennetegn for de som skårer svakest.

Artikkelen argumenterer for en individuell tilnærming til læring og understreker at dette stiller store krav til lærernes kompetanse. Forskerne stiller spørsmål om lærerne får det faglige påfyllet de trenger for å imøtekomme elevenes behov.

\section{Teacher attitudes and practices in international studies and their relationship to PISA performance: Nordic countries in an international context}

Ragnar F. Ólafsson and Júlíus K. Björnsson, Educational Testing Institute Reykjavik

I denne artikkelen viser forskerne at det er kulturelle forskjeller når det gjelder lærernes holdninger og undervisningspraksis. Disse kulturelle forskjellene er knyttet til geografi, og forskerne finner et hovedskille mellom lærere i Øst-Europa og vestlige land, hvor de Nordiske landene igjen utgjør en egen gruppe. De kulturelle forskjellene beskrives ved grad av engasjement og involvering.

Lærere i vestlige land rapporterte at de var mindre sikre på sine ferdigheter, brukte undervisningsformer som krevde mindre engasjement og involvering fra elevene, hadde færre tester og brukte læreboken mindre enn lærere i Øst-Europa.

Videre finner forskerne at land med undervisningskulturer som kjennetegnes av høy grad av engasjement og involvering også er de landene som har størst framgang i PISA.

\section{Mathematics in the Nordic countries - Trends and challenges in students' achievement in Norway, Sweden, Finland and Denmark} Liv Sissel Grønmo, Inger Christin Borge og Arne Hole, University of Oslo

Denne artikkelen oppsummerer forskning på matematikk i de nordiske landene og viser hva som kan gjøres for å forbedre matematikkopplæringen. Forskerne mener det er en forskjell mellom Norge og Sverige når det gjelder læringstrykk i skolen. De finner at læringstrykket har økt i 
Norge de siste årene, mens det samme ikke har skjedd i Sverige. Dette kan være noe av forklaringen på at de norske elevene viser framgang på TIMSS og PIRLS.

Artikkelen inneholder også analyser av matematikk i læreplanene og forskjellen mellom intensjonene i læreplanene og det som lærerne faktisk legger vekt på i undervisningen. Analysen viser blant annet at algebra er et lite prioritert område.

\section{A Nordic comparison of national objectives for reading instruction and teachers' responses about actual reading practice Louise Rønberg og Jan Mejding, Aarhus University, Department of Edu-cation (DPU)}

Hva er forskjellen mellom intensjoner og praksis når det kommer til leseopplæring i de ulike nordiske land? I denne artikkelen ser forskerne på innholdet i læreplanene og sammenligner med hva lærerne svarer om sin egen leseundervisning i PIRLS-studien.

Artikkelen viser hva som er hovedskillene mellom de ulike landenes læreplaner. Disse varierer fra store overordnede målsetninger i Norge til mer spesifikke og funksjonelle mål i de finske læreplanene. Forskerne mener også at de finske læreplanene er mest i tråd med leseforskningen.

Svenske og norske lærere varierer leseopplæringen i større grad enn danske og finske lærere. De bruker blant annet flere ulike teksttyper. Finske og norske lærere legger mest vekt på høytlesning. Danske lærere skiller seg ut ved at de i minst grad bruker formativ vurdering i leseopplæringen. 

Nordic Council of Ministers

Ved Stranden 18

DK-1061 Copenhagen K

www.norden.org

\section{Northern Lights on TIMSS and PIRLS 2011}

- How is reading literacy taught in Nordic classrooms, and how is this influenced by the curricula?

- How can we improve mathematics teaching in Nordic classrooms?

- What is the relationship between school performance and policy variations?

- How do teachers' attitudes, beliefs and practices influence pupils' learning outcomes?

- What characterizes the top performing pupils, and how can we stimulate more pupils to perform at the highest levels?

These are some of the questions that are discussed in this collection of articles that are based on the results of the IEA studies TIMSS and PIRLS 2011. The articles aim to provide input for policy discussions and further policy development within the Nordic countries. Therefore, the main target groups are educational ministers and policymakers at all levels. These analyses will also provide input to the joint Nordic initiatives on educational development.

TemaNord 2014:528

ISBN 978-92-893-2772-5

ISBN 978-92-893-2773-2 (EPUB)

ISSN 0908-6692

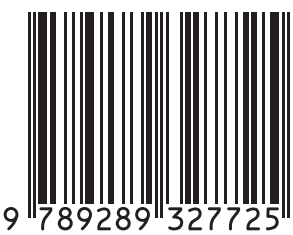

